VANESSA APARECIDA FAVERO BISQUOLO

\title{
Efeitos do exercício aeróbio nas respostas fisiológicas à hiperinsulinemia aguda realizada pós-exercício em indivíduos resistentes e sensíveis à ação da insulina
}

Dissertação apresentada à Faculdade de Medicina da Universidade de São Paulo para a obtenção do título de Mestre em Ciências.

Área de concentração: Fisiopatologia Experimental

Orientadora: Dra. Cláudia Lúcia de Moraes Forjaz

SÃO PAULO

2004 
Ao termino dessa etapa, restam três reflexões: Que iniciar foi difícil... Realizar necessário... E que continuar... é imprescindível! 


\section{Agradecimentos}

Ao Professor Paulo Augusto Bisquolo, meu marido, pelo carinho, paciência despendida durante todos esses anos, em particular durante as adversidades inevitáveis a quem deseja iniciar a carreira acadêmica e principalmente, pelo incentivo para que eu iniciasse essa pesquisa.

Aos meus pais, Élio Ângelo Fávero e Tereza Meireles Fávero, por me darem por herança a retidão de caráter.

À Professora Doutora Cláudia Lúcia de Moraes Forjaz, por ter me confiado a continuidade de seu trabalho de Doutorado, pelo zelo, muitas vezes confundido injustamente com austeridade, à minha formação acadêmica e como docente.

Ao Professor Doutor Carlos Eduardo Negrão, pelas colocações sempre relevantes a esse trabalho e por ter permitido meu ingresso no laboratório.

Aos meus amigos de laboratório, com os quais convivi nesses últimos anos, pela ajuda, paciência e principalmente pelo companheirismo, em especial aos Mestres Márcío de Oliveira, Danilo Forghieri Santaella, . que me acompanharam desde o inicío dessa jornada e ao Professor Crivaldo Cardoso Jr que muito me ajudou na execução desse trabalho. 
À todos os voluntários que participaram dessa pesquisa, que contou com homens de diversas classes sociais e diferentes graus de formação, os quais compareceram diversas vezes em nosso laboratório, e que em nosso país diferentemente da maior parte dos outros nada recebem por isso, o que demonstra o desprendimento e colaboração com o próximo demonstrado pelo nosso povo, que nos devem encher de orgulho de fazer parte dessa nação.

E, em especial ao Professor Doutor Décio Mion Jr., chefe da Liga de Hipertensão do Hospital das Clínicas da Universidade de São Paulo, pelo pronto apoio e por disponibilizar a Liga para a realização desta pesquisa. 
SUMÁRIO

Resumo $\quad v$

Summary vi

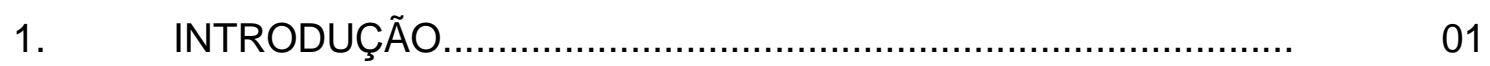

2. OBJETIVOS................................................................... 06

3. REVISÃO DA LITERATURA................................................... 08

3.1 Insulina, resistência à insulina e relevância clínica............. 09

3.2 Resposta à infusão de insulina........................................ 10

3.3 Resposta fisiológica pós-exercício..................................... 15

3.4 Efeito do exercício físico na resposta fisiológica à Infusão de

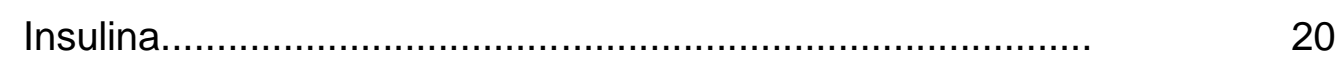

$4 \quad$ CASUÍSTICA E MÉTODOS................................................... 24

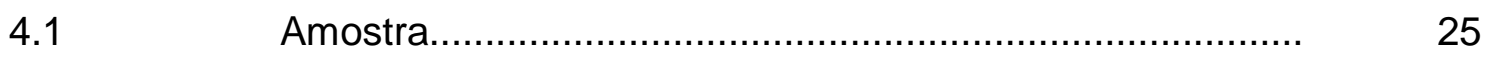

4.2 Avaliações preliminares............................................... 26

4.2.1 Avaliação clínica......................................................... 26

4.2.2 Diagnóstico de obesidade................................................... 26

4.2.3 Diagnóstico de diabetes.................................................... 27

4.2.4 Diagnóstico de hipercolesterolemia e hipertrigliceridemia.. 28

4.2.5 Diagnóstico de hipertensão............................................... 28

4.2.6 Diagnóstico de doenças cardiovasculares.......................... 29

4.2.7 Avaliação do $\mathrm{VO}_{2}$ pico............................................... 30

$4.3 \quad$ Protocolo experimental..................................................... 30

4.3.1 Medidas................................................................ $\quad 30$

4.3.1.1 Medida da pressão arterial e da freqüência cardíaca......... 30

4.3.1.2 Medida da atividade nervosa simpática muscular............... 31 
4.3.1.3 Medida do fluxo sangüíneo muscular............................. 32

$4.4 \quad$ Procedimentos Experimentais....................................... 33

4.4.1 Protocolo de exercício agudo................................... 33

4.4.2 Clampleamento euglicêmico/hiperinsulinêmico.................. 34

4.4.3 Análises laboratoriais.................................................... $\quad 35$

$4.5 \quad$ Desenho experimental............................................. 36

4.6 Análise de dados..................................................... 38

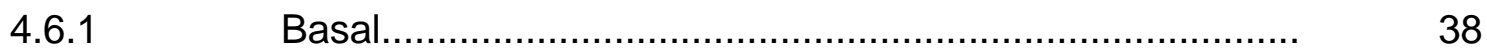

4.6.2 Infusão de insulina...................................................... 39

$4.7 \quad$ Análise estatística....................................................... 40

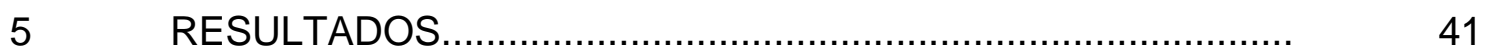

Características da amostra........................................ 42

$5.2 \quad$ Execução do experimento......................................... 45

5.3 Efeito fisiológico do exercício e da hiperinsulinemia........... 47

$6 \quad$ DISCUSSÃO

6.1 Características da execução do protocolo.......................... 68

6.2 Respostas metabólicas........................................... 70

6.3 Respostas neurais e hemodinâmicas periféricas............... 75

$6.4 \quad$ Respostas cardiovasculares................................... 83

$6.5 \quad$ Efeito fisiológico do exercício físico na condição basal...... 86

6.7eitos fisiológicos da infusão de insulina......................... 87

6.8 Efeito do exercício físico prévio na resposta à infusão de insulina........................................................................ 88

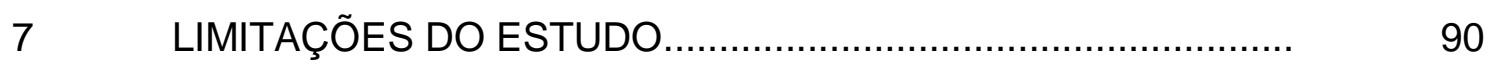

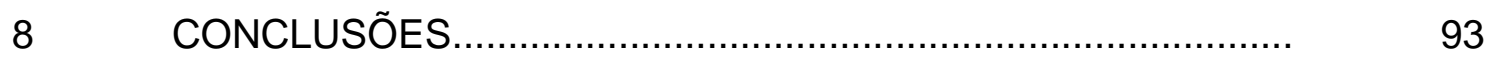

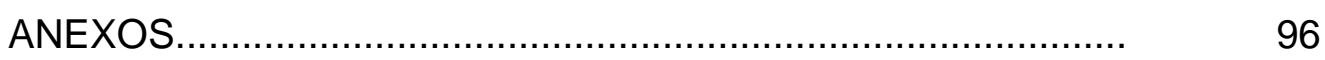

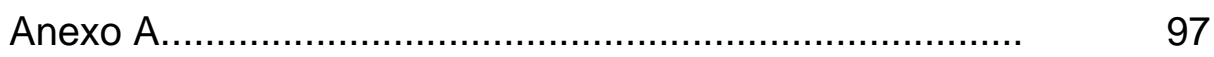

Anexo B............................................................... 101

Anexo C.......................................................... 102

REFERÊNCIAS BIBLIOGRÁFICAS.......................................... 103 


\section{RESUMO}

\section{BISQUOLO, V.A.F. Efeitos do exercício aeróbio nas respostas fisiológicas à hiperinsulinemia aguda realizada pós-exercício em indivíduos resistentes e sensíveis à ação da insulina . São Paulo, 2004, xi, p. Dissertação - Faculdade de Medicina, Universidade de São Paulo.}

A infusão aguda de insulina promove aumento da atividade nervosa simpática e do fluxo sangüíneo muscular, sendo esses efeitos influenciados pela sensibilidade do organismo à ação da insulina no metabolismo de carboidratos. Por outro lado, a execução de uma única sessão de exercício aeróbio diminui a atividade nervosa simpática, aumenta o fluxo sanguíneo muscular e pode modificar a sensibilidade à insulina pós-exercício. Dessa forma, a execução prévia de uma única sessão de exercício físico pode modificar as respostas fisiológicas à infusão aguda de insulina, essa influência pode ser diferente em indivíduos sensíveis e resistentes à ação desse hormônio. Para investigar essa problemática, 18 homens saudáveis foram submetidos a dois clampeamentos euglicêmicos/hiperinsulinêmicos realizados, em ordem aleatória, 90 minutos após 45 minutos de: a) exercício no cicloergômetro em $50 \%$ do $\mathrm{VO}_{2}$ pico (Exercício) ou b) repouso sentado (Controle). Posteriormente, os indivíduos foram divididos em dois grupos: sensíveis $(n=8)$ e resistentes $(n=10)$ à insulina, com base no índice de sensibilidade à insulina da amostra total. Antes e durante os clampeamentos, a glicemia, a insulina plasmática, a pressão arterial (oscilométrico), a freqüência cardíaca (EGC), a atividade nervosa simpática muscular (microneurografia) e o fluxo sanguíneo do antebraço (pletismografia) foram medidos. O exercício físico: a) reduziu a glicemia nos dois grupos, b) diminuiu a insulina plasmática durante os clampeamentos nos indivíduos resistentes e a aumentou nos sensíveis, c) não modificou a sensibilidade à insulina nos resistentes e a reduziu nos sensíveis, d) não modificou o aumento da pressão arterial sistólica promovido pela infusão de insulina, que era maior nos sensíveis, e) aumentou a elevação pressão arterial média em resposta à infusão de insulina nos indivíduos sensíveis, f) no grupo sensível, diminuiu a pressão arterial diastólica basal e aumentou essa pressão durante a infusão de insulina, g) aumentou a freqüência cardíaca, sem modificar sua resposta à infusão de insulina, h) reduziu a atividade nervosa simpática basal, sem modificar a resposta de aumento dessa atividade durante a hiperinsulinemia, I) aumentou o fluxo sanguíneo muscular basal, sem modificar a resposta desse fluxo à infusão de insulina, que aumentava apenas nos indivíduos sensíveis, j) reduziu a resistência vascular do antebraço basal, impedindo a diminuição dessa resistência com a infusão de insulina. Em conclusão: a execução prévia de uma sessão de exercício aeróbio modifica a resposta à hiperinsulinemia aguda de forma diferente em indivíduos sensíveis e resistentes à ação desse hormônio. 


\section{SUMMARY}

\section{BISQUOLO, V.A.F. Effects of aerobic exercise on physiological responses to acute hyperinsulinemia conducted post-exercise in insulin-resistant and sensible subjects. São Paulo, 2004, xi, p. Dissertação - Faculdade de Medicina, Universidade de São Paulo.}

Acute insulin infusion increases sympathetic nervous activity, and muscle blood flow. Moreover, these effects are influenced by insulin sensitivity on carbohidrate metabolism. On the other hand, a single bout of aerobic exercise decreases sympathetic activity, increases muscle blood flow, and can increase insulin sensitivity during the post-exercise period. Thus, it is possible that previous exercise can change physiological responses to acute hyperinsulinemia, and this influence might be different in insulin-resistant and sensible subjects. To test this hypotesis, eighteen healthy males underwent two euglycemic/hyperinsulinemic clamps performed, in a random order, 90 minutes after 45 minutes of: a) cycle ergometer exercise at $50 \%$ of $\mathrm{VO}_{2}$ peak (Exercise), or b) sitting rest (Control). After the experiments, subjects were divided in two groups: sensibles $(n=8)$, and resistants $(n=10)$ to insulin action, based on insulin sensitivity index of the total sample. Before and during the clamps, glycemia, plasma insulin, blood pressure (oscilometric), heart rate (EGC), sympathetic nervous activity (microneurography), and blood flow (plethismography) were measured. Aerobic exercise: a) reduced glycemia in both groups, b) decreased plasma insulin during the clamps in the resistant group, and increased it in the sensible one, c) did not change insulin sensitivity in the resistant subjects, but decreased it in the sensible ones, d) did not change systolic blood pressure increase promoted by insulin infusion, which was greater in the sensible group, e) enhanced mean blood pressure increase to insulin infusion in sensible subjects, f) in the sensible group, reduced baseline diastolic blood pressure, and increased it during hyperinsulinemia, g) increased heart rate, without changing its increase during insulin infusion, h) decreased baseline sympathetic nervous activity, and did not change its increase during hyperinsulinemia, i) increased baseline forearm blood flow, without changing blood flow response to insulin infusion, which was characterized by an increase only in the sensible subjects, j) reduced baseline forearm vascular resistance, abolishing the reduction observed during insulin infusion. In conclusion: previous aerobic exercise modifies physiological responses to acute hyperinsulinemia in different ways in insulin-sensible and resistant subjects. 
Capitulo 1:

INTRODUÇÃO 


\section{INTRODUÇÃO}

A insulina caracteriza-se por um hormônio produzido pelo pâncreas que tem como função principal promover a captação de glicose plasmática para os tecidos, sendo sua principal ação no tecido muscular e no tecido adiposo (GUYTON, 1992). A presença da ação deficiente desse hormônio sobre a captação de carboidratos caracteriza o quadro de resistência à insulina (GUYTON \& HALL, 1998), que parece estar presente em várias doenças como o diabetes mellitus (HENRIKSEN et. al., 2001; ROTHMAN et. al., 1995), obesidade (FAGIUS et. al, 2003; HENRIKSEN et. al., 2001; VOLLENWEIDER et. al., 1994) e hipertensão arterial (HENRIKSEN et. al., 2001; RHÉAUME et. al., 2002). Além de suas ações no metabolismo de carboidratos e outros substratos, a insulina parece ter importantes ações vasculares e neurais. Nesse sentido, tem sido verificado que a infusão de insulina promove aumento da atividade nervosa simpática muscular (BERNE et. al., 1992; FORJAZ et. al.,1999; HAUSBERG et. al.,1995; MUNTZEL et. al., 2001; ROWE et. al., 1981; SCOTT et. al., 2002; VOLLENWEIDER et. al., 1995; VOLLENWEIDER et. al.,1993; VOLLENWEIDER et. al., 1994) e, paradoxalmente, eleva o fluxo sanguíneo muscular (FORJAZ et. al.,1999; LIND et. al., 2002; SCHERRER et. al., 1994. 
SCOTT et. al., 2002; VEEN \& CHANG 1997; VOLLENWEIDER et. al., 1995; VOLLENWEIDER et. al.,1993; VOLLENWEIDER et. al., 1994). Essas ações caracterizam, respectivamente os chamados mecanismos pressores e depressores da insulina, e resultam na manutenção (BERGHOLM et. al., 2001 ; LIND et. al., 2002; VOLLENWEIDER et. al.,1993; VOLLENWEIDER et. al., 1994) ou elevação (BERNE et. al., 1992, FORJAZ et. al., 1999) da pressão arterial durante a hiperinsulinemia aguda. Entretanto, é interessante observar que a magnitude desses efeitos da insulina parece estar relacionada à sensibilidade do organismo à ação desse hormônio no metabolismo de carboidratos, visto que, indivíduos sensíveis à insulina apresentam maior aumento da atividade nervosa simpática (BERGHOLIM et. al., 2001; SCHERRER \& SARTORI, 1997; VOLLENWEIDER et. al., 1994) e do fluxo sanguíneo muscular (SCHERRER \& SARTORI, 1997; VOLLENWEIDER et. al., 1994) durante a infusão desse hormônio que indivíduos resistentes à ação da insulina. Dessa forma, a resposta da pressão arterial à infusão de insulina em indivíduos resistentes e sensíveis pode diferir, visto que o efeito desse hormônio sobre a ativação simpática e a vasodilatação local é diferente nessas duas populações.

A resistência à insulina e sua hiperinsulinemia compensatória, assim como o aumento da atividade nervosa simpática muscular e a redução do fluxo sanguíneo muscular são quadros característicos de várias doenças crônicas, como a obesidade (DEVLIN et. al., 1985; LAAKSO et. al., 1990; MUSCELLI et. al., 1998; SCHERRER \& SARTORI, 1997; VOLLENWEIDER et. al., 1994; WEYER et. al., 2000) e a hipertensão arterial (LENDER et. al., 1997 RHEAUME et. al., 2002). Dessa forma, a relação entre esses fatores tem sido alvo de 
diversos estudos. Além disso, condutas que possam reverter cada um desses aspectos ou mesmo todos eles têm sido procuradas. Nesse sentido o exercício físico aeróbio merece lugar de destaque, visto que promove adaptações hemodinâmicas, neurais e metabólicas. De fato, a execução de uma única sessão de exercício reduz significantemente a atividade nervosa simpática muscular (FORJAZ et. al., 1999; HALLIWILL et. al., 1996) e aumenta o fluxo sanguíneo muscular (FORJAZ et. al., 1999; HALLIWILL et. al., 1996; HARA \& FLORAS 1992; HUSSAIN et. al., 1996; RUECKERT et. al., 1996) no período pós-exercício. Além disso, a execução prévia do exercício também pode aumentar a sensibilidade à insulina, o que foi verificado por alguns autores (BEN-EZRA et. al., 1995; BRAUN et. al., 1995; DEVLIN et. al., 1985; MIKINES et. al., 1988; RHEAUME et. al., 2002), mas não por outros (FORJAZ et. al., 1999; RHEAUME et. al., 2002; YOUNG et. al., 1989). Entretanto, também nesse caso, o efeito do exercício parece estar relacionado à presença de resistência ou sensibilidade à insulina, sendo que o exercício físico aumenta mais a sensibilidade à insulina nos indivíduos resistentes à ação desse hormônio (DEVLIN et. al., 1985; RHEAUME et. al., 2002).

Diante do exposto, seria possível supor que a execução prévia de uma sessão de exercício poderia, além de diminuir a atividade nervosa simpática e aumentar o fluxo sanguíneo em situação basal no período pós-exercício, modificar as respostas da atividade nervosa simpática muscular e do fluxo sanguíneo do antebraço à infusão de insulina realizada após o exercício. O que poderia ter importância clínica nas respostas às situações fisiológicas que promovem aumento da insulina plasmática, como após as refeições. No entanto, 
os poucos estudos existentes sobre esse assunto verificaram resultados conflitantes, como a não alteração das respostas neurais e hemodinâmicas (dados não publicados) ou aumento da atividade nervosa simpática muscular, sem alteração do fluxo sanguíneo muscular (FORJAZ et. al., 1999) durante a infusão de insulina realizada após o exercício. Entretanto, nesses estudos, essa resposta foi avaliada num grupo de indivíduos, independentemente da presença ou não de resistência à insulina, o que pode ter camuflando os efeitos do exercício.

Dessa forma, como os indivíduos sensíveis e resistentes à insulina respondem de maneira diferente à infusão de insulina e como o exercício tem maior efeito sensibilizador à ação da insulina em indivíduos resistentes, é possível supor que o efeito do exercício prévio na resposta fisiológica à hiperinsulinemia aguda seja diferente em indivíduos mais ou menos sensíveis à ação desse hormônio. Entretanto, essa questão, pelo nosso conhecimento, ainda não foi estudada empiricamente. Além disso, ela precisa ser testada em indivíduos com e sem resistência à insulina que não apresentem doenças concomitantes, que podem alterar as respostas em função de alterações vasculares e neurais características à dessas doenças. 
Capitulo 2: OBJETIVOS 


\section{OBJETIVOS}

Diante do exposto, este estudo teve os seguintes objetivos:

Geral:

Verificar e comparar o efeito da execução prévia de uma sessão de exercício aeróbio sobre as respostas fisiológicas à hiperinsulinemia aguda em indivíduos sensíveis e resistentes à ação da insulina.

Específico:

Verificar e comparar em indivíduos sensíveis e resistentes à insulina, o efeito da execução prévia de uma única sessão de exercício físico dinâmico prolongado sobre a glicemia, insulina plasmática, pressão arterial, freqüência cardíaca, atividade nervosa simpática muscular, fluxo sanguíneo do antebraço

e resistência vascular do antebraço medidos no período basal e durante a infusão aguda de insulina realizada pela técnica do clampeamento euglicêmico/hiperinsulinêmico. 
Capitulo 3:

\section{REVISÃO DA}

\section{LITERATURA}




\section{REVISÃO DA LITERATURA}

\subsection{Insulina, resistência à insulina e relevância clínica}

A insulina é um hormônio protéico secretado pelas células beta do pâncreas, que tem como função principal estimular a captação de glicose pelas células teciduais, sendo seus principais sítios de ação o tecido muscular e o tecido adiposo (SHEPHERD \& KAHN, 1999). Além da captação de glicose, a insulina possui também outras importantes ações metabólicas, como estimular a lipogênese e o anabolismo protéico, inibindo a glicogenolise e neoglicogenese (GUYTON, 1992),

Em alguns indivíduos, a ação da insulina sobre a captação tecidual de glicose encontra-se reduzida, o que caracteriza o quadro de resistência à insulina (STERN, 2000). Cabe ressaltar que a função deficiente da insulina pode ocorrer em suas diferentes funções; porém, na área da cardiologia, o quadro denominado resistência à insulina caracteriza-se por uma deficiência na captação de glicose e, portanto, nesse estudo o termo será utilizado nesse sentido. Para compensar a ação deficiente da insulina, a secreção desse hormônio eleva-se acima dos níveis da normalidade, produzindo um quadro 
de hiperinsulinemia (STERN, 2000) compensatória crônica, que consegue promover uma captação adequada de glicose por determinado período (STERN, 2000).

Entretanto, nas ultimas décadas têm sido demonstrado que a presença da resistência à insulina é um quadro que caracteriza o desenvolvimento de uma série de doenças, como a hipertensão arterial (HENRINKSEN, 2002; KAHN \& FLIER, 2000; RHENAUME et. al., 2002), a obesidade (HENRINKSEN, 2002; VOLLENWEIDER et. al., 1994) e o diabetes mellitus (HENRINKSEN, 2002; KAHN \& FLIER, 2000). Na realidade, a presença conjunta dessas doenças caracteriza o quadro de "síndrome X" ou "síndrome plurimetabólica" que parece ter como chave crucial a resistência à insulina crônica (HENRINKSEN, 2002; KAHN \& FLIER, 2000).

Dessa forma, fica claro que a insulina é um hormônio de grande importância metabólica em nosso organismo e que a presença da resistência à insulina pode levar ao aparecimento de diversas doenças.

\subsection{Resposta à infusão de insulina}

Além dos efeitos metabólicos, a insulina possui efeitos neurais e hemodinâmicos bastante importantes e que podem estar relacionados ao desenvolvimento de doenças nos indivíduos resistentes à insulina. Nesse sentido, tem sido observado que a infusão aguda de insulina aumenta a atividade nervosa simpática (ANDERSON et al., 1991, 1992; BERNE et. al., 
1992; FERRARI \& WEIDMANN, 1990; FORJAZ et. al.,1999; HAUSBERG et. al.,1995; LEMBO et al., 1992; MINAKER et al., 1982; MUNTZEL et. al., 2001; ROCCHINI et al., 1989, 1990; ROWE et al., 1981; SCOTT et. al., 2002; SCHERRER \& SARTORI, 1997; VOLLENWEIDER et. al., 1995; VOLLENWEIDER et. al.,1993; VOLLENWEIDER et. al., 1994) e aumenta do fluxo sanguíneo muscular (ANDERSON et al., 1991, 1992; BARON et al., 1993; FORJAZ et al., 1999; HANN et al., 1997; LAAKSO et al., 1990; LEMBO et al., LIANG et al., 1982; LIND et. al., 2002; NEAHRING et al., 1993; SCHERRER et al., 1994;1992; SCHERRER \& SARTORI, 1997; SCOTT et. al., 2002; VEEN \& CHANG, 1997; VOLLENWEIDER et. al., 1995; VOLLENWEIDER et. al.,1993; VOLLENWEIDER et. al., 1994).

Esses efeitos são observados em indivíduos saudáveis (BERNE et. al., 1992; FORJAZ et. al., 1999; HAUSBERG et. al., 1995; MUNTZEL et. al., 2001; ROWE et. al., 1981; SCHERRER \& SARTORI, 1997; VOLLENWEIDER et. al., 1995; VOLLENWEIDER et. al.,1993; VOLLENWEIDER et. al., 1994) e em populações resistentes à ação da insulina tais como: indivíduos hipertensos (ANDERSON et al. 1991 e 1992) e obesos (BARON et. al., 1993; SCHERRER \& SARTORI, 1997; VOLLENWEIDER et. al., 1994).

O aumento da atividade nervosa simpática ocasionado pela infusão de insulina tem sido amplamente discutido na literatura e é observado tanto na periferia (ANDERSON et al., 1991, 1992; BERNE et. al., 1992; FERRARI \& WEIDMANN, 1990; FORJAZ et. al.,1999; HAUSBERG et. al.,1995; LEMBO et al., 1992; MINAKER et al., 1982; MUNTZEL et. al., 2001; ROCCHINI et al., 
1989, 1990; ROWE et al., 1981; SCOTT et. al., 2002; SCHERRER \& SARTORI, 1997; VOLLENWEIDER et. al., 1995; VOLLENWEIDER et. al.,1993; VOLLENWEIDER et. al., 1994) como no coração ( BERGHOLIM et. al., 2001; TANAKA et. al., 2003).

De fato, BERGHOLIM et. al. (2001) ao realizarem um clampeamento euglicêmico/hiperinsulinêmico, com uma infusão de insulina de $1 \mathrm{mU} / \mathrm{kg}$.min realizado por 120 minutos, observaram pela realização da técnica da análise espectral, aumento do componente de baixa freqüência ( $36 \pm 5$ vs $50 \pm 6 \mathrm{U}$ ) e uma redução do componente de alta freqüência ( $66 \pm 9$ vs $48 \pm 7 U$ ), o que indica um aumento da ativação simpática para o coração provocado por esse hormônio. Em relação à periferia, em um estudo anterior (FORJAZ et. a., 1999) observamos aumento da atividade nervosa simpática muscular, medida pela técnica de microneurografia, com infusão de insulina durante 0 clampeamento euglicêmico/hiperinsulinêmico. A ativação simpática promovida pela insulina se deve a um efeito central desse hormônio (MUNTZEL et. al. 2001), visto que LEMBO et. al. (1992) observaram que a infusão sistêmica desse hormônio, mas não a infusão local promoveu aumento da norepinefrina plasmática. Além disso, estudos mais recentes (MUNTZEL et. al. 2001) observaram que a ativação simpática parece estar relacionada à ativação central do óxido nítrico, uma vez que o uso L-NMMA, um inibidor da secreção de óxido nítrico, aboliu o aumento da atividade nervosa simpática promovido pela insulina.

A infusão aguda de insulina também ocasiona aumento do fluxo sanguíneo da musculatura esquelética (BISQUOLO et. al.; FORJAZ et. al., 
1999, VOLLENWEIDER et. al., 1994). Por exemplo, VOLLENWEIDER et. al. (1994), ao realizarem um clampeamento euglicêmico/hiperinsulinêmico, com uma taxa de infusão de insulina de $1 \mathrm{mU}$ (kg.min) durante 120 minutos, mediram o fluxo sanguíneo através da técnica de pletismografia de oclusão venosa e observaram aumento do fluxo sanguíneo do antebraço, $(2,0 \pm 0,2$ vs $\left.2,5 \pm 03 \mathrm{ml} \cdot 100 \mathrm{ml}^{-1} \cdot \mathrm{min}^{-1}\right)$. Entretanto, diferentemente do efeito ativador simpático, o efeito vasodilatador da insulina se deve a uma ação local desse hormônio (NEAHRING et al., 1993) e é, provavelmente, mediado pela liberação endotelial de óxido nítrico e prostaglandinas (SCHERRER et al., 1994; VEEN \& CHANG,1997).

Dessa forma, a insulina possui um efeito vasodilatador local que se opõe ao efeito vasoconstritor central, via aumento da atividade nervosa simpática. Assim, é possível dizer que a insulina estimula mecanismos pressores, como o aumento da atividade nervosa simpática, e mecanismos depressores, como a vasodilatação muscular, de modo que o efeito sobre a pressão arterial depende do balanço entre esses mecanismos. Dessa forma, observa-se aumento (BERNE et. al., 1992) ou manutenção da pressão arterial (BERGHOLM et. al., 2001 ; LIND et. al., 2002; VOLLENWEIDER et. al.,1993; VOLLENWEIDER et. al., 1994) durante a infusão de insulina.

Como a resposta à hiperinsulinemia aguda depende do balanço entre a ativação desses mecanismos (atividade nervosa simpática e fluxo sanguíneo), é interessante levantar quais fatores alteram as respostas neurais e hemodinâmicas à infusão de insulina. Entre os fatores estudados até o 
momento, a presença ou ausência do quadro de resistência à insulina parece ser importante.

Vários estudos (RHEAUMÉ et. al., 2001, SCHERRER \& SARTORI, 1997; VOLLENWEIDER et. al., 1994) realizados com indivíduos sensíveis e resistentes à ação da insulina observaram que tanto o aumento da atividade nervosa simpática, quanto o aumento do fluxo sanguíneo muscular promovido pela insulina, eram maiores nos indivíduos sensíveis do que nos resistentes à ação desse hormônio. De fato, VOLLEIWEIDER et. al. (1994) ao realizarem um clampeamento euglicêmico/hiperinsulinêmico, em 8 indivíduos magros e 8 obesos, com uma taxa de infusão de insulina de $1 \mathrm{mU}$ (kg.min), observaram que a infusão de insulina ocasionou um aumento do fluxo sanguíneo (medido pela técnica de pletismografia de oclusão venosa) e da atividade nervosa simpática muscular (medida pela técnica de microneurografia) nos dois grupos. Mas esse aumento foi significantemente maior nos indivíduos magros que nos obesos. Corroborando com esse achado, RHEAUMÉ et. al. (2001) observaram maior aumento do fluxo sanguíneo em indivíduos normotensos que em hipertensos com a administração de glicose em "bolus".

Entretanto, cabe ressaltar que, nos estudos realizados com indivíduos resistentes e sensíveis à insulina devido à presença de doenças correlacionadas, os indivíduos resistentes já apresentavam no período basal, ou seja, antes da infusão de insulina, diferenciação na atividade nervosa simpática. De fato, os indivíduos resistentes à insulina, tais como obesos (NEGRAO et. al., 2001; SCHERRER \& SARTORI, 1997; VOLLENWEIDER et. al., 1994) e hipertensos (ANDERSON et. al., 1989; MEYRELLES et. al., 
1997; RHEAUMÉ et. al., 2001) possuem maior atividade nervosa simpática muscular que os indivíduos saudáveis.

Diante do exposto, fica claro que a infusão aguda de insulina provoca, além dos efeitos metabólicos,ações neurais e hemodinâmicas importantes que podem modificar a função cardiovascular. Além disso, esses efeitos são modulados de forma diferente na presença de resistência à insulina. Dessa forma, condutas (intervenções) que provoquem alterações neurais, hemodinâmicas e/ou na sensibilidade à insulina, podem alterar essas respostas à infusão aguda de insulina. Dentro dessas condutas, o exercício físico pode ter papel relevante, visto que ele possui essas ações.

\subsection{Resposta fisiológica pós-exercício}

Vários estudos demonstram que uma única sessão de exercício físico promove uma redução da pressão arterial (FORJAZ et al., 1997; 1998; 1999; e 2000; HALLIWILL et al., 2001; MACDONALD et al., 2002; VÉRAS-SILVA et al., 1995) durante o período de recuperação, o que tem sido denominado hipotensão pós-exercício.

De fato, diversos estudos anteriores do nosso laboratório (FORJAZ et. al.,1998a, 1998b 2000, SANTAELLA, 2003) demonstram mesmo em indivíduos normotensos, reduções significantes de pressão arterial sistólica, na ordem de 10 / 5 mmHg após a realização de uma única sessão de 45 minutos de exercício no cicloergometro, com uma intensidade de $50 \%$ do $\mathrm{VO}_{2}$ pico. Essa hipotensão foi verificada por 90 minutos em condições laboratoriais 
(FORJAZ et al, 1998a) e reduziu também a media da pressão arterial de 24 pós-exercício (FORJAZ et. al., 2000).

Os mecanismos responsáveis pela hipotensão pós-exercício ainda estão sendo investigados, porém diversos autores (FORJAZ et. al., 1999; HALLIWILL et. al., 1996) têm observado redução da atividade nervosa simpática periférica durante o período pós-exercício. Essa redução foi relatada em diversos estudos da literatura (FLORAS et. al., 1989; HALLIWILL et. al., 1996) e de nosso laboratório (FORJAZ et. al., 1999; BISQUOLO et. al.), que mediram a atividade nervosa simpática muscular diretamente no nervo peroneiro, pela técnica da microneurografia. Além disso, a redução simpática pós-exercício também foi observada em estudos que mediam a atividade nervosa simpática pela concentração de plasmática norepinefrina (CLEROUX et. al., 1992). Entretanto, cabe ressaltar que esses achados não são únicos na literatura, visto que alguns autores (HARA \& FLORAS, 1992) não observaram redução da atividade nervosa simpática após o exercício físico. Porém, mesmo nesse estudo, a atividade nervosa simpática estava reduzida em relação ao esperado para a queda pressórica observada.

Nesse momento, os mecanismos responsáveis pela redução da atividade nervosa simpática pós-exercício foram pouco investigados, não havendo uma posição final a respeito. Entretanto, alguns candidatos têm sido apontados. Entre eles, a liberação de opióides durante o exercício (THORÈN et. al., 1990; Hara \& Floras 1992) poderia inibir a ativação simpática, o que poderia se manter após a finalização do exercício. Entretanto, Hara \& Floras (1992) não observaram modificação da atividade nervosa simpática pós- 
exercício com o bloqueio de opióides via naloxone, embora tenham observado que esse bloqueio alterou a regulação do barorreflexo. Um outro aspecto que tem sido abordado é a modificação do próprio barorreflexo. Alguns autores (HALLIWILL, 2001; Hara \& Floras 1992) verificaram uma mudança do ponto de ajuste do controle do barorreflexo da atividade nervosa simpática para níveis menores após a execução de uma única sessão de exercício físico. Os próprios opióides ou mesmo uma modificação do reflexo cardiopulmonar poderiam estar envolvidos na modificação do ponto de ajuste do barorreflexo, o que precisa ser mais bem investigado.

A redução da atividade nervosa simpática pós-exercício, pode, juntamente com outros mecanismos, ser responsável pelo aumento do fluxo sanguíneo muscular observado nesse momento. De fato, diversos autores (FORJAZ et. al., 1999; HALLIWILL et. al., 1996; HARA \& FLORAS 1992; HUSSAIN et. al., 1996; RUECKERT et. al., 1996) têm verificado aumento do fluxo sanguíneo muscular durante o período pós-exercício. Essa vasodilatação muscular tem sido observada tanto no território muscular ativo, quanto no território inativo (COATS et. al., 1989), embora seja maior no território ativo (COATS et. al., 1989). Além da redução da atividade nervosa simpática periférica, outros fatores, como a liberação de opióides (THOREN et. al., 1990), a produção de óxido nítrico (HALLIWILL, 2001; HARA \& FLORAS, 1992; JUNGERSTAN et. al., 1997; MONCADA et. al., 1992; PATIL et. al., 1993; SCHERRER et. al., 1994; VEEN \& CHANG 1997; VINCENT et. al., 2003), a produção de substâncias vasodolatadoras locais (HUSSAIN et. al., 1996), a necessidade de liberar o calor produzido (FRANKLIN et. al., 
1993), entre outros, têm sido citados como possíveis mecanismos relacionados com o aumento do fluxo sanguíneo muscular após a execução de uma única sessão de exercício.

O aumento do fluxo sanguíneo muscular é responsável pela redução da resistência vascular periférica observada em alguns estudos (CLEROUX et. al., 1992; HARA \& FLORAS, 1992; HALLIWILL et. al., 1996), o que explica a redução da pressão arterial pós-exercício. Porém, nem sempre a hipotensão pós-exercício tem sido atribuída à diminuição da resistência vascular periférica; alguns autores (HAGBERG et. al., 1987; VERAS-SILVA et. al., 1995) têm observado redução do débito cardíaco. Entretanto, mesmo nesses estudos, a redução do débito cardíaco não é totalmente compensada pelo aumento da resistência vascular periférica devido à vasodilatação do território muscular, o que demonstra a importância dessa vasodilatação na gênese da hipotensão pós-exercício.

Dessa forma, fica claro que o exercício físico, mesmo agudo, apresenta efeitos importantes, reduzindo a atividade nervosa simpática, aumentando o fluxo sanguíneo e diminuindo a pressão arterial após sua execução. Dentro do contexto deste estudo, um outro aspecto importante em relação ao exercício físico é seu possível efeito sobre a sensibilidade à insulina. Vários estudos (BEN-EZRA et. al., 1995; BRAUN et. al., 1995; DEVLIN et. al., 1985; MIKINES et. al., 1988; RHEAUME et. al., 2002) demonstraram aumento da sensibilidade à insulina após a execução de uma única sessão de exercício físico. Esse aumento tem sido verificado com diferentes técnicas de medida de sensibilidade à insulina, como o teste oral à sobrecarga de glicose, HOMA 
e o clampeamento euglicêmico/hiperinsulinêmico. De fato, BEN-EZRA et. al. (1995) observaram manutenção da resposta glicêmica e redução da insulinemia plasmática durante o teste de tolerância à sobrecarga oral de glicose realizado entre 3 e 7 h após a execução de uma única sessão de exercício de 50 min. a $70 \%$ do $\mathrm{VO}_{2}$ pico, o que demonstra um aumento da sensibilidade à insulina nesse momento. De forma semelhante, DEVLIN \& HORTON (1995) verificaram, em indivíduos obesos, aumento da taxa de captação de glicose durante o clampeamento euglicêmico/hiperinsulinêmico realizado $12 \mathrm{~h}$ após a execução de uma única sessão de exercício físico aeróbio em $85 \%$ do $\mathrm{VO}_{2}$ pico. Entretanto, esses dados não são definitivos na literatura. De fato, vários estudos (FORJAZ et. al., 1999; RHEAUME et. al., 2002; YOUNG et. al., 1989) não observaram aumento da sensibilidade à insulina após a execução de uma única sessão de exercício físico. FORJAZ et. al. (1999), estudando indivíduos saudáveis, após a execução de uma sessão de 50 minutos de exercício físico a 50\% do $\mathrm{VO}_{2}$ pico, não observaram aumento da sensibilidade à insulina, medida pela técnica de clampeamento euglicêmico/hiperinsulinêmico.

Um fato que pode explicar a discrepância de resultados entre os estudos apresentados é a presença ou ausência da resistência à insulina, ou seja, o exercício parece promover maior aumento da sensibilidade à insulina em indivíduos mais resistentes à ação desse hormônio. Nesse sentido, RHENAUME et. al. (2002) observaram que uma única sessão de exercício físico em cicloergômetro com a duração de 30 minutos a 50\% do $\mathrm{VO}_{2}$ pico, aumentava a sensibilidade à insulina em indivíduos hipertensos, mas não em 
indivíduos normotensos. É interessante ressaltar que os indivíduos do grupo hipertenso que participaram desse estudo possuíam uma menor sensibilidade à insulina que os normotensos.

Dessa forma, se a execução de uma única sessão de exercício físico pode modificar a atividade nervosa simpática muscular, o fluxo sanguíneo muscular e a sensibilidade à insulina, e se a resposta à infusão de insulina pode ser influenciada pela execução prévia de uma sessão de exercício, é possível supor que o exercício possa modificar as respostas neurais e hemodinâmicas à infusão de insulina.

\subsection{Efeito do exercício físico na resposta fisiológica à Infusão de Insulina}

O efeito do exercício prévio sobre as respostas fisiológicas à infusão aguda de insulina foi pouco estudado. Em um estudo anterior (FORJAZ et. al., 1999), observamos, em indivíduos saudáveis, que a execução de uma única sessão de exercício aeróbio em cicloergômetro em 50\% do $\mathrm{VO}_{2}$ pico não aumentou a sensibilidade à insulina dessa população, mas exacerbou a resposta da atividade nervosa simpática muscular à infusão de insulina, sem, no entanto, diminuir a vasodilatação promovida por esse hormônio, ou seja, durante a infusão de insulina realizada após o exercício físico a atividade nervosa simpática muscular aumentou mais, mas o fluxo sanguíneo muscular aumentou de forma semelhante à observada em um dia controle, sem a execução de exercício. O fato de o fluxo sanguíneo ter aumentado de forma 
semelhante, apesar de uma maior ativação simpática, sugere que o efeito vasodilatador local da insulina também estava maior após o exercício, o que compensou o maior estímulo vasoconstritor simpático. Entretanto, em um estudo recente (dados não publicados), obtivemos resultados um pouco diferentes dos originalmente observados, ou seja, a execução prévia de uma sessão de exercício não aumentou a sensibilidade à insulina e também não mudou a resposta de ativação simpática e vasodilatação durante a infusão de insulina. A discrepância observada entre esses dois estudos pode estar relacionada à população estudada, visto que, embora os dois estudos incluíssem indivíduos saudáveis, no primeiro o número de indivíduos era menor e a maioria apresentava grande sensibilidade à insulina. De fato, é conhecido que mesmo na população saudável não diabética, o grau de sensibilidade à insulina varia bastante (HOLLENBECK \& REAVEN, 1997).

Dessa forma, visto que a resposta à infusão de insulina é diferente em indivíduos sensíveis e resistentes à insulina, e a sensibilidade à ação da insulina pelo exercício também pode diferir entre os indivíduos sensíveis e resistentes, é possível supor que a execução prévia de uma única sessão de exercício físico tenha efeitos diferentes sobre as respostas fisiológicas observadas durante a hiperinsulinemia aguda em indivíduos sensíveis e resistentes à insulina, o que poderia explicar a discrepância de resultados observada nos estudos anteriores. Pelo nosso conhecimento, esse aspecto ainda não foi diretamente investigado na literatura. Porém, RHEAUMÉ et. al. (2002), comparando indivíduos normotensos e hipertensos, que apresentavam graus de sensibilidade à insulina diferentes, observaram um 
aumento da sensibilidade à insulina pós-exercício apenas nos indivíduos hipertensos. Entretanto, o aumento de fluxo sanguíneo, provocado pela infusão aguda de glicose, não foi modificado pela execução prévia de exercício em indivíduos dos dois grupos. No entanto, nesse estudo a resposta foi avaliada por infusão em "bolus" de glicose, o que promove além da hiperinsulinemia, que também pode influenciar na resposta. Além disso, a população hipertensa, além de apresentar resistência à insulina, pode apresentar alterações vasculares decorrentes da hipertensão (LOOMANS et. al., 2004), que podem alterar a resposta à insulina, de modo que o efeito do exercício prévio na resposta fisiológica à hiperinsulinemia aguda em indivíduos sensíveis e resistentes à insulina continua sem o devido esclarecimento.

Dessa forma, o presente estudo teve por objetivo, observar e comparar em indivíduos sensíveis e resistentes à ação da insulina, o efeito da execução prévia de uma sessão de exercício físico nas respostas hemodinâmicas e neurais à infusão de insulina aguda pós-exercício.

A partir do exposto, a hipótese inicial foi de que, nos indivíduos resistentes, o exercício prévio aumentaria a sensibilidade à insulina. Dessa forma, durante a hiperinsulinemia realizada pós-exercício, nessa população, a atividade nervosa simpática aumentaria mais expressivamente no dia de exercício que no dia de controle e, apesar disso, a vasodilatação muscular também seria maior no dia de exercício, de modo que as respostas de pressão arterial e de freqüência cardíaca não difeririam entre os dias. 
Entretanto, nos indivíduos sensíveis à insulina, todas as respostas seriam iguais com e sem exercício prévio. 
Capitulo 4:

CASUÍSTICA E MÉTODOS 


\section{CASUÍSTICA E MÉTODOS}

\subsection{Amostra}

Foram estudados 18 homens saudáveis (sem doenças conhecidas, sem distúrbios metabólicos e sem problemas cardiovasculares), não obesos, com idade entre 20 e 50 anos, que não praticavam atividade física regular e que não faziam uso crônico de nenhum medicamento. Os voluntários foram convocados a partir de visitas ao Corpo de Bombeiros, anúncios na mídia e cartazes distribuídos por diferentes locais. Todos os indivíduos foram informados de todos os procedimentos e riscos envolvidos no estudo e assinaram um termo de consentimento pós-informado (ANEXO 1). Esse estudo foi aprovado pelo Comitê de Ética do Instituto do Coração (InCor) e do Hospital das Clínicas da Faculdade de Medicina da Universidade de São Paulo (ANEXOS 2 e 3).

Após a finalização da coleta de dados, os indivíduos foram divididos em 2 grupos, segundo a sensibilidade à insulina. $O$ critério utilizado para essa divisão foi o índice de sensibilidade à insulina (M/I), que os indivíduos apresentaram durante o clampeamento euglicêmico/hiperinsulinêmico realizado na sessão de controle. O índice de sensibilidade à insulina médio do 
grupo foi $0,126 \pm 0,024 \mathrm{mg} \cdot \mathrm{kg}^{-1} \cdot \mathrm{min}^{-1} / \mathrm{uU} \cdot \mathrm{ml}^{-1}$. Dessa forma, os indivíduos que apresentaram o índice de sensibilidade à insulina acima do valor médio foram classificados como sensíveis à insulina, e os que apresentaram valores abaixo da média foram classificados como resistentes à insulina.

\subsection{Avaliações preliminares}

\subsubsection{Avaliação clínica}

Os indivíduos foram avaliados em uma consulta realizada na Liga de Hipertensão da Disciplina de Nefrologia do Hospital das Clínicas da Faculdade de Medicina da Universidade de São Paulo. Nessa consulta foram realizados uma anamnese completa e o exame clínico. No caso de suspeita de patologias, foram solicitados exames complementares.

\subsubsection{Diagnóstico de obesidade}

Os indivíduos foram pesados e medidos em uma balança Filizola, trajando somente calção. O índice de massa corporal foi calculado pelo quociente entre o peso $(\mathrm{kg})$ e o quadrado da estatura $\left(\mathrm{m}^{2}\right)$. Foram excluídos do estudo indivíduos cujo índice de massa corporal for igual ou superior a 
$30 \mathrm{~kg} / \mathrm{m}^{2}$ (NATIONAL HEART, LUNG AND BLOOD INSTITUTE, NATIONAL INSTITUTE OF HEALTH, 1998).

\subsubsection{Diagnóstico de diabetes}

Foi realizado um teste de tolerância à sobrecarga oral de glicose (OGTT). Para isso, os voluntários compareceram ao laboratório com 12 horas de jejum. Foi inserido um catéter na veia cubital para a coleta de sangue, que foi mantido por uma infusão constante e lenta de solução fisiológica. Uma primeira coleta (- 30min) foi realizada imediatamente após a punção venosa. Trinta minutos depois (tempo 0) foi feita a segunda coleta para aferir a não interferência da solução fisiológica nos valores de glicemia e insulina plasmática. Após essa coleta, os voluntários ingeriram uma solução de $75 \mathrm{~g}$ de glicose diluídas em $300 \mathrm{ml}$ de água. Novas coletas de sangue foram realizadas após $30,60,90,120$ e 180 minutos.

Foram excluídos do estudo os indivíduos que apresentaram diabetes diagnosticada por glicose plasmática de jejum maior ou igual a $126 \mathrm{mg} / \mathrm{dl}$, ou que apresentaram valor da glicose plasmática maior de $200 \mathrm{mg} / \mathrm{dl}$ em qualquer momento do teste, seguindo o critério do American Diabetes Association., (The Expert Committe on diagnosis and classication of diabetes mellitus, 1997). 


\subsubsection{Diagnóstico de hipercolesterolemia e hipertrigliceridemia}

Juntamente com a primeira coleta de sangue do OGTT, foi coletada uma amostra de sangue para a dosagem de tríglicérides, colesterol total e frações de colesterol.

Foram excluídos do estudo os indivíduos cujo nível do colesterol total foi maior ou igual a $240 \mathrm{mg} / \mathrm{dl}$ e/ou o nível de triglicérides plasmáticos foi maior ou igual a $250 \mathrm{mg} / \mathrm{dl}$, seguindo os critérios do NATIONAL CHOLESTEROL EDUCATION PROGRAM NATIONAL HEART, LUNG, AND BLOOD INSTITUTE NATIONAL INSTITUTES OF HEALTH (2002).

\subsubsection{Diagnóstico de hipertensão}

Todos os indivíduos tiveram sua pressão arterial medida por três vezes, após cinco minutos de repouso na posição deitada, em duas ocasiões diferentes. A pressão arterial foi medida pelo método auscultatório com a utilização de um esfigmomanômetro de coluna de mercúrio. O nível pressórico de cada indivíduo foi calculado pela média das seis medidas realizadas e foram excluídos do estudo os indivíduos hipertensos, ou seja, aqueles que apresentaram níveis sistólicos/diastólicos iguais ou superiores a 140/90mmHg, respectivamente (VI JOINT NATIONAL COMMITTE ON DECTECTION, EVALUATION, AND TREATMENT OF HIGH BLOOD 
PRESSURE: National Institute of heart; National heart, lung and blood institute; National High blood pressure education program, 1997).

\subsubsection{Diagnóstico de doenças cardiovasculares}

Foi realizado um teste ergoespirométrico máximo em cicloergômetro, seguindo um protocolo escalonado com incremento de potência de $30 \mathrm{~W}$ a cada 3 minutos até a exaustão. Durante esse teste, a freqüência cardíaca e o sinal eletrocardiográfico foram monitorizados continuamente por um eletrocardiógrafo (Tecnologia Eletrônica do Brasil, SM300) e registrados ao final de cada minuto. A pressão arterial foi medida ao final de cada estágio pelo método auscultatório, utilizando-se um esfigmomanômetro de coluna de mercúrio. O teste foi interrompido em caso de cansaço físico intenso; pressão arterial sistólica maior que $260 \mathrm{mmHg}$ e diastólica maior que $120 \mathrm{mmHg}$ (Diretrizes da sociedade brasileira de cardiologia sobre teste ergométrico, 2002). Antes da realização do teste, foi realizado um eletrocardiograma de repouso, com o registro das 12 derivações-padrão: D1, D2, D3, aVL, aVR, aVF, V1, V2, V3, V4, V5 e V6. Foram excluídos do estudo os voluntários que apresentaram alterações eletrocardiográficas em repouso ou durante o esforço indicativas de doenças cardiovasculares. 


\subsubsection{Avaliação do $\mathrm{VO}_{2}$ pico}

Durante o teste ergoespirométrico máximo descrito anteriormente, o ar expirado foi coletado e analisado a cada ciclo respiratório por um analisador de gases computadorizado (Medical Graphics Corporation, CAD/NET-2001). Esse equipamento mediu o fluxo de ar através de um pneumotacógrafo linear, a concentração de dióxido de carbono por um analisador de absorção infravermelha e a concentração de oxigênio por uma célula de zircônio. 0 consumo de oxigênio foi calculado em médias de 30 segundos e o consumo pico de oxigênio $\left(\mathrm{VO}_{2}\right.$ pico) de cada indivíduo foi definido pelo maior valor do consumo de oxigênio atingido durante o exercício.

\subsection{Protocolo experimental}

\subsubsection{Medidas}

\subsubsection{Medida da pressão arterial e da freqüência cardíaca}

A pressão arterial e a freqüência cardíaca foram medidas no braço esquerdo dos voluntários por um monitor automático de pressão arterial não invasivo (Dixtal, modelo 2710). A calibração desse monitor, que utiliza o método oscilométrico para a medida da pressão arterial, foi periodicamente checada pela comparação com a coluna de mercúrio. 


\subsubsection{Medida da atividade nervosa simpática muscular}

A atividade nervosa simpática muscular foi medida através da técnica denominada microneurografia, que possibilita o registro dos potenciais de ação nas fibras A e C simpáticas em nervos periféricos. Neste estudo, a atividade nervosa simpática foi medida no nervo fibular. Conforme o descrito por ANDERSON \& MARK (1989), o procedimento técnico desse método consiste em três fases: 1.estimulação elétrica percultânea para mapear o trajeto do nervo; 2. introdução do eletrodo no nervo utilizando estímulos fracos e; 3. pequenos ajustes na posição do eletrodo para obter um sinal satisfatório. O nervo foi mapeado por estimulação externa (trancultânea com 60 a 100V). Os locais onde foram encontradas as maiores respostas contráteis involuntárias ao estímulo externo foram marcados com caneta dermográfica. Nesses locais foi introduzido um microeletrodo de tungstênio de ponta não isolada (diâmetro 1-5um) e a $1 \mathrm{~cm}$ desse eletrodo foi introduzido outro para referência. Com o eletrodo ativo foi feita uma estimulação interna de 1 a 4V, até a obtenção de um local onde esse estímulo deflagrasse contração involuntária sem parestesia. Uma vez localizada essa posição, o sinal obtido foi processado por um pré-amplificador com ganho de 1000 e um amplificador com ganho de 40-60. O sinal passou então por um filtro $(700-2000 \mathrm{~Hz})$ e um circuito integrador de resistência-capacitância com o tempo constante de 0,1, 
para que fosse possível obter um neurograma de voltagem média. O sinal nervoso foi levado a um alto-falante, mostrado em um osciloscópio e foi registrado em papel através de um polígrafo. Foram aceitos os registros que apresentaram os seguintes parâmetros: 1. percussão suave dos músculos e dos tendões suprimidos pelo fascículo impactado evocando descargas mecanorreceptoras aferentes ao passo que o estímulo da pele no campo sensorial do nervo com algodão não evocasse resposta aferente; 2. os impulsos espontâneos, intermitentes e síncronos com o pulso diferenciandose do sinal de fundo, e 3. os impulsos que aumentassem de freqüência e amplitude durante expiração forçada e durante as fases 2 e 3 da manobra de Valsalva.

\subsubsection{Medida do fluxo sangüíneo muscular}

O fluxo sangüíneo do antebraço foi medido pela técnica de pletismografia de oclusão venosa a ar (SIGGAARD-ANDERSEN, 1970). O braço direito do voluntário foi mantido acima do nível do coração e dois manguitos foram posicionados, um no punho e outro no braço do voluntário. Um manguito de látex preenchido com ar até uma pressão de $4 \mathrm{~cm}$ de água foi colocado na parte mais larga do antebraço direito. Para se determinar o fluxo sangüíneo no antebraço, o manguito do punho foi inflado até $200 \mathrm{mmHg}$, interrompendo a circulação sangüínea para a mão, e o manguito do braço foi 
inflado (até uma pressão subdiastólica de 40 a $60 \mathrm{mmHg}$ ) e desinflado em intervalos de $7 / 8$ segundos. Esse procedimento provocou a oclusão do retorno venoso sem interromper a entrada arterial de sangue no antebraço, ocasionando uma dilatação nessa região que provocou um aumento na pressão interna no manguito de látex, que foi registrada em um polígrafo. $O$ fluxo sangüíneo do antebraço foi calculado através da velocidade de incremento da pressão no manguito de látex. A pressão arterial média foi aferida a cada minuto durante a medição do fluxo sangüíneo. O fluxo sangüíneo do antebraço foi expresso em ml.min-1 ${ }^{-1} 100 \mathrm{ml}^{-1}$ de tecido, e a resistência vascular do antebraço foi calculada pela divisão da pressão arterial média pelo fluxo sangüíneo local, sendo expressa em unidades (U). Antes e após cada experimento, o fluxometro foi calibrado através de infusão de volumes conhecidos de ar no manguito de látex e foi observado o aumento da pressão no manguito.

\subsection{Procedimentos Experimentais}

\subsubsection{Protocolo de exercício agudo}

Foi realizada uma sessão de 45 minutos de exercício físico no cicloergômetro (FUNBEC, Ciclo 2) em $50 \%$ do $\mathrm{VO}_{2}$ pico, mantendo-se uma velocidade de $60 \mathrm{rpm}$. Essa sessão foi precedida por 7 minutos de repouso sentado no cicloergômetro e de 3 minutos de aquecimento com a potência equivalente a $50 \%$ da potência que foi utilizada durante o exercício 
propriamente dito. Após o exercício, foi realizada uma recuperação ativa de 2 minutos, sendo que no primeiro minuto a potência foi reduzida pela metade e, no segundo minuto, a potência foi zero. $\mathrm{O}$ protocolo foi finalizado com 3 minutos de recuperação passiva na posição sentada no cicloergômetro. Para a determinação da potência de exercício correspondente a 50\% do $\mathrm{VO}_{2}$ pico, foi utilizada a regressão linear entre o consumo de oxigênio e a potência do exercício medidos durante o teste ergoespirométrico máximo. Além disso, em alguns indivíduos o consumo de oxigênio foi medido durante a realização do exercício, físico para aferir a precisão da determinação da intensidade do exercício.

\subsubsection{Clampleamento euglicêmico/hiperinsulinêmico}

Com os indivíduos deitados, foi introduzido um catéter na veia cubital direita para a infusão de glicose e insulina. Um segundo catéter foi inserido na veia cubital esquerda para as coletas sangüíneas. $O$ cateter de coleta foi mantido constante por uma infusão contínua de solução fisiológica. Para se elevar e manter os níveis plasmáticos de insulina em 100uU/ml, uma primeira infusão variável de insulina humana (NOVO-NORDISK, NOVOLIN R) foi realizada por 10 minutos, seguindo a proposta de DEFRONZO et al. (1979). Em seguida, fez-se uma infusão contínua de insulina $\left(50,7\right.$ uU. $\left.\mathrm{m}^{-2} \cdot \mathrm{min}^{-1}\right)$ por 110 minutos. Uma infusão variável de glicose $50 \%$ foi iniciada 4 minutos após o início da infusão de insulina e foi ajustada a cada 5 minutos, a partir da 
análise da glicemia em um aparelho automático (Glucometer Advanced, Roche), para que os níveis glicêmicos basais fossem mantidos. O ajuste da taxa de infusão de glicose foi realizado através das fórmulas sugeridas por DEFRONZO et al. (1979). As amostras de sangue coletadas foram analisadas para a obtenção das concentrações plasmáticas de glicose e insulina, antes do início da infusão $(-4,-2,0)$ e aos $3,6,10,15,20,25,30,35,40,45,50$, $55,60,65,70,75,80,85,90,95,100,105,110,115,120$ minutos de infusão.

\subsubsection{Análises laboratoriais}

As amostras de sangue para a dosagem de glicose plasmática foram coletadas em tubos contendo fluoreto de sódio. A concentração de glicose foi determinada pelo método enzimático - GOD/POP (Kit Merck) no Laboratório de Análises Clínicas do HCFMUSP. As coletas para a dosagem de insulina plasmática foram feitas em tubos contendo liquemina. $O$ sangue foi centrifugado, armazenado em freezer e analisado em duplicata pelo método de radioimunoensaio (kit CIS Bio International). As coletas para a dosagem de colesterol e triglicérides foram feitas em tubo seco. A concentração de colesterol foi medida pelo método CHOD-PAP(Kit Boehringer Mannheim) e a de triglicérides pelo método CHOP-PAP(KIT Merck), no Laboratório de Análises Clínicas do HCFMUSP.

A medida do hematócrito foi realizada pelo analisador automático dos elementos do sangue, fornecendo 22 parâmetros, sendo que as séries 
eritrocítica e plaquetária foram analisadas por impedanciometria, e a série granulocítica foi analisada por luz de dispersão através de raio lazer. A aparelhagem utilizada para a análise foi o Cell Dyn 3000 ou o Cell Dyn 3500. Essa análise também foi realizada no Laboratório de Análises Clínicas do HCFMUSP.

\subsection{Desenho experimental}

Os indivíduos que se voluntariaram a participar do estudo foram, inicialmente, submetidos aos procedimentos preliminares descritos anteriormente. Aqueles que não preencheram todos os critérios de inclusão foram excluídos do estudo.

Os voluntários submeteram-se, de maneira aleatória e com um intervalo mínimo de um mês, a duas sessões experimentais (Controle e Exercício). Nessas duas sessões, os indivíduos compareceram ao laboratório às sete horas da manhã, após jejum de doze horas, precedido por três dias de dieta irrestrita com uma ingestão mínima de $250 \mathrm{~g}$ de carboidratos por dia. Nenhum tipo de exercício físico foi realizado nas 48 horas que precederam os experimentos.

Em uma das sessões experimentais (Exercício), os voluntários permaneceram 15 minutos em repouso deitado, durante os quais a pressão arterial foi aferida a cada cinco minutos. Em seguida, os indivíduos se posicionaram no cicloergômetro e realizaram a sessão de exercício físico 
agudo descrito anteriormente (Item 4.2.6). Durante essa sessão, a freqüência cardíaca foi medida a cada cinco minutos. Após o exercício, foi solicitado aos indivíduos que esvaziem a bexiga e se deitassem na maca para se iniciarem os procedimentos preparatórios para 0 clampeamento euglicêmico/hiperinsulinêmico (punção de veias), a pletismografia (colocação dos manguitos), a microneurografia (imobilização da perna) e a aferição da pressão arterial (colocação de manguito). Em seguida, iniciou-se o procedimento de localização do sinal nervoso, que foi completado em, no máximo, 60 minutos. Uma vez localizado o sinal nervoso, foram realizados 10 minutos de registro sem infusão (Basal), durante os quais a atividade nervosa simpática foi registrada continuamente, o fluxo sangüíneo do antebraço foi medido por três minutos a partir do quinto minuto e a pressão arterial foi medida a cada minuto durante a medida do fluxo sanguíneo. Em seguida, a infusão de insulina foi iniciada através da técnica de clampeamento euglicêmico/hiperinsulinêmico. Durante esse procedimento, a atividade nervosa simpática foi registrada continuamente, a pressão arterial foi medida a cada cinco minutos (exceto durante as medidas de fluxo, quando a mesma foi medida a cada minuto) e o fluxo sangüíneo do antebraço foi medido por três minutos a cada quinze minutos. No início, após o exercício e no final da infusão de insulina, foram coletadas amostras de sangue para medir o hematócrito.

$\mathrm{Na}$ outra sessão experimental (Controle), os procedimentos foram idênticos aos descritos acima, exceto que, ao em vez do exercício físico, os indivíduos permaneceram sentados em repouso por 60 minutos, ou seja, no 
período correspondente ao período de exercício físico na sessão de Exercício. O desenho experimental das sessões controle e exercício estão representados na Figura 1.

\begin{tabular}{|c|c|c|c|c|}
\hline \multicolumn{2}{|c|}{ REPOUSO } & & $\begin{array}{c}\text { PA, FSA a } \\
\text { cada 15 } \\
\text { min; ANSM } \\
\text { continua } \\
\text { Basal }\end{array}$ & $\begin{array}{c}\text { PA, FSA a } \\
\text { cada 15 } \\
\text { min; ANSM } \\
\text { continua } \\
\text { Clamp }\end{array}$ \\
$\begin{array}{c}\text { repouso } \\
\text { deitado } \\
15\end{array}$ & repouso sentado & $\begin{array}{c}\text { preparação dos } \\
\text { procedimentos }\end{array}$ & 10 & 120 \\
\hline
\end{tabular}

\section{EXERCÍCIO}

\begin{tabular}{|c|c|c|c|c|}
\hline $\begin{array}{l}\text { repouso } \\
\text { deitado }\end{array}$ & $\begin{array}{c}\text { exercício } \\
\text { (cicloergométrico } \\
50 \% \text { VO2 pico- } \\
45 \mathrm{~min} \text { ) }\end{array}$ & $\begin{array}{l}\text { preparação dos } \\
\text { procedimentos }\end{array}$ & $\begin{array}{c}\text { PA, FSA a } \\
\text { cada } 15 \\
\text { min; ANSM } \\
\text { continua } \\
\text { Basal }\end{array}$ & $\begin{array}{c}\mathrm{PA}, \mathrm{FSA} \text { a } \\
\text { cada } 15 \\
\text { min; ANSM } \\
\text { continua } \\
\text { Clamp }\end{array}$ \\
\hline 15 & 60 & 90 & 10 & 120 \\
\hline
\end{tabular}

$\mathrm{PA}=$ pressão arterial; FSA = fluxo sanguíneo do antebraço; $\mathrm{ANSM}=$ atividade nervosa simpática muscular.

Figura 1 - Desenho experimental das sessões Controle e Exercício.

\subsection{Análise de dados}

\subsubsection{Basal}

Durante o período basal, o número de impulsos simpáticos foi contado a cada minuto, e a atividade nervosa simpática nesse período foi calculada pela 
média obtida nos 10 minutos. O fluxo sangüíneo e a resistência vascular do antebraço foram calculados pelas médias das medidas realizadas nesse período. Da mesma forma, os valores da pressão arterial e da freqüência cardíaca basais foram calculados pelas médias das medidas realizadas durante as medidas do fluxo sangüíneo. Os níveis basais de glicemia e insulina plasmática foram calculados pela média das três coletas realizadas antes da infusão.

\subsubsection{Infusão de insulina}

Durante o clampeamento euglicêmico/hiperinsulinêmico, a análise dos dados foi realizada durante o período de equilíbrio individual, caracterizado por um período mínimo de 15 minutos, após o vigésimo minuto de infusão de insulina, que apresentasse glicemia estável e próxima ao nível basal (variação máxima de $\pm 10 \%$ ) e insulina plasmática próxima a $100 \mathrm{uU} / \mathrm{ml}$. Além disso, o período de equilíbrio nas duas sessões experimentais (Controle e Exercício) foi considerado em períodos de tempo de infusão de insulina semelhantes.

A taxa de metabolização da glicose (M) foi calculada, durante o período de equilíbrio, a partir da taxa de infusão de glicose e dos valores da glicemia medidos no início e no final do período, seguindo-se os cálculos propostos por DEFRONZO et al. (1979) e entendendo-se que a produção endógena de glicose estivesse completamente suprimida (MIKINES et al., 1988, RIZZA et al., 1981). O índice de sensibilidade à insulina (M/l) foi calculado pelo 
coeficiente entre a taxa de metabolização de glicose e a concentração de insulina plasmática (I) durante esse período. A atividade nervosa simpática, o fluxo sangüíneo do antebraço, a resistência vascular periférica, a pressão arterial e a freqüência cardíaca foram avaliados pela média das medidas realizadas no período de Equilíbrio.

\subsection{Análise estatística}

O efeito do exercício e da infusão de insulina nos indivíduos sensíveis e resistentes à insulina foram avaliados por uma análise de variância (ANOVA) de três fatores, tendo como fator principal independente o grupo (Sensível ou Resistente) e como fatores principais dependentes a sessão experimental (Controle e Exercício) e o estágio do clampleamento (Basal e Equilíbrio). Quando houve significância, foi utilizado como teste de "post-hoc", o teste de Newman Keuls.

Foram considerados significantes os resultados cujos valores apresentaram $P<0,05$. Os dados são apresentados como média \pm erro padrão. 
Capitulo 5:

RESULTADOS 


\section{RESULTADOS}

\subsection{Características da amostra}

Foram estudados 18 indivíduos saudáveis, que foram divididos segundo o critério anteriormente descrito, em 2 grupos: Resistentes e Sensíveis à ação da insulina, de modo que 10 indivíduos foram alocados no primeiro grupo e 8 no segundo. As características físicas, cardiovasculares, funcionais e metabólicas dos dois grupos estão apresentadas na Tabela 1.

Quanto às variáveis idade, peso, altura, índice de massa corporal e superfície corporal observa-se que todos os voluntários apresentaram as características necessárias para a inclusão no estudo.

Da mesma forma, as características cardiovasculares (pressão arterial sistólica, média e diastólica e freqüência cardíaca) estavam de acordo com os critérios de inclusão, ou seja, todos os indivíduos eram normotensos e não houve diferenças significantes entre os grupos.

Em relação à capacidade funcional, todos os indivíduos alcançaram no teste ergoespirométrico máximo, freqüência cardíaca máxima superior a $84 \%$ da prevista para a idade e razão de troca respiratória acima de 1,10, o que 
demonstra que todos os testes foram realmente máximos. Embora a carga máxima alcançada tenha sido igual entre os grupos, os indivíduos sensíveis à insulina apresentaram $\mathrm{VO}_{2}$ pico maior que os resistentes. Cabe ressaltar que nenhum dos indivíduos praticava atividade física regular e que os valores de $\mathrm{VO}_{2}$ pico observados se encontravam próximos ao esperado para a população geral (entre 80 e 120\% do predito pela fórmula de WASSERMAN e WHIPP, 1975).

Quanto às características metabólicas, os dois grupos (Resistentes e Sensíveis) apresentaram valores semelhantes de glicemia de jejum, insulina plasmática de jejum, colesterol total, HDL-colesterol, LDL-colesterol e triglicérides. É interessante observar que existiram grandes variações nos valores das variáveis metabólicas entre os indivíduos; entretanto, todos obtiveram valores dentro da faixa de inclusão do estudo. Quanto aos resultados do teste de tolerância à sobrecarga oral de glicose, observa-se que os 2 grupos apresentaram áreas sob a curva de glicemia semelhantes, porém a área sob a curva da insulina plasmática foi significantemente menor no grupo sensível à insulina, o que confirma a maior sensibilidade à insulina desse grupo.

Diante do exposto, verifica-se que todos os indivíduos que participaram do estudo preencheram todos os critérios de inclusão estabelecidos. 
TABELA 1- CARACTERÍSTICAS FÍSICAS, CARDIOVASCULARES, FUNCIONAIS E METABÓLICAS DOS DOIS GRUPOS ESTUDADOS: INDIVÍDUOS RESISTENTES ( $\mathrm{N}=10)$ E SENSÍVEIS $(\mathrm{N}=8)$ À AÇÃO DA INSULINA

\begin{tabular}{|c|c|c|}
\hline - & Resistentes & Sensíveis \\
\hline Idade (anos) & $31 \pm 3$ & $35 \pm 2$ \\
\hline Peso (kg) & $76 \pm 3$ & $71 \pm 5$ \\
\hline Estatura (cm) & $174 \pm 2$ & $173 \pm 4$ \\
\hline IMC (kg/m²) & $24,9 \pm 0,7$ & $23,4 \pm 1,0$ \\
\hline Superfície corporal (m²) & $1,89, \pm 0,05$ & $1,81 \pm 0,08$ \\
\hline PAS (mmHg) & $122 \pm 4$ & $123 \pm 5$ \\
\hline PAM (mmHg) & $91 \pm 3$ & $94 \pm 3$ \\
\hline PAD (mmHg) & $75 \pm 3$ & $80 \pm 3$ \\
\hline FC (bpm) & $58 \pm 2$ & $58 \pm 2$ \\
\hline $\mathrm{VO}_{2}$ pico $\left(\mathrm{ml} \cdot \mathrm{kg}^{-1} \cdot \mathrm{min}^{-1}\right)$ & $32,2 \pm 1,7$ & $43,4 \pm 2,4 \$$ \\
\hline CM (W) & $183 \pm 4$ & $203 \pm 5$ \\
\hline COL (mg/dl) & $181 \pm 10$ & $174 \pm 25$ \\
\hline HDL (mg/dl) & $44 \pm 4$ & $44 \pm 3$ \\
\hline LDL (mg/dl) & $119 \pm 10$ & $112 \pm 9$ \\
\hline $\mathrm{TG}$ (mg/dl) & $104 \pm 17$ & $88 \pm 9$ \\
\hline Glicemia (mg/dl) & $88 \pm 2$ & $87 \pm 2$ \\
\hline Insulina Plasmática (uU/mI) & $14 \pm 2$ & $11 \pm 1$ \\
\hline Área Glicemia (OGTT) & $4634 \pm 662$ & $3486 \pm 760$ \\
\hline Área Insulina Plasmática (OGTT) & $7373 \pm 741$ & $5060 \pm 641 \$$ \\
\hline \multicolumn{3}{|c|}{$\begin{array}{l}\text { IMC = Índice de massa corporal, } \mathrm{PAS}=\text { Pressão arterial sistólica, } \mathrm{PAM}=\text { Pressã } \\
\text { arterial média, } \mathrm{PAD}=\text { Pressão arterial diastólica, } \mathrm{FC}=\mathrm{Frequê} \text { cia cardíaca, } \mathrm{CM}= \\
\text { Carga máxima, } \mathrm{COL}=\mathrm{Colesterol}, \mathrm{HDL}=\text { Colesterol de alta densidade, } \mathrm{LDL} \\
\text { colesterol de baixa densidade, } \mathrm{TG}=\text { triglicérides. } \mathrm{OGTT}=\text { Teste à tolerância oral } \\
\text { glicose } \\
\$ \text { diferença significante dos resistentes }(\mathrm{P}<0,05) .\end{array}$} \\
\hline
\end{tabular}




\subsection{Execução do experimento}

Os procedimentos experimentais das duas sessões Controle e Exercício estão representados na Tabela 2.

TABELA 2 - DADOS DO PROCEDIMENTO EXPERIMENTAL DO CLAMPEAMENTO EUGLICÊMICO/HIPERINSULINÊMICO REALIZADO NAS DUAS SESSÕES EXPERIMENTAIS (CONTROLE E EXERCÍCIO) EM INDIVÍDUOS RESISTENTES ( $\mathrm{N=10}$ ) E SENSÍVEIS $(\mathrm{N}=8)$ À AÇÃO DA INSULINA

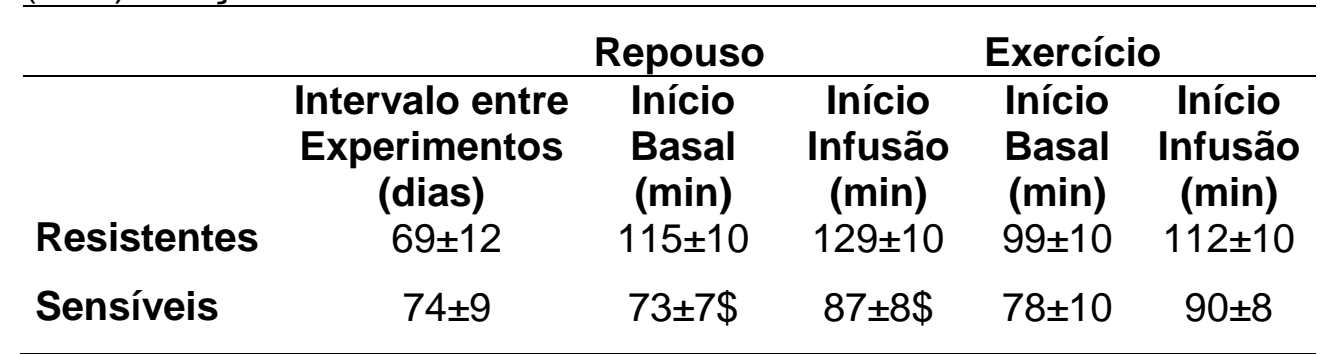

$\$$ diferença significante dos resistentes $(\mathrm{P}<0,05)$

O sorteio da ordem de realização das 2 sessões experimentais foi aleatória e realizado antes da divisão dos grupos. O número de indivíduos que iniciou o estudo realizando a sessão Controle foi de 8 , enquanto 10 indivíduos iniciaram com a sessão Exercício, o que demonstra o sucesso da randomização. No grupo de indivíduos Resistentes à insulina, 6 indivíduos iniciaram o experimento com a sessão Controle, e 4 com a sessão Exercício e do grupo Sensível à insulina; 2 indivíduos iniciaram o experimento com a sessão Controle, e 6 com a sessão Exercício.

Após a divisão dos grupos, pôde-se observar que não houve diferença significante no intervalo de tempo entre as sessões experimentais (Controle e Exercício) nos dois grupos. Entretanto, apenas na sessão Controle, o tempo para o início do período basal e de infusão de insulina foi significantemente maior no grupo resistente que no grupo sensível. 
Outra análise importante antes de se verificar o efeito dos experimentos é avaliar o exercício realizado. Todos os voluntários conseguiram realizar os 45 minutos de exercício na carga preconizada. Além disso, em 6 indivíduos de cada grupo, mediu-se $\mathrm{o} \mathrm{VO}_{2}$ e foi possível verificar que os dois grupos realizaram o exercício físico na intensidade desejada $\left(54 \pm 2\right.$ e $54 \pm 3 \%$ do $\mathrm{VO}_{2}$ pico nos grupos Sensível e Resistente, respectivamente), e que não houve diferença significante entre os grupos.

Nas duas sessões de clampeamento experimentais, medimos 0 hematócrito nos dois grupos Resistentes e Sensíveis. Esses dados estão apresentados na Tabela 3.

\begin{tabular}{|c|c|c|c|c|}
\hline \multicolumn{5}{|c|}{ 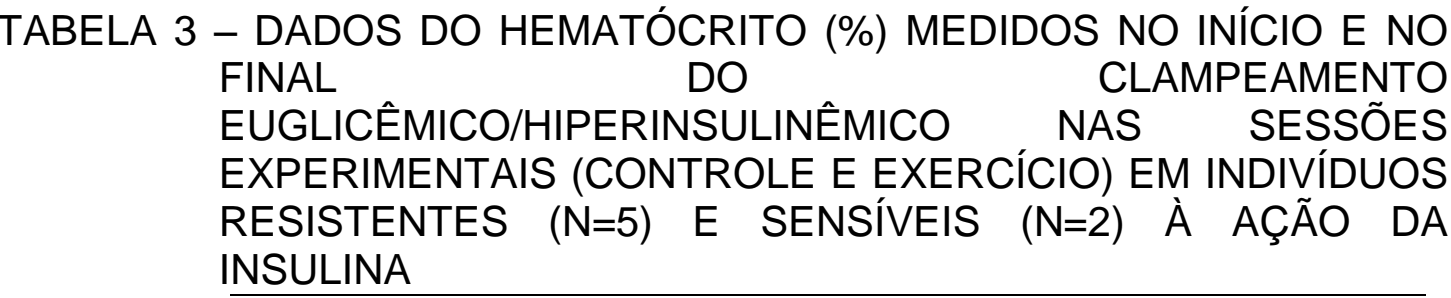 } \\
\hline \multirow{3}{*}{$\begin{array}{l}\text { - DADOS DO } \\
\text { FINAL } \\
\text { EUGLICÊMICC } \\
\text { EXPERIMENT/ } \\
\text { RESISTENTES } \\
\text { INSULINA } \\
\\
\\
\text { Resistentes } \\
\text { Sensíveis }\end{array}$} & Repouso & & Exercício & \\
\hline & $\begin{array}{c}\text { inicial } \\
46,5 \pm 0,9\end{array}$ & & $\begin{array}{c}\text { inicial } \\
45,3 \pm 0,9\end{array}$ & \\
\hline & $47,4 \pm 1,4$ & $44,9 \pm 1,3$ & $46,5 \pm 0,2$ & $45,2 \pm 2,0$ \\
\hline
\end{tabular}

Em relação ao hematócrito, observou-se significância apenas no fator principal sessão $(p=0,03)$. Dessa forma, não houve variação na concentração plasmática nos grupos entre os períodos Basal e Equilíbrio nas duas sessões experimentais. Porém, como se observa na Figura 2, independentemente do grupo e do período, o hematócrito foi significantemente menor na sessão de Exercício que na sessão Controle. 


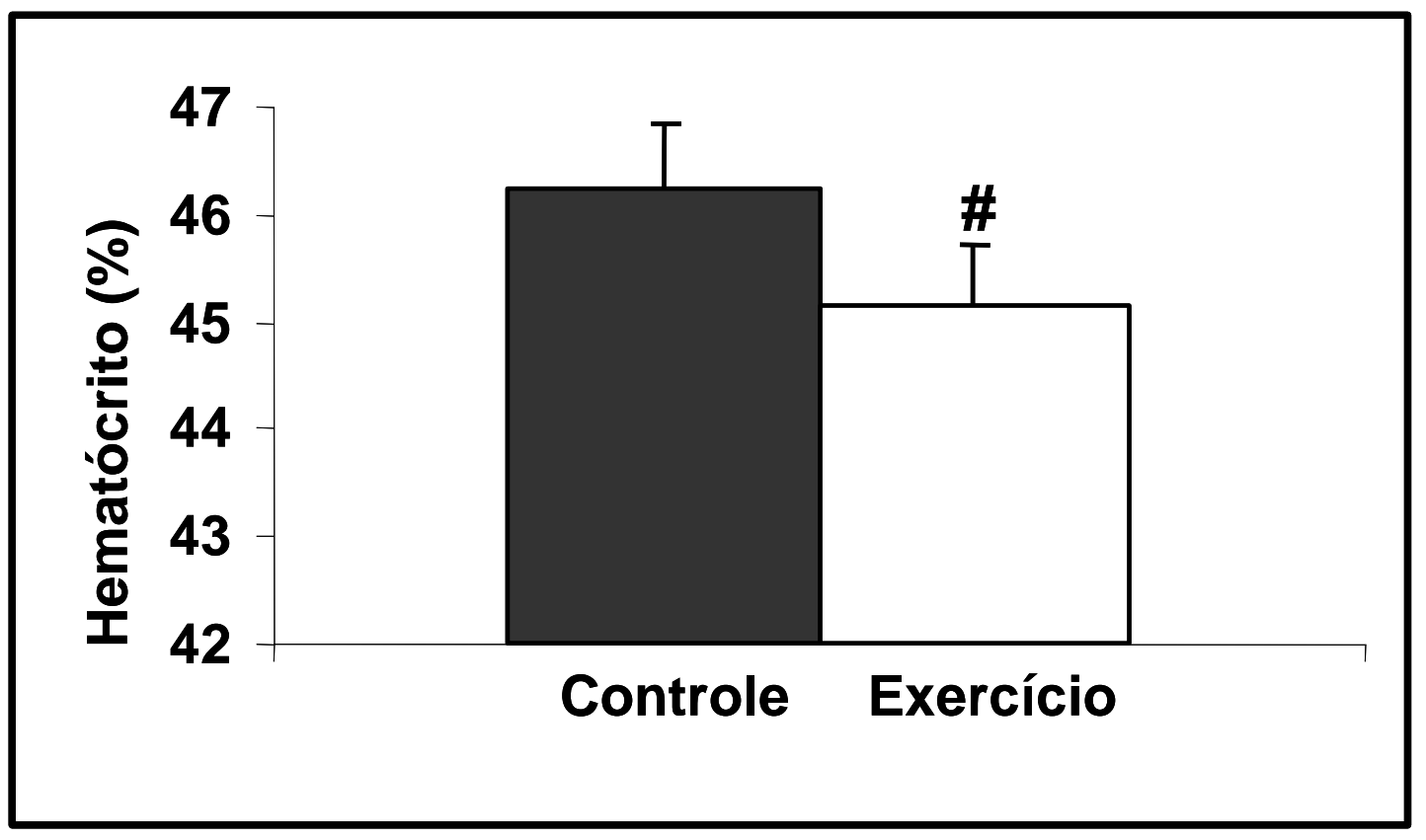

\# diferença significante da sessão controle $(P<0,05)$

Figura 2 - Hematócrito medida nas duas sessões experimentais (Controle e Exercício). Devido à significância apenas do fator principal da ANOVA (sessão), os dados dos grupos resistentes e sensíveis e dos períodos basal e equilíbrio foram combinados.

\subsection{Efeito fisiológico do exercício e da hiperinsulinemia}

Neste item, serão apresentados os resultados da resposta da glicemia, insulina plasmática, taxa de metabolização de glicose, índice de sensibilidade à insulina, pressão arterial sistólica, pressão arterial média, pressão arterial diastólica, freqüência cardíaca, atividade nervosa simpática muscular, fluxo sanguíneo do antebraço e resistência vascular do antebraço, medidos antes e durante a infusão de insulina, nas duas sessões experimentais (Controle e Exercício) nos 2 grupos (Resistentes e Sensíveis). 
Devido à complexidade da análise estatística (ANOVA de 3 fatores para amostras repetidas) e da dificuldade de expressar as significâncias com símbolos em tabelas contendo todos os dados, optou-se por mostrar as tabelas com os valores medidos em cada situação, sem expressar significâncias e apontar as significâncias encontradas no texto e em figuras específicas.

Os dados de glicemia, medidos no período basal e de equilíbrio dos clampeamentos euglicêmicos/hiperinsulinêmicos realizados nas duas sessões experimentais, estão apresentados na Tabela 4.

TABELA 4 - GLICEMIA MEDIDA NO PERÍODO BASAL E DURANTE O PERÍODO DE EQUILÍBRIO DO CLAMPEAMENTO EUGLICÊMICO HIPERINSULINÊMICO REALIZADO NAS SESSÕES EXPERIMENTAIS (CONTROLE E EXERCÍCIO) EM INDIVÍDUOS RESISTENTES ( $\mathrm{N}=10)$ E SENSÍVEIS ( $\mathrm{N}=8)$ À AÇÃO DA INSULINA

\begin{tabular}{rcccc}
\hline & \multicolumn{2}{c}{ Controle } & \multicolumn{2}{c}{ Exercício } \\
\hline \multirow{2}{*}{ Resistentes } & Basal & Equilíbrio & Basal & Equilíbrio \\
Sensíveis & $84 \pm 3$ & $82 \pm 3$ & $82 \pm 2$ & $82 \pm 2$ \\
& $86 \pm 3$ & $86 \pm 4$ & $79 \pm 3$ & $78 \pm 3$ \\
\hline
\end{tabular}

Em relação à glicemia, observou-se significância apenas no fator principal sessão $(p=0,03)$. Assim, a glicemia foi semelhante entre os grupos e não variou do período basal para o de equilíbrio nas duas sessões experimentais. Porém, como se observa na Figura 2, independentemente do grupo e do período, a glicemia foi significantemente menor na sessão de exercício que na sessão controle. 


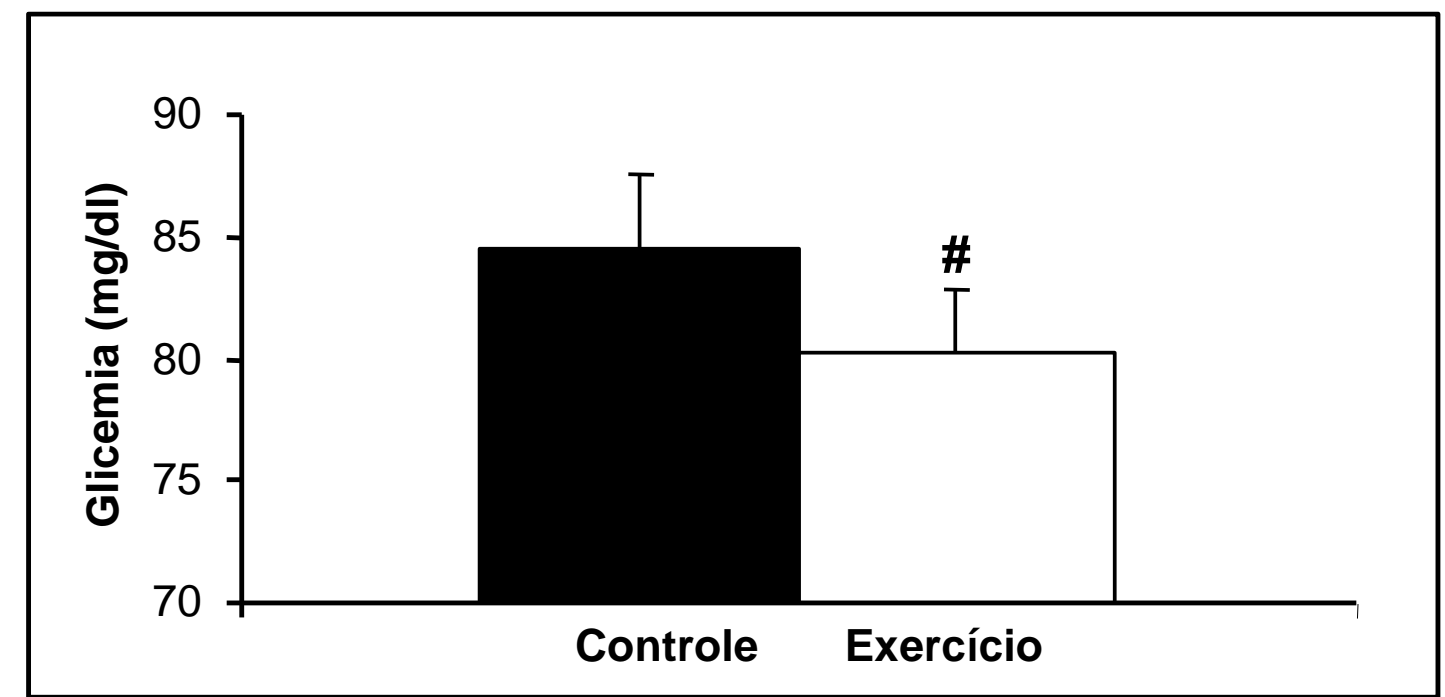

\# diferença significante da sessão controle $(\mathrm{P}<0,05)$

Figura 2 - Glicemia medida nas duas sessões experimentais (Controle e Exercício). Devido à significância apenas do fator principal da ANOVA (sessão), os dados dos grupos resistentes e sensíveis e dos períodos basal e equilíbrio foram combinados.

Os dados de insulina plasmática, medidos nos períodos Basal e de Equilíbrio dos clampeamentos euglicêmicos/hiperinsulinêmicos realizados nas duas sessões experimentais, estão apresentados na Tabela 5.

TABELA 5 - INSULINA PLASMÁTICA (Uu/ml) MEDIDA NO PERÍODO BASAL E DURANTE O PERÍODO DE EQUILÍBRIO DO CLAMPEAMENTO EUGLICÊMICO HIPERINSULINÊMICO REALIZADO NAS DUAS SESSÕES EXPERIMENTAIS (CONTROLE E EXERCÍCIO) EM INDIVÍDUOS RESISTENTES $(\mathrm{N}=10)$ E SENSÍVEIS $(\mathrm{N}=8)$ À AÇÃO DA INSULINA

\begin{tabular}{ccccc}
\hline & \multicolumn{2}{c}{ Controle } & \multicolumn{2}{c}{ Exercício } \\
\hline \multirow{2}{*}{ Resistentes } & Basal & Equilíbrio & Basal & Equilíbrio \\
Sensíveis & $8,1 \pm 2,0$ & $119,6 \pm 10,6$ & $12,0 \pm 1,4$ & $89,8 \pm 6,1$ \\
& $8,8 \pm 0,7$ & $66,5 \pm 5,5$ & $9,0 \pm 2,3$ & $108,7 \pm 18,8$
\end{tabular}

Em relação à insulina plasmática, observou-se significância na interação entre os três fatores analisados (grupo, sessão e estágio $p=0,01$ ). 
Assim, conforme se observa na Figura 3, nos dois grupos, nas duas sessões experimentais, a insulina plasmática aumentou significantemente do período Basal para o de Equilíbrio. Entretanto, na sessão Controle, durante a hiperinsulinemia, os níveis plasmáticos de insulina foram significantemente maiores nos indivíduos Resistentes que nos Sensíveis. Além disso, no grupo Resistente, na sessão de Exercício, a concentração plasmática de insulina durante o período de Equilíbrio foi significantemente menor que na sessão Controle, enquanto o comportamento oposto foi observado no grupo Sensível, ou seja, a concentração de insulina plasmática durante o clampeamento foi maior na sessão de Exercício que na sessão Controle.

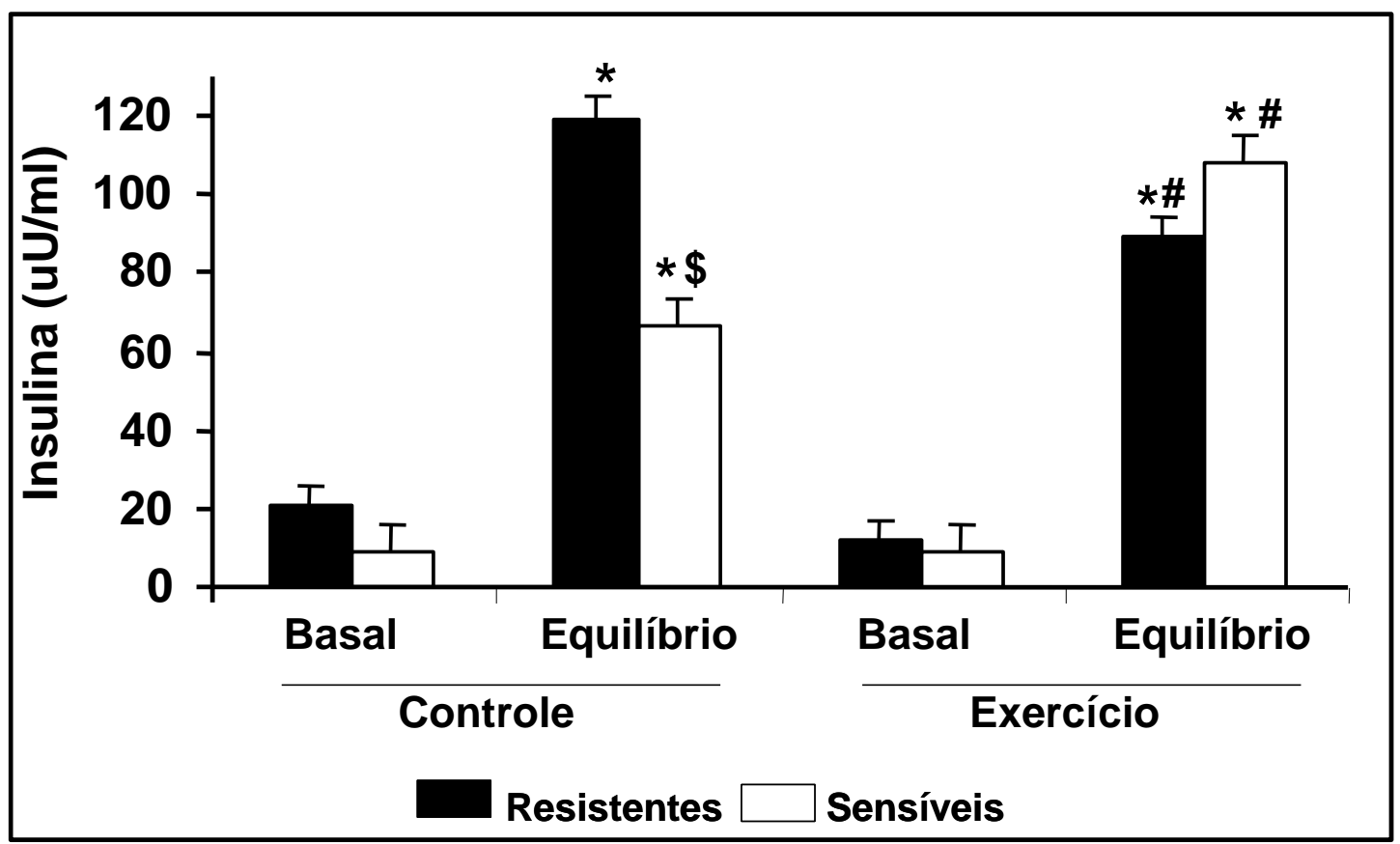

* diferença significante do basal $(\mathrm{P}<0,05)$

\# diferença significante da sessão controle $(P<0,05)$

$\$$ diferença significante dos resistentes $(P<0,05)$

Figura 3 - Insulina plasmática medida no período basal e durante o período de equilíbrio do clampeamento euglicêmico hiperinsulinêmico realizado nas duas sessões (Controle e Exercício) em indivíduos resistentes $(n=10)$ e sensíveis $(\mathrm{n}=8)$ à ação da insulina. 
Os dados da taxa de metabolização de glicose, medidos no período de Equilíbrio dos clampeamentos euglicêmicos/hiperinsulinêmicos realizados nas duas sessões experimentais, estão apresentados na Tabela 6.

TABELA 6 - TAXA DE METABOLIZAÇÃO DE GLICOSE (mg.kg-1 $\left.\mathrm{min}^{-1}\right)$ MEDIDA NO PERÍODO DE EQUILÍBRIO DO CLAMPEAMENTO EUGLICÊMICO HIPERINSULINÊMICO REALIZADO NAS DUAS SESSÕES EXPERIMENTAIS (CONTROLE E EXERCÍCIO) EM INDIVÍDUOS RESISTENTES $(\mathrm{N}=10) \quad \mathrm{E}$ SENSÍVEIS (N=8) À AÇÃO DA INSULINA

\begin{tabular}{ccc} 
& Controle & Exercício \\
\hline Resistentes & $5,5 \pm 0,3$ & $5,8 \pm 0,7$ \\
Sensíveis & $14,5 \pm 1,8$ & $11,0 \pm 0,9$
\end{tabular}

Em relação à taxa de metabolização de glicose, observou-se significância apenas no fator principal grupo $(p=0,00)$. Assim, a taxa de metabolização de glicose foi semelhante entre as duas sessões experimentais. Porém, como se observa na Figura 4, independentemente da sessão, a taxa de metabolização de glicose foi significantemente maior no grupo Sensível que no grupo Resistente à insulina. 


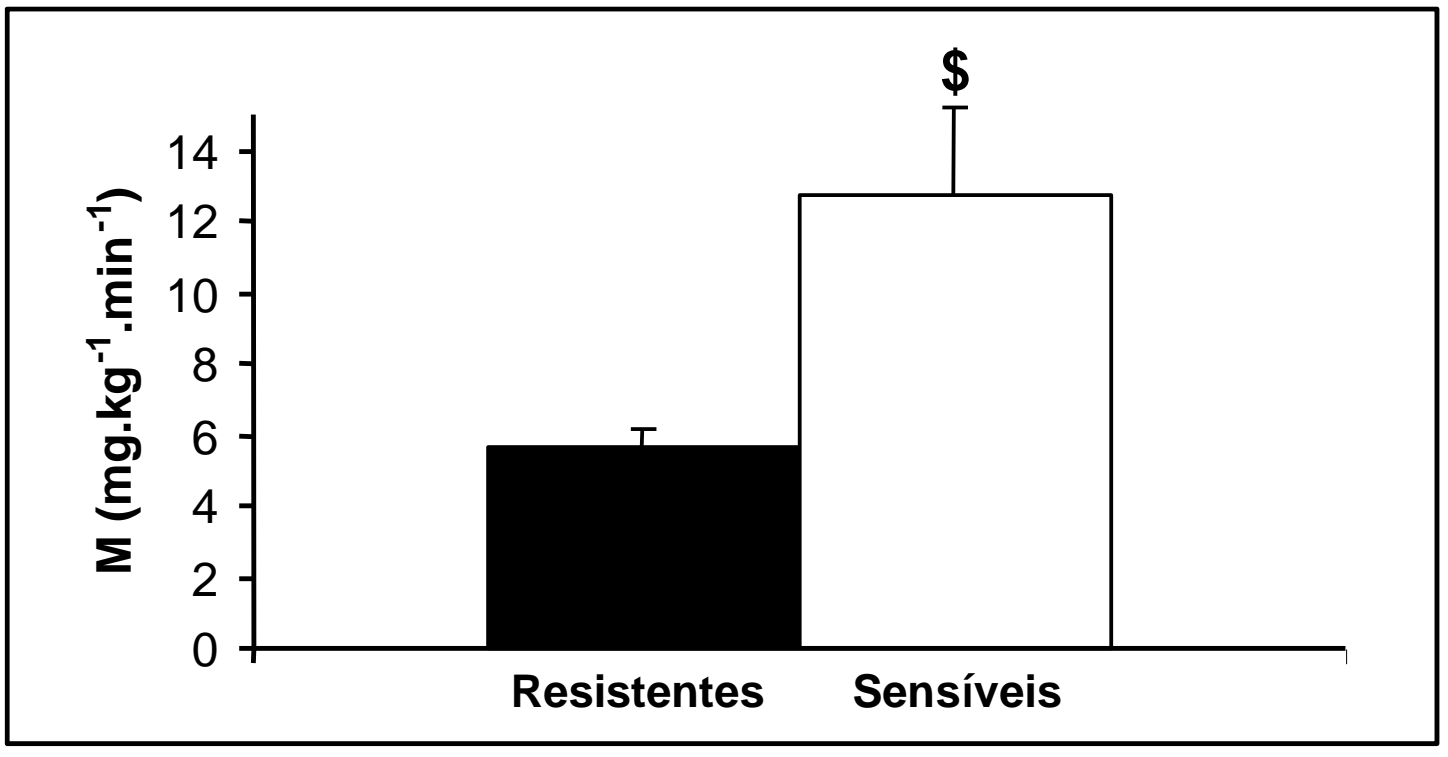

$\$$ diferença significante dos resistentes $(P<0,05)$

Figura 4 - Taxa de metabolização de glicose (M) medida no período de equilíbrio do clampeamento euglicêmico hiperinsulinêmico nos indivíduos resistentes $(n=10)$ e sensíveis $(n=8)$ à ação da insulina. Devido à significância apenas do fator principal da ANOVA (grupo), os dados das duas sessões experimentais (controle e exercício) foram combinados.

Os dados do índice de sensibilidade à insulina, medidos no período de equilíbrio dos clampeamentos euglicêmicos hiperinsulinêmicos realizados nas duas sessões experimentais, estão apresentados na Tabela 7.

TABELA 7 - ÍNDICE DE SENSIBILIDADE À INSULINA MEDIDO NO PERÍODO DE EQUILÍBRIO DO CLAMPEAMENTO EUGLICÊMICO HIPERINSULINÊMICO REALIZADO NAS DUAS SESSÕES EXPERIMENTAIS (CONTROLE E EXERCÍCIO) EM INDIVÍDUOS RESISTENTES ( $\mathrm{N=10}$ ) E SENSÍVEIS (N=8) À AÇÃO DA INSULINA

\begin{tabular}{ccc}
\hline & Controle & Exercício \\
\hline Resistentes & $0,05 \pm 0,00$ & $0,07 \pm 0,01$ \\
Sensíveis & $0,22 \pm 0,03 \$$ & $0,12 \pm 0,02$ \\
\hline
\end{tabular}

Em relação ao índice de sensibilidade à insulina, observou-se significância na interação entre os fatores grupo e sessão $(p=0,00)$. Assim, como se observa na Figura 5, o índice de sensibilidade à insulina foi maior 
nos indivíduos Sensíveis, tanto na sessão Controle quanto na sessão de Exercício. Além disso, nos indivíduos Sensíveis, o índice de sensibilidade à insulina foi significantemente menor na sessão de Exercício que na sessão Controle.

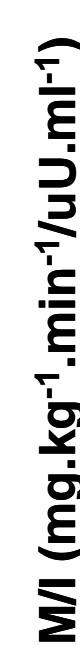

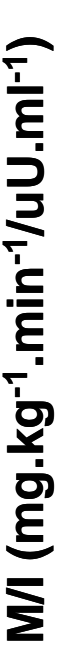

0,3

0,25

0,2

0,15

0,1

0,05

0

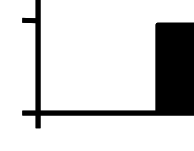

Controle

Exercício

$\square$ Resistentes $\square$ Sensíveis

\# diferença significante da sessão repouso $(P<0,05)$

$\$$ diferença significante dos resistentes $(P<0,05)$

Figura 5 - Índice de sensibilidade à insulina (M/I) medido no período de equilíbrio do clampeamento euglicêmico hiperinsulinêmico realizado nas duas sessões experimentais (Controle e Exercício) nos indivíduos resistentes $(n=10)$ e sensíveis $(n=8)$ à ação da insulina.

Os dados da pressão arterial sistólica, medidos no período basal e de equilíbrio dos clampeamentos euglicêmicos/hiperinsulinêmicos realizados nas duas sessões experimentais, estão apresentados na Tabela 8. 
TABELA 8 - PRESSÃO ARTERIAL SISTÓLICA (mmHg) MEDIDA NO PERÍODO BASAL E DURANTE O PERÍODO DE EQUILÍBRIO DO CLAMPEAMENTO EUGLICÊMICO HIPERINSULINÊMICO REALIZADO NAS DUAS SESSÕES EXPERIMENTAIS (CONTROLE E EXERCÍCIO) EM INDIVÍDUOS RESISTENTES $(\mathrm{N}=10)$ E SENSÍVEIS $(\mathrm{N}=8)$ A AÇÃO DA INSULINA

\begin{tabular}{ccccc}
\hline & \multicolumn{2}{c}{ Controle } & \multicolumn{2}{c}{ Exercício } \\
\hline \multirow{2}{*}{ Resistentes } & Basal & Equilíbrio & Basal & Equilíbrio \\
Sensíveis & $126 \pm 3$ & $129 \pm 3$ & $125 \pm 3$ & $128 \pm 3$ \\
& $125 \pm 2$ & $132 \pm 3$ & $123 \pm 3$ & $135 \pm 4$ \\
\hline
\end{tabular}

Em relação à pressão arterial sistólica, observou-se significância na interação entre grupo e estágio $(p=0,01)$. Assim, a pressão arterial sistólica foi semelhante nas sessões Controle e Exercício. Porém, independentemente da sessão, como se observa na Figura 6, a pressão arterial sistólica aumentou significantemente no período de Equilíbrio em relação ao Basal nos dois grupos, sendo esse aumento maior no grupo Sensível, o que pôde ser observado pela comparação do aumento obtido nos dois grupos (Sensíveis = $+9,1 \pm 1,6$ vs. Resistentes $=+3,1 \pm 1,0 \mathrm{mmHg}, \mathrm{P}<0,05-$ teste $\mathrm{T}$ para medidas independentes). 


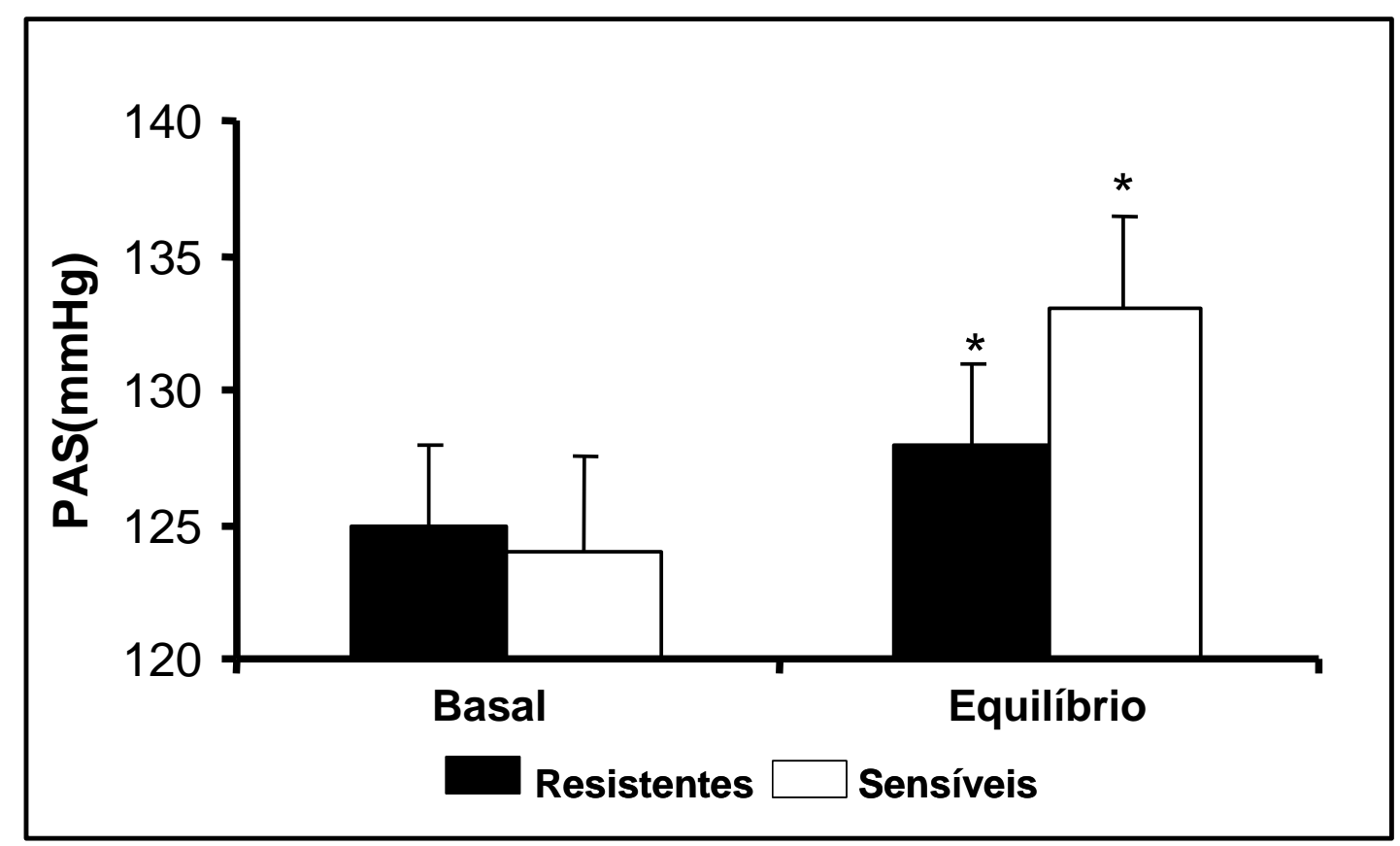

*diferença significante do basal $(P<0,05)$

Figura 6 - Pressão arterial sistólica (PAS) medida no período basal e durante o período de equilíbrio do clampeamento euglicêmico hiperinsulinêmico em indivíduos resistentes $(n=10)$ e sensíveis $(n=8)$ à ação da insulina. Devido à significância ter sido observada apenas na interação grupo e estágio na ANOVA, os dados das duas sessões (Controle e Exercício) foram combinados.

Os dados da pressão arterial média, medidos no período Basal e de Equilíbrio dos clampeamentos euglicêmicos/hiperinsulinêmicos realizados nas duas sessões experimentais, estão apresentados na Tabela 9.

TABELA 9 - PRESSÃO ARTERIAL MÉDIA (mmHg) MEDIDA NO PERÍODO BASAL E DURANTE O PERÍODO DE EQUILÍBRIO DO CLAMPEAMENTO EUGLICÊMICO HIPERINSULINÊMICO REALIZADO NAS DUAS SESSÕES EXPERIMENTAIS (CONTROLE E EXERCÍCIO) EM INDIVÍDUOS RESISTENTES (N=10) E SENSÍVEIS ( $\mathrm{N}=8)$ A AÇÃO DA INSULINA

\begin{tabular}{ccccc}
\hline & \multicolumn{2}{c}{ Controle } & \multicolumn{2}{c}{ Exercício } \\
\hline \multirow{2}{*}{ Resistentes } & Basal & Equilíbrio & Basal & Equilíbrio \\
Sensíveis & $90 \pm 3$ & $92 \pm 2$ & $89 \pm 3$ & $90 \pm 2$ \\
& $92 \pm 2$ & $93 \pm 3$ & $88 \pm 4$ & $94 \pm 3$ \\
\hline
\end{tabular}


Em relação à pressão arterial média, observou-se significância na interação entre grupo, sessão e estágio $(p=0,02)$. Assim, conforme se observa na Figura 7, nos indivíduos Sensíveis, na sessão de Exercício, a pressão arterial média aumentou significantemente no período de Equilíbrio em relação ao Basal, o que não se observou na sessão Controle, nem no grupo.

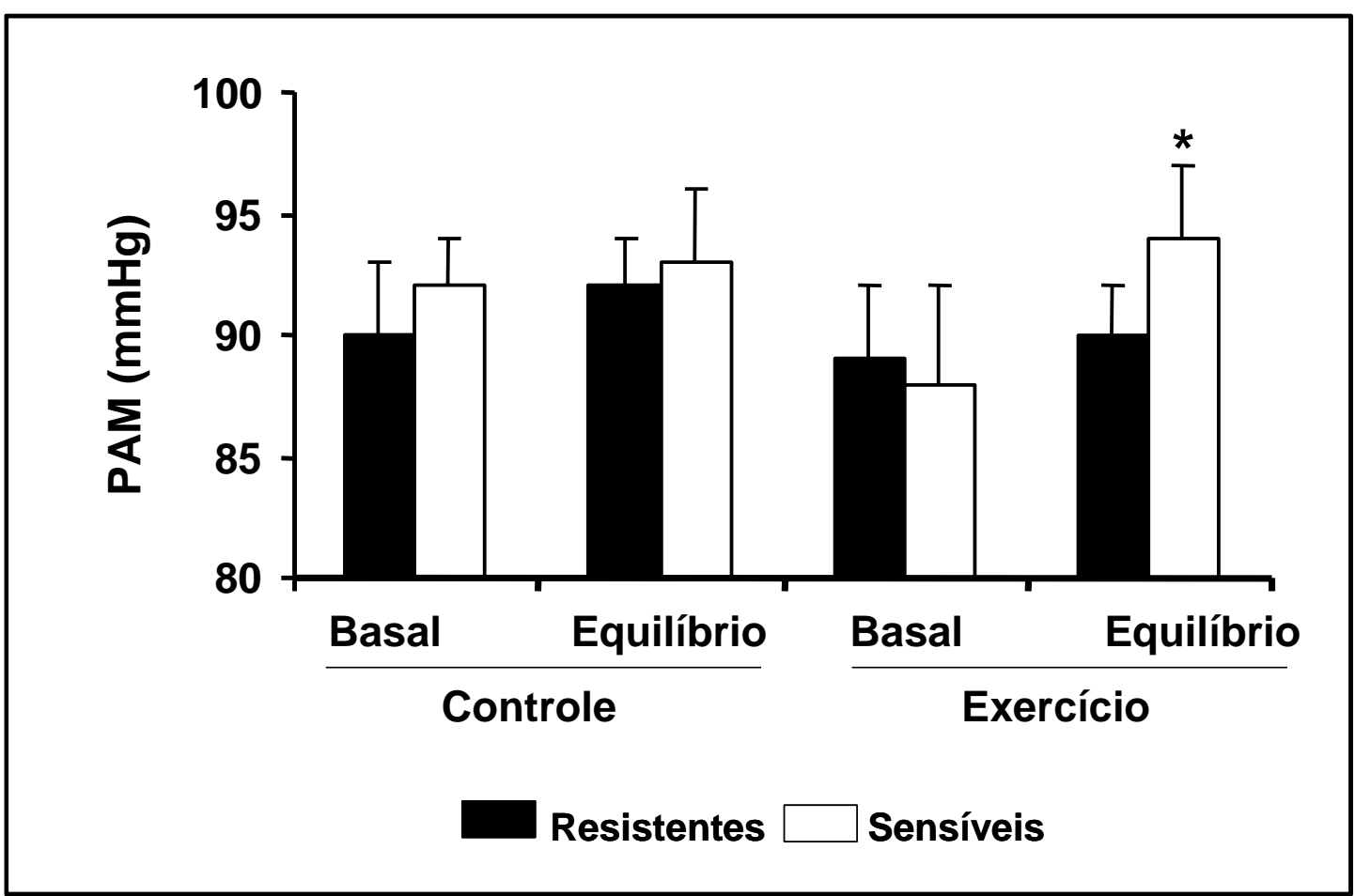

* diferença significante do basal $(P<0,05)$

Figura 7 - Pressão arterial média (PAM) medida no período basal e durante o período de equilíbrio do clampeamento euglicêmico hiperinsulinêmico realizado nas duas sessões experimentais (Controle e Exercício) em indivíduos resistentes $(n=10)$ e sensíveis $(n=8)$ à ação da insulina.

Os dados da pressão arterial diastólica, medidos no período Basal e de Equilíbrio dos clampeamentos euglicêmicos/hiperinsulinêmicos, realizados nas duas sessões experimentais, estão apresentados na Tabela 10. 
TABELA 10- PRESSÃO ARTERIAL DIASTÓLICA (mmHg) MEDIDA NO PERÍODO BASAL E DURANTE O PERÍODO DE EQUILÍBRIO DO CLAMPEAMENTO EUGLICÊMICO HIPERINSULINÊMICO, REALIZADO NAS DUAS SESSÕES EXPERIMENTAIS (CONTROLE E EXERCÍCIO) EM INDIVÍDUOS RESISTENTES $(\mathrm{N}=10)$ E SENSÍVEIS $(\mathrm{N}=8)$ A AÇÃO DA INSULINA

\begin{tabular}{ccccc} 
& \multicolumn{2}{c}{ Controle } & \multicolumn{2}{c}{ Exercício } \\
\hline \multirow{2}{*}{ Resistentes } & Basal & Equilíbrio & Basal & Equilíbrio \\
Sensíveis & $73 \pm 3$ & $74 \pm 2$ & $73 \pm 3$ & $72 \pm 2$ \\
& $75 \pm 3$ & $78 \pm 3$ & $71 \pm 3$ & $77 \pm 3$ \\
\hline
\end{tabular}

Em relação à pressão arterial diastólica, observou-se significância na interação entre grupo, sessão e estágio $(p=0,01)$. Assim, conforme se observa na Figura 8, no período Basal, os indivíduos Sensíveis apresentaram pressão arterial diastólica significantemente menor na sessão de Exercício que na sessão Controle. Além disso, nesse grupo, na sessão de Exercício, houve um aumento significante da pressão arterial diastólica no período de Equilíbrio em relação ao Basal. Somando-se a isso, no período de Equilíbrio das duas sessões experimentais, a pressão arterial diastólica foi significantemente maior no grupo Sensível que no Resistente. 


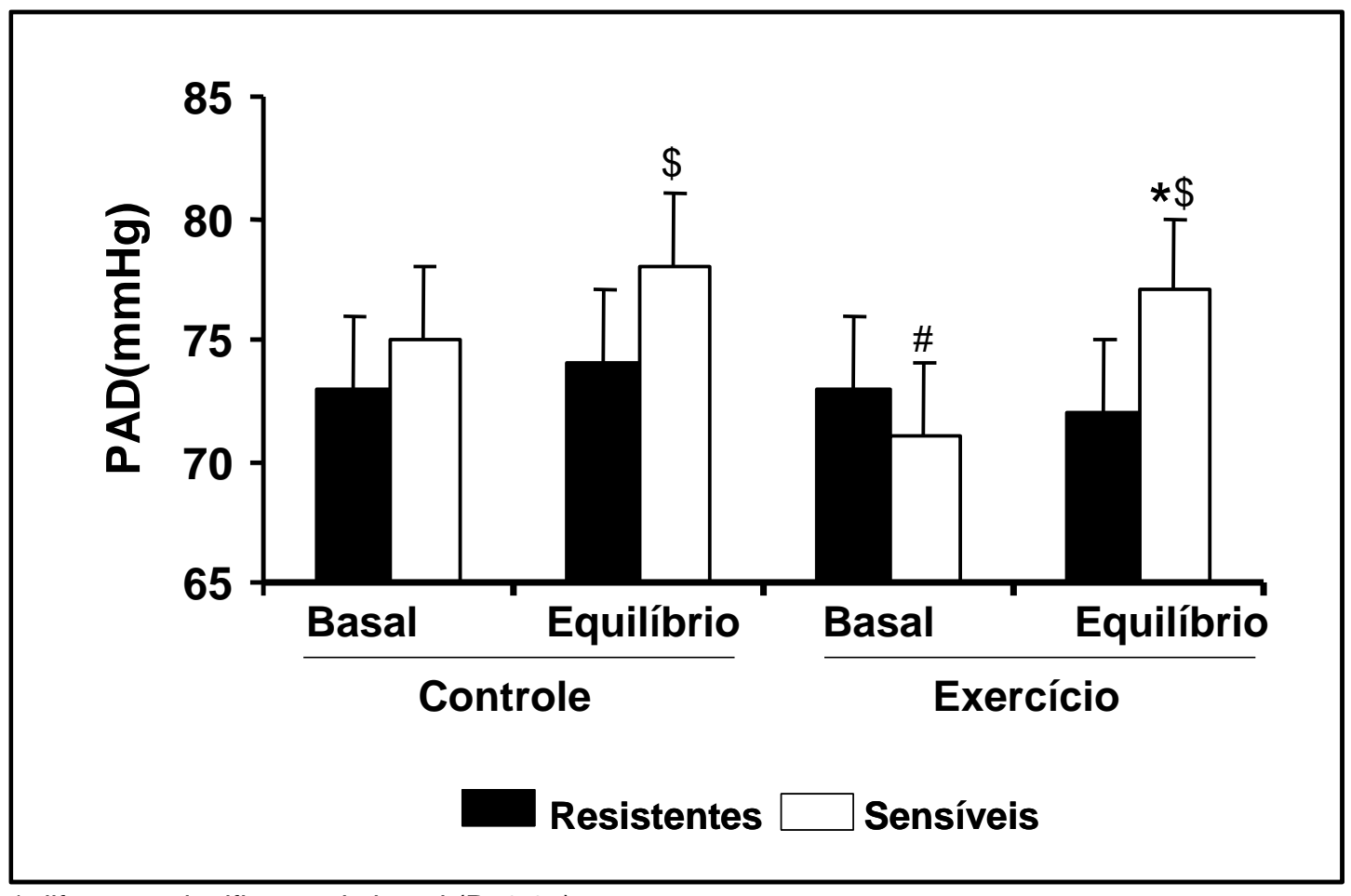

* diferença significante do basal $(\mathrm{P}<0,05)$

\# diferença significante da sessão controle $(P<0,05)$

$\$$ diferença significante dos resistentes $(P<0,05)$

Figura 8 - Pressão arterial diastólica (PAD) medida no período basal e durante o período de equilíbrio do clampeamento euglicêmico hiperinsulinêmico realizado nas duas sessões experimentais (Controle e Exercício) em indivíduos resistentes $(n=10)$ e sensíveis $(n=8)$ à ação da insulina.

Os dados da freqüência cardíaca, medidos no período Basal e de Equilíbrio dos clampeamentos euglicêmicos/hiperinsulinêmicos realizados nas duas sessões experimentais, estão apresentados na Tabela 11.

TABELA 11 - FREQÜÊNCIA CARDÍACA (bat/min) MEDIDA NO PERÍODO BASAL E DURANTE O PERÍODO DE EQUILÍBRIO DO CLAMPEAMENTO EUGLICÊMICO/HIPERINSULINÊMICO REALIZADO NAS SESSÕES EXPERIMENTAIS (CONTROLE E EXERCÍCIO) EM INDIVÍDUOS RESISTENTES $(\mathrm{N}=10) \quad \mathrm{E}$ SENSÍVEIS (N=8) À AÇÃO DA INSULINA

\begin{tabular}{ccccc}
\hline & \multicolumn{2}{c}{ Controle } & \multicolumn{2}{c}{ Exercício } \\
\hline \multirow{2}{*}{ Resistentes } & $56 \pm 2$ & $60 \pm 2$ & $61 \pm 3$ & $64 \pm 3$ \\
Sensíveis & $56 \pm 2$ & $62 \pm 2$ & $62 \pm 3$ & $64 \pm 3$ \\
\hline
\end{tabular}


Em relação à freqüência cardíaca, observou-se significância nos fatores principais: sessão $(P=0,04)$ e estágio $(P=0,00)$. Assim, não houve diferença significante na freqüência cardíaca dos indivíduos Resistentes e Sensíveis à ação da insulina. Entretanto, independentemente do grupo e do estágio, a freqüência cardíaca, como se observa na Figura 9, foi significantemente maior na sessão de Exercício que na sessão Controle. Além disso, independentemente do grupo e da sessão, como visto na Figura 10, a freqüência cardíaca foi significantemente maior no período de Equilíbrio que no período Basal.

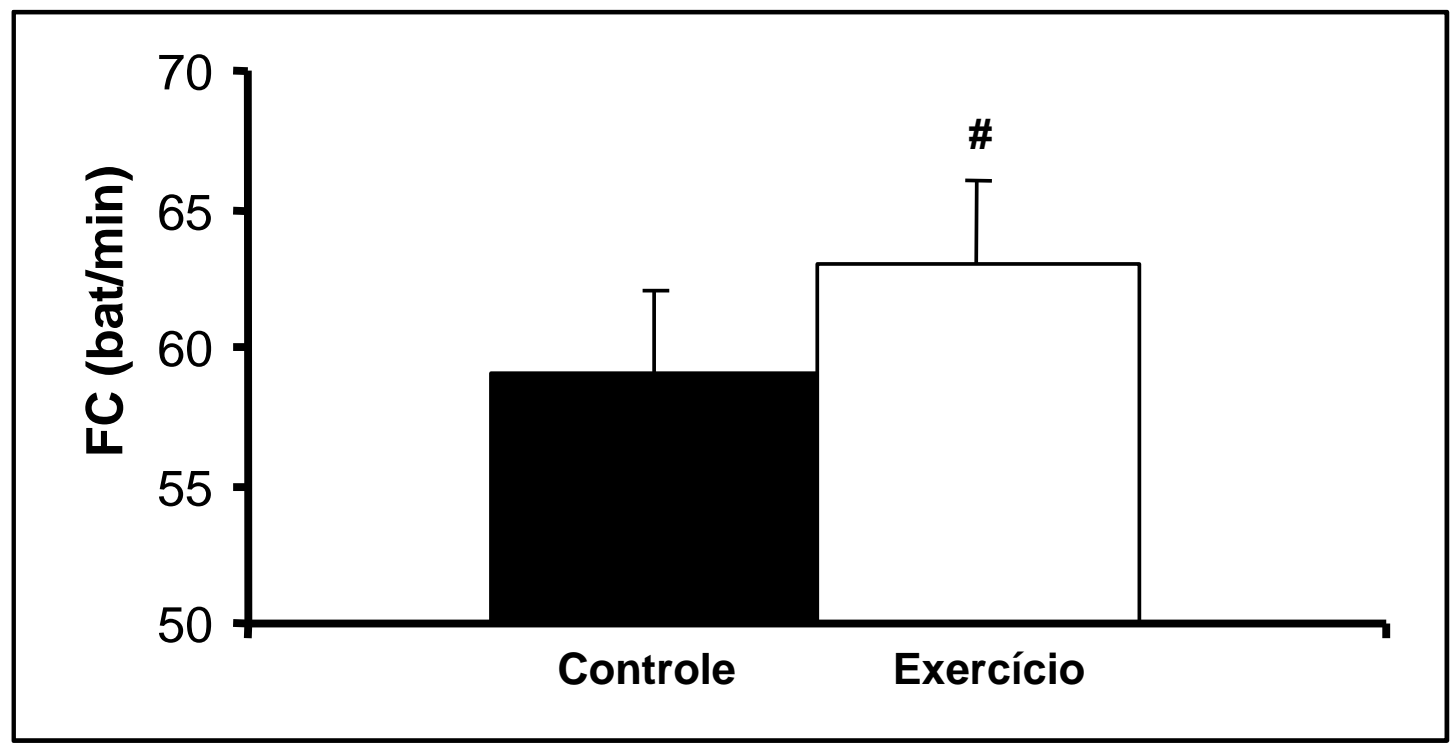

\# diferença significante da sessão controle $(P<0,05)$

Figura 9 - Freqüência cardíaca $(F C)$ medida nas duas sessões experimentais (Controle e Exercício). Devido à significância do fator principal da ANOVA (sessão), os dados dos grupos resistentes e sensíveis e dos períodos basal e equilíbrio foram combinados. 


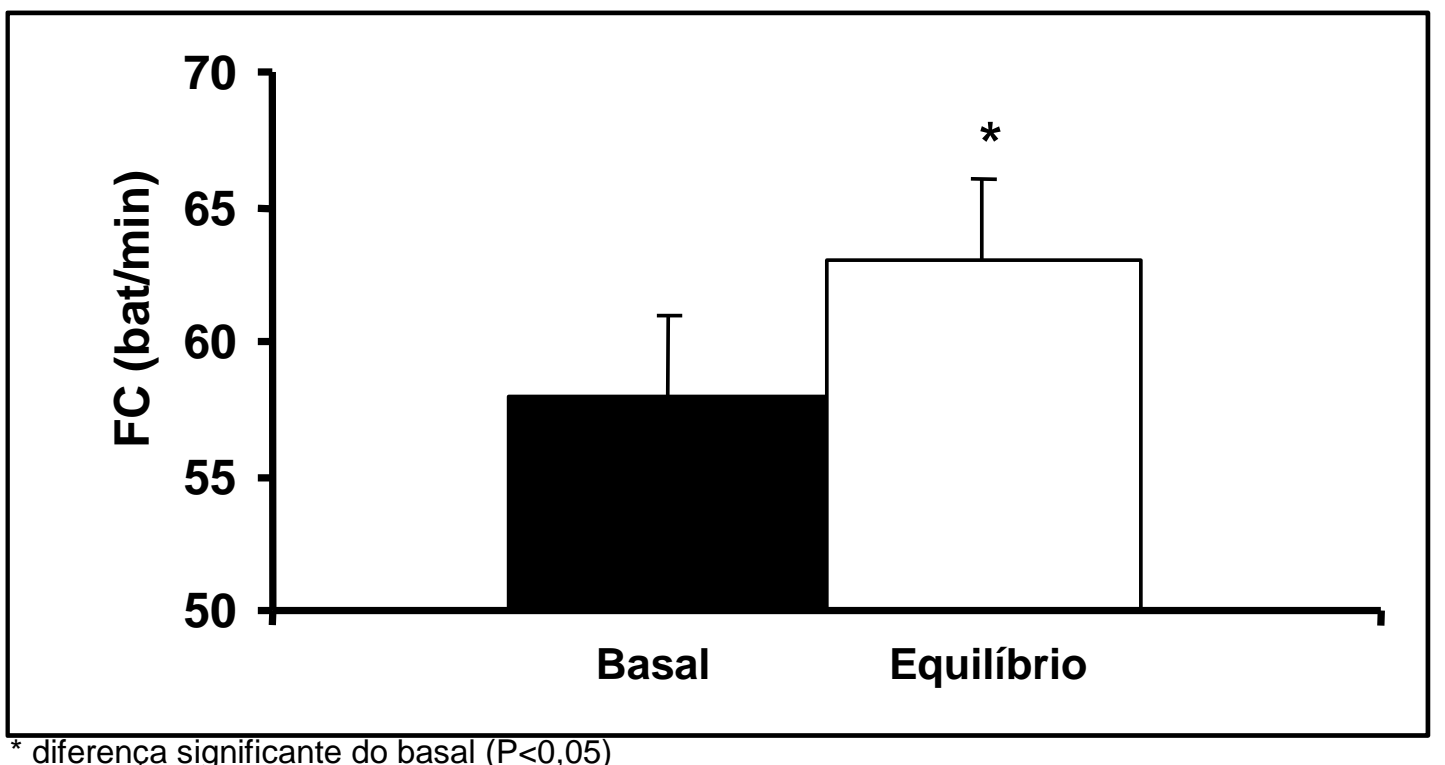

Figura 10 - Freqüência cardíaca (FC) medida no período basal e de equilíbrio do clampeamento euglicêmico hiperinsulinêmico. Devido à significância do fator principal da ANOVA (estágio), os dados dos grupos resistentes e sensíveis e das sessões controle e exercício foram combinados.

Os dados da atividade nervosa simpática, medidos no período Basal e de Equilíbrio dos clampeamentos euglicêmicos/hiperinsulinêmicos realizados nas duas sessões experimentais, estão apresentados na Tabela 12.

TABELA 12 - ATIVIDADE NERVOSA SIMPÁTICA (impulsos/min) MEDIDA NO PERÍODO BASAL E DURANTE O PERÍODO DE EQUILÍBRIO DO CLAMPEAMENTO EUGLICÊMICO HIPERINSULINÊMICO REALIZADO NAS SESSÕES EXPERIMENTAIS (CONTROLE E EXERCÍCIO) EM INDIVÍDUOS RESISTENTES ( $\mathrm{N}=9)$ E SENSÍVEIS $(\mathrm{N}=7)$ À AÇÃO DA INSULINA

\begin{tabular}{ccccc}
\hline & \multicolumn{2}{c}{ Controle } & \multicolumn{2}{c}{ Exercício } \\
\hline \multirow{2}{*}{ Besistentes } & $22,4 \pm 2,9$ & Equilíbrio & Basal & Equilíbrio \\
Sensiveis & $29,0 \pm 4,0$ & $18,4 \pm 2,6$ & $31,6 \pm 3,8$ \\
& 29,0 & $45,2 \pm 5,9$ & $23,1 \pm 2,5$ & $39,1 \pm 3,9$ \\
\hline
\end{tabular}

Em relação à atividade nervosa simpática, observou-se significância nos fatores principais: sessão $(P=0,02)$ e estágio $(P=0,00)$. Assim, não houve diferença significante na atividade nervosa simpática dos indivíduos 
Resistentes e Sensíveis à ação da insulina. Entretanto, independentemente do grupo e do estágio, a atividade nervosa simpática, como se observa na Figura 11, foi significantemente menor na sessão de Exercício que na sessão Controle. Além disso, independentemente do grupo e da sessão, como visto na Figura 12, a atividade nervosa simpática foi significantemente maior no período de Equilíbrio que no período Basal.

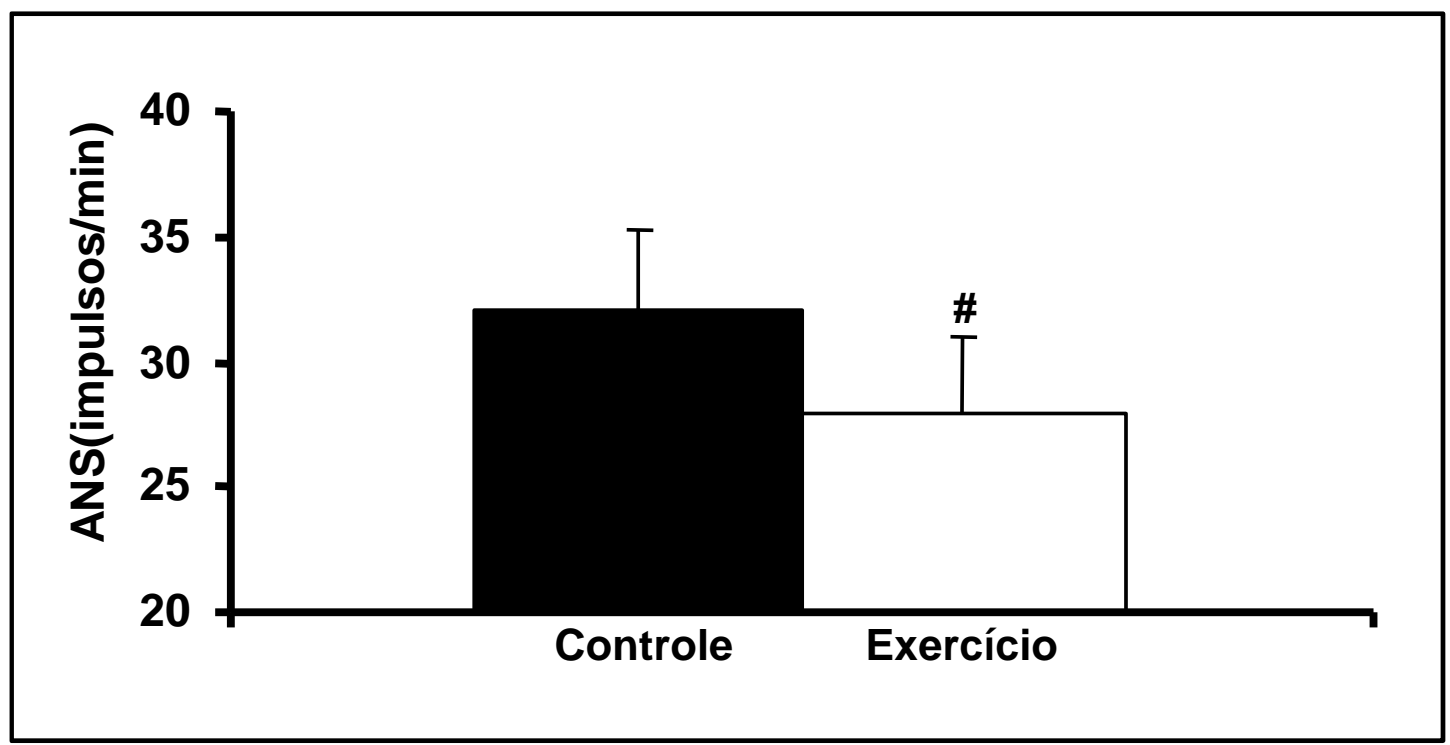

\# diferença significante da sessão controle $(P<0,05)$

Figura 11 - Atividade nervosa simpática (ANS) medida nas duas sessões experimentais (Controle e Exercício). Devido à significância do fator principal da ANOVA (sessão), os dados dos grupos resistentes e sensíveis e dos períodos basal e equilíbrio foram combinados. 


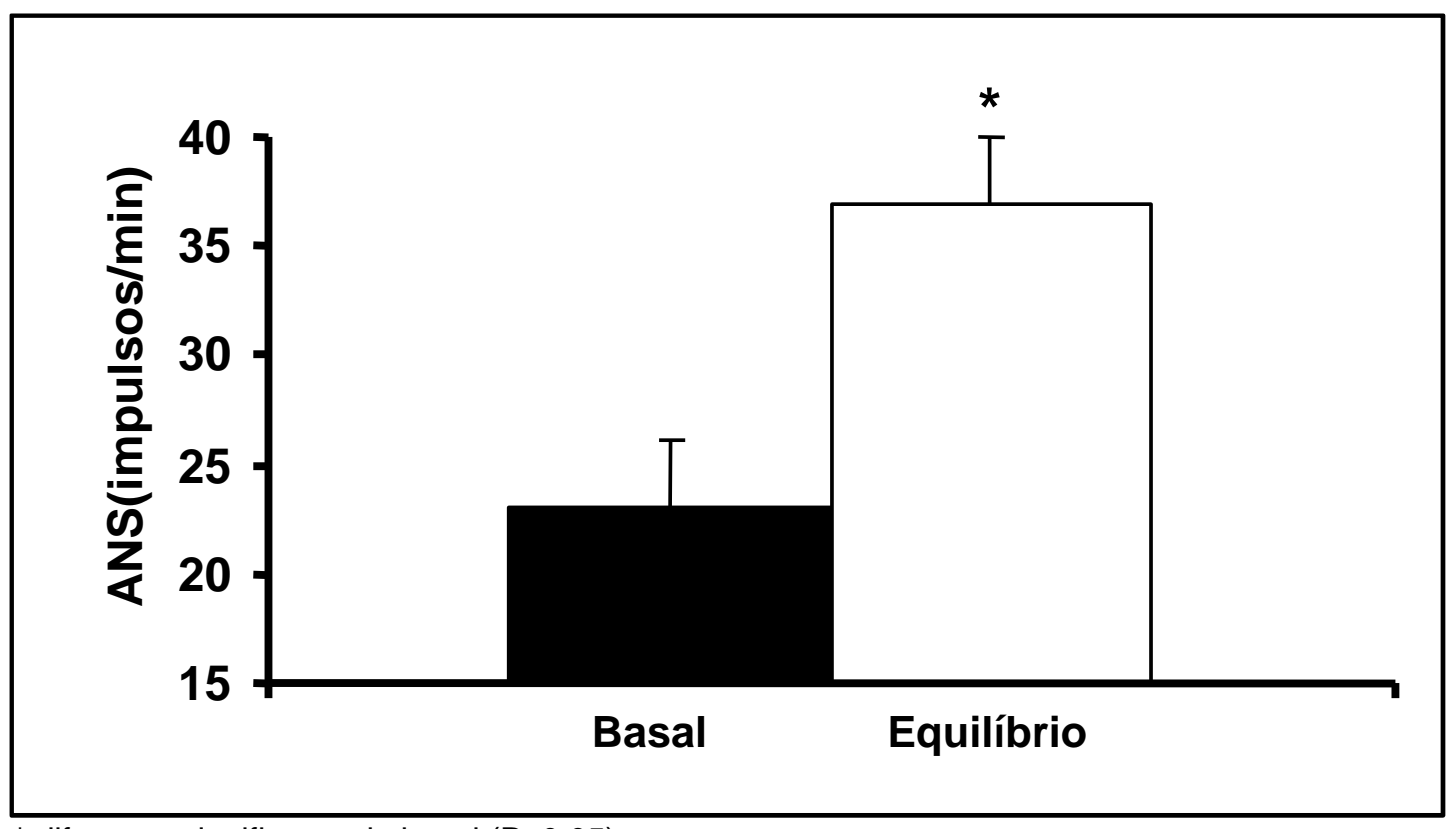

* diferença significante do basal $(\mathrm{P}<0,05)$

Figura 12 - Atividade nervosa simpática (ANS), medida no período basal e de equilíbrio do clampeamento euglicêmico hiperinsulinêmico. Devido à significância do fator principal da ANOVA (estágio), os dados dos grupos resistentes e sensíveis e das sessões controle e exercício foram combinados.

Os dados do fluxo sanguíneo do antebraço, medidos no período Basal e de Equilíbrio dos clampeamentos euglicêmicos/hiperinsulinêmicos realizados nas duas sessões experimentais, estão apresentados na Tabela 13.

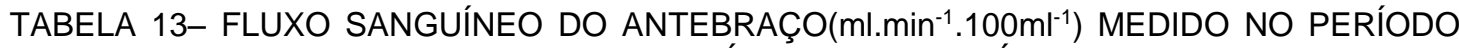
BASAL E DURANTE O PERÍODO DE EQUILÍBRIO DO CLAMPEAMENTO EUGLICEMICO/HIPERINSULINEMICO REALIZADO NAS SESSÕES EXPERIMENTAIS (CONTROLE E EXERCÍCIO) EM INDIVIIDUOS RESISTENTES ( $\mathrm{N}=10)$ E SENSÍVEIS ( $\mathrm{N}=8)$ À AÇÃO DA INSULINA

\begin{tabular}{ccccc} 
& \multicolumn{2}{c}{ Controle } & \multicolumn{2}{c}{ Exercício } \\
\hline Resistentes & Basal & Equilíbrio & Basal & Equilíbrio \\
Sensíveis & $1,65 \pm 0,18$ & $1,82 \pm 0,13$ & $1,84 \pm 0,22$ & $1,99 \pm 0,24$ \\
& $1,40 \pm 0,19$ & $2,37 \pm 0,41$ & $2,27 \pm 0,31$ & $2,81 \pm 0,48$ \\
\hline
\end{tabular}

Em relação ao fluxo sanguíneo do antebraço, observou-se significância no fator principal sessão $(\mathrm{P}=0,04)$ e na interação entre grupo e estágio $(p=0,02)$. Assim, em relação ao fator sessão, verificou-se, como observado na

Figura 13, que o fluxo sanguíneo do antebraço foi significantemente maior na 
sessão de Exercício que na sessão Controle. Em relação à interação grupo e estágio, observou-se, como na Figura 14, que independentemente da sessão, no período Basal não houve diferença no fluxo sanguíneo do antebraço dos indivíduos Resistentes e Sensíveis à insulina. Entretanto, nos indivíduos Sensíveis, o fluxo sanguíneo do antebraço foi significantemente maior no período de Equilíbrio que no Basal, o que não ocorreu nos indivíduos Resistentes. Dessa forma, no período de equilíbrio, o fluxo sanguíneo do antebraço foi significantemente maior nos Sensíveis que nos Resistentes.

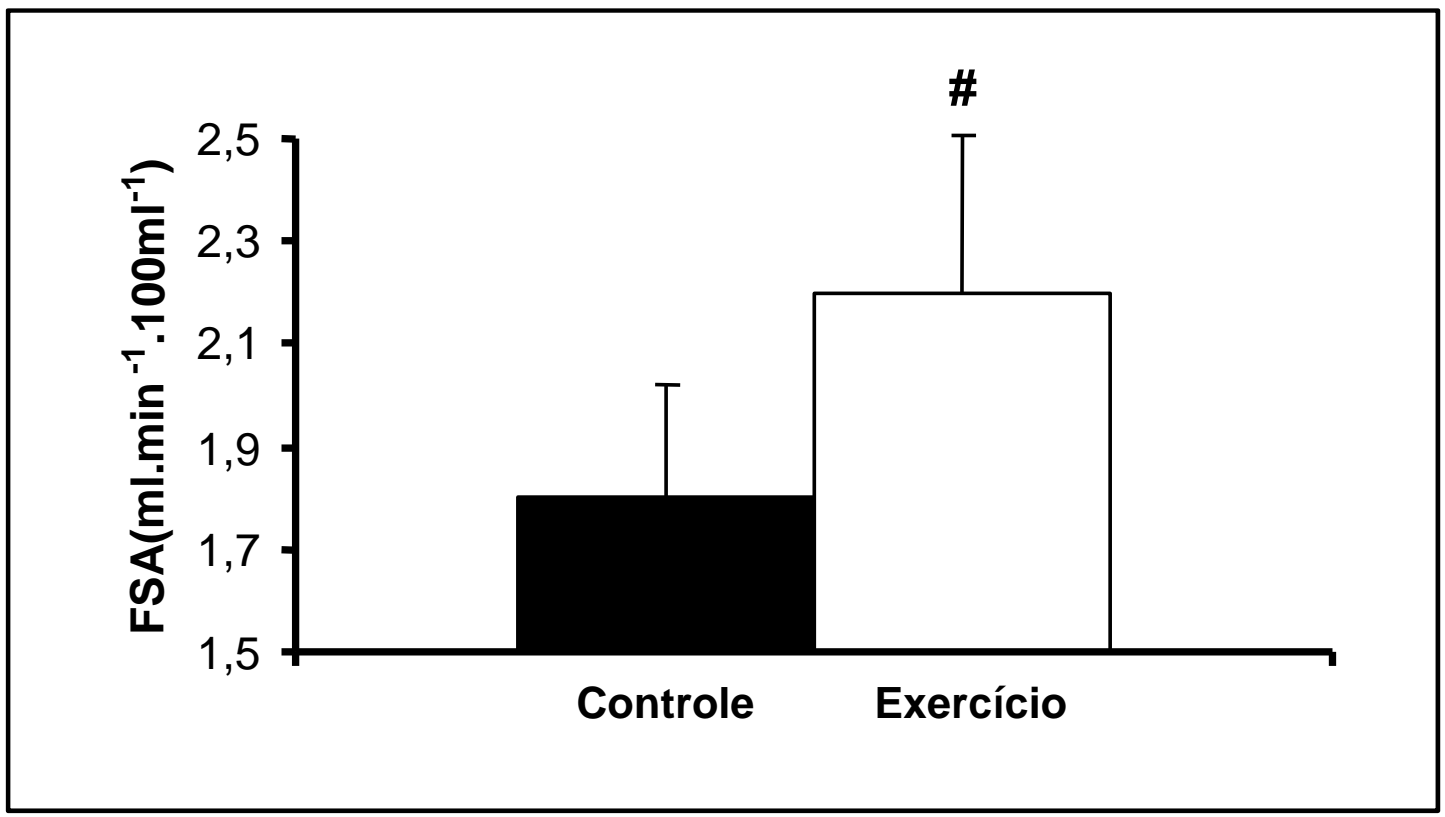

\# diferença significante da sessão controle $(\mathrm{P}<0,05)$

Figura 13 - Fluxo sanguíneo do antebraço (FSA) medido nas duas sessões experimentais (Controle e Exercício). Devido à significância do fator principal da ANOVA (sessão), os dados dos grupos resistentes e sensíveis e dos períodos basal e equilíbrio foram combinados. 


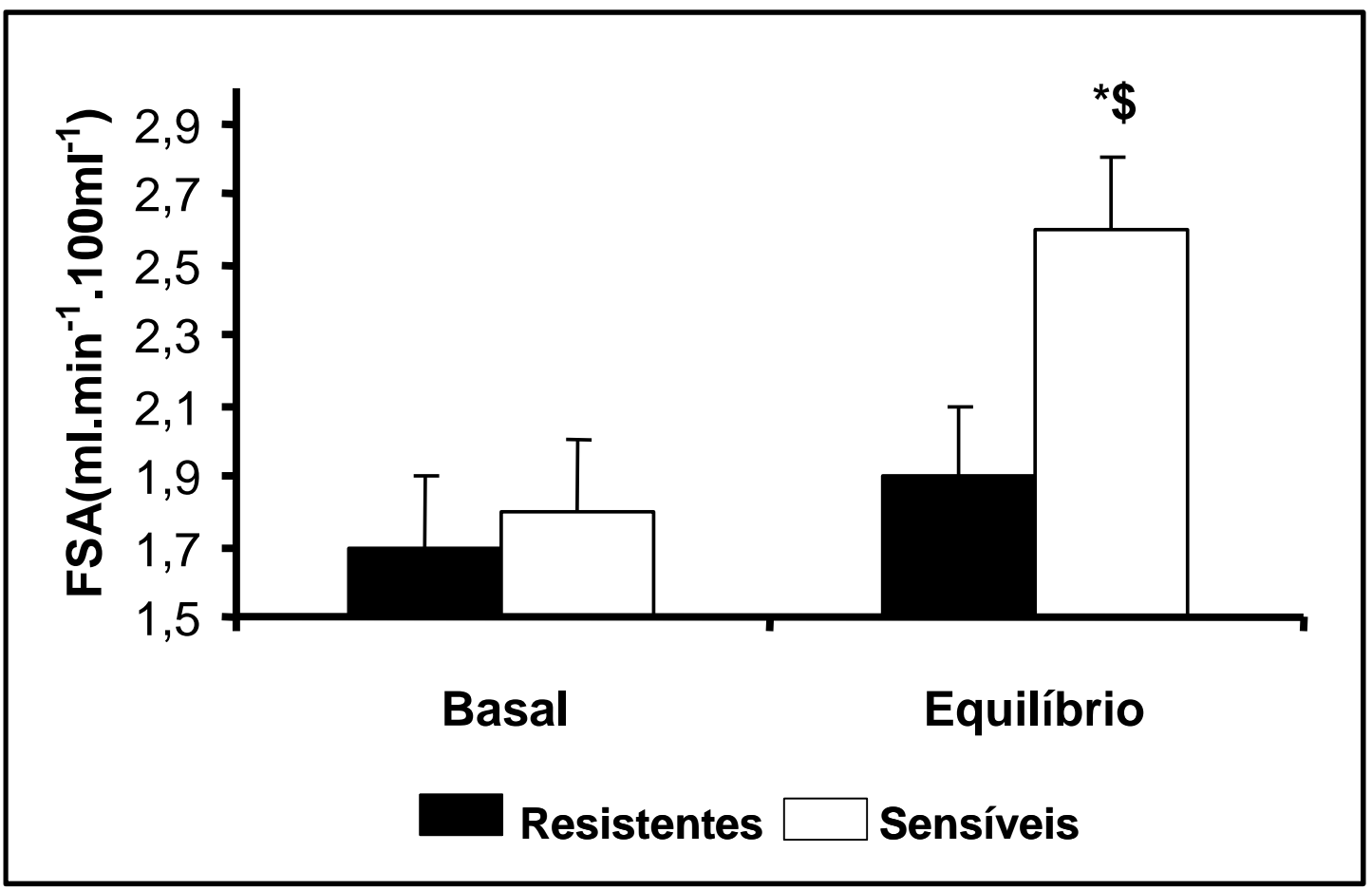

* diferença significante do basal $(P<0,05)$

$\$$ diferença significante dos resistentes $(\mathrm{P}<0,05)$

Figura 14 - Fluxo sanguíneo do antebraço (FSA) medido no período basal e durante o período de equilíbrio do clampeamento euglicêmico hiperinsulinêmico em indivíduos resistentes $(n=10)$ e sensíveis $(n=8)$ à ação da insulina. Devido à significância ter sido observada na interação grupo e fase na ANOVA, os dados das duas sessões (Controle e Exercício) foram combinados.

Os dados de resistência vascular do antebraço, medidos no período basal e de equilíbrio dos clampeamentos euglicêmicos/hiperinsulinêmicos realizados nas duas sessões experimentais, estão apresentados na Tabela 14.

TABELA 14 - RESISTÊNCIA VASCULAR DO ANTEBRAÇO (U) MEDIDA NO PERÍODO BASAL E DURANTE O PERIIODO DE EQUILÍBRIO DO CLAMPEAMENTO EUGLICÊMICO HIPERINSULINÊMICO REALIZADO NAS SESSÕES EXPERIMENTAIS (CONTROLE E EXERCÍCIO) EM INDIVÍDUOS RESISTENTES ( $N=10) \quad$ E SENSÍVEIS ( $N=8)$ À AÇÃO DA INSULINA

\begin{tabular}{ccccc} 
& \multicolumn{2}{c}{ Controle } & \multicolumn{2}{c}{ Exercício } \\
\hline \multirow{2}{*}{ Basal } & Equilíbrio & Basal & Equilíbrio \\
Resistentes & $62,3 \pm 7,8$ & $54,7 \pm 5,3$ & $55,6 \pm 6,1$ & $52,0 \pm 6,6$ \\
Sensíveis & $75,1 \pm 10,3$ & $47,6 \pm 7,2$ & $44,9 \pm 6,5$ & $41,7 \pm 7,5$
\end{tabular}


Em relação à resistência vascular do antebraço, observou-se significância na interação sessão e estágio $(P=0,01)$. Assim, a resistência vascular do antebraço foi semelhante entre os grupos. Porém, como se observa na Figura 15, independentemente do grupo, a resistência vascular do antebraço, no período Basal, foi significantemente menor na sessão de Exercício que na sessão Controle. Além disso, na sessão Controle, a resistência vascular do antebraço diminuiu significantemente do Basal para o período de Equilíbrio, o que não ocorreu na sessão de Exercício.

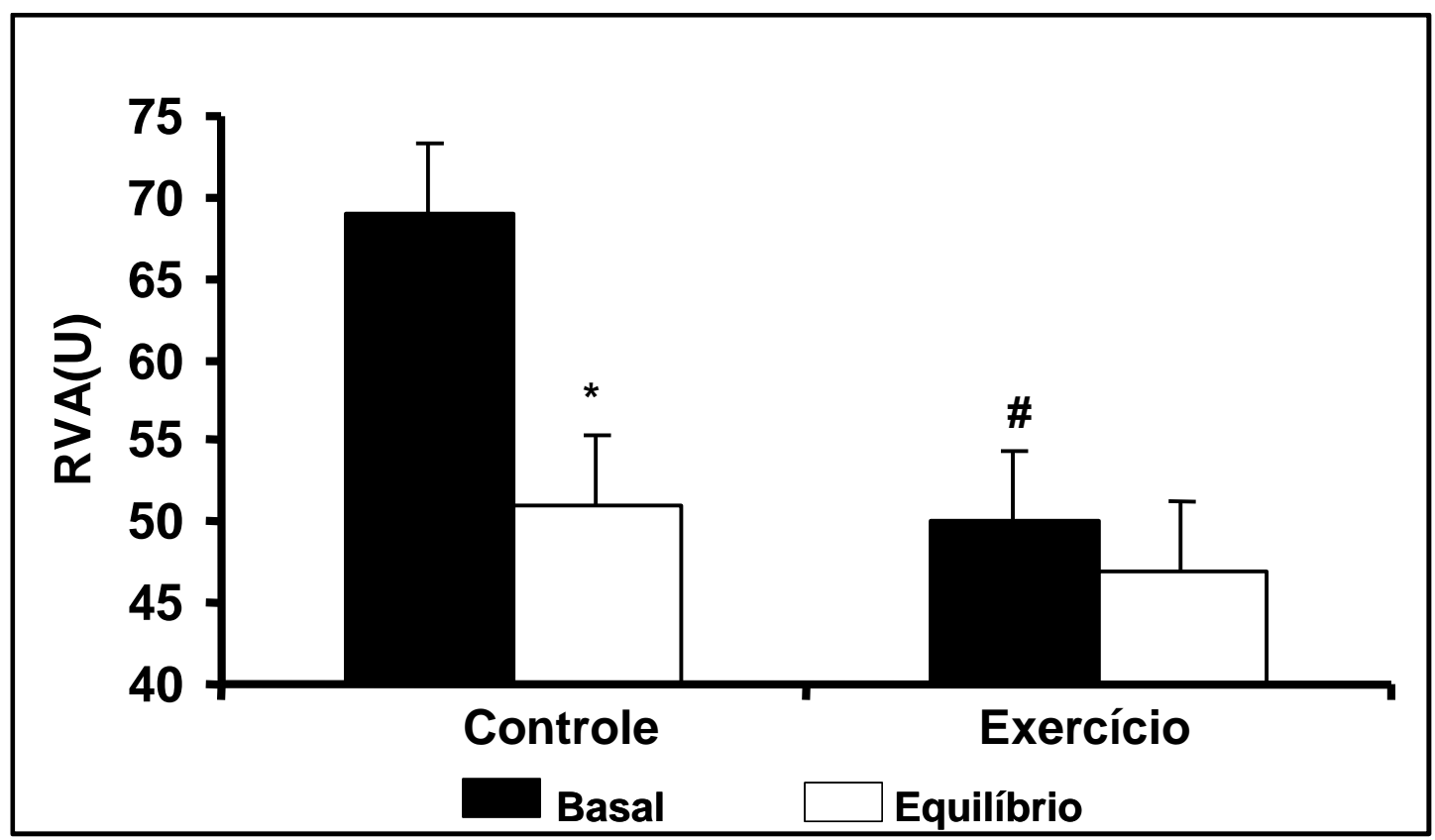

* diferença significante do basal $(P<0,05)$

\# diferença significante da sessão controle $(P<0,05)$

Figura 15 - Resistência vascular do antebraço (RVA) medida nas duas sessões experimentais (Controle e Exercício) no período basal e de equilíbrio do clampeamento euglicêmico hiperinsulinêmico. Devido à significância da interação sessão e estágio da ANOVA, os dados dos grupos resistentes e sensíveis foram combinados. 
Capitulo 6: DISCUSSÃO 


\section{DISCUSSÃO}

Os principais achados desse estudo foram:

a) A execução prévia de uma sessão de exercício físico reduziu a glicemia de forma semelhante em indivíduos sensíveis e resistentes à ação da insulina. b) A infusão da mesma dose de insulina, aumentou mais a insulinemia nos indivíduos resistentes à insulina que nos sensíveis. Porém, a execução prévia de uma única sessão de exercício diminui a hiperinsulinemia promovida pela infusão de insulina nos indivíduos resistentes e aumentou essa hiperinsulinemia nos indivíduos sensíveis, fazendo com que a concentração plasmática de insulina durante a infusão realizada pós-exercício fosse igual nos dois grupos.

c) A execução prévia de uma sessão de exercício modificou a sensibilidade à insulina de forma diferente nos indivíduos sensíveis e resistentes à ação desse hormônio. Dessa forma, o exercício prévio reduziu a sensibilidade à insulina nos indivíduos sensíveis e não a alterou nos resistentes, nos quais $60 \%$ apresentaram aumento da sensibilidade.

d) A infusão de insulina aumentou a pressão arterial sistólica nos dois grupos, de forma semelhante nas duas sessões experimentais, porém o aumento foi maior nos indivíduos sensíveis. 
e) A infusão de insulina aumentou a pressão arterial média apenas nos indivíduos sensíveis após o exercício.

f) O exercício físico diminuiu a pressão arterial diastólica basal dos indivíduos sensíveis. A infusão de insulina aumentou a pressão arterial diastólica apenas no dia de exercício. Além disso, nas duas sessões, a pressão arterial diastólica durante a hiperisulinemia foi maior nos indivíduos sensíveis.

g) O exercício e a infusão de insulina aumentaram a freqüência cardíaca de forma semelhante nos dois grupos.

h) Nos dois grupos, a infusão de insulina ocasionou aumento semelhante da atividade nervosa simpática, e o exercício físico reduziu essa atividade tanto no basal quanto durante a infusão de insulina.

i) O exercício físico aumentou o fluxo sanguíneo do antebraço nos dois grupos (resistente e sensível), enquanto a infusão de insulina aumentou o fluxo sanguíneo do antebraço apenas nos indivíduos sensíveis.

j) O exercício físico diminuiu a resistência vascular do antebraço na situação basal. Além disso, a infusão de insulina também diminuiu essa resistência, porém apenas quando não houve exercício anterior.

\subsection{Características da execução do protocolo}

Os dois grupos estudados, sensíveis e resistentes, apresentaram características físicas e cardiovasculares semelhantes e dentro dos critérios de inclusão.Conforme o esperado pelo critério adotado, os indivíduos 
resistentes à ação da insulina apresentaram no teste de OGTT a área sob a curva de glicose semelhante à do grupo sensível, mas a área sob a curva de insulina significantemente maior, o que comprova a condição de maior resistência à insulina deste grupo, mesmo se utilizando um critério diferente do usado para a separação dos grupos. É importante observar que os grupos também diferiram no consumo pico de oxigênio, que foi significantemente maior no grupo sensível. De fato, estudos anteriores (SEIBAEK et. al., 2003) têm mostrado uma relação inversa entre o $\mathrm{VO}_{2}$ pico e a sensibilidade à insulina. Entretanto, cabe apontar que, apesar da diferença estatística, todos os indivíduos, dos dois grupos, não eram treinados regularmente e apresentaram $\mathrm{VO}_{2}$ pico próximo ao esperado para sua idade, o que sugere que a diferença encontrada se deve às características dos grupos e não a uma interferência de um treinamento físico.

Analisando-se o protocolo experimental realizado, é possível verificar que sua execução ocorreu conforme planejado. A intensidade de exercício executado (sensíveis $=54 \pm 2 \%$ e resistentes $=54 \pm 3 \%$ ) foi próxima à proposta (50\%) e não diferiu entre os grupos, demonstrando que tanto os sensíveis quanto os resistente receberam o mesmo estímulo metabólico durante o exercício. É interessante ressaltar que essa intensidade de exercício foi escolhida devido ao fato de promover queda da pressão arterial após sua execução, o que já foi observado em outros estudos de nosso laboratório (FORJAZ et. al., 1998). Além disso, os programas de condicionamento físico visando à melhora e manutenção da saúde em indivíduos sedentários, são iniciados com essa intensidade de treinamento (ACSM, 2003). 
Um outro aspecto importante de ser abordado diz respeito ao tempo decorrido entre as sessões experimentais, Controle e Exercício, e o tempo decorrido entre o final do exercício/repouso e o início do período basal/infusão. Quanto ao tempo entre as sessões, embora o tempo mínimo tenha sido de 30 dias (período necessário para a reposição total do sangue coletado), o tempo médio foi bem maior, em torno de 70 dias (no dois grupos). Esse grande período foi necessário em função da dificuldade dos voluntários de retornarem para uma nova avaliação e devido à ocorrência de vários experimentos em que não foi possível localizar a atividade nervosa simpática. Assim, esses experimentos precisaram ser repetidos e, para tal, foi necessário um intervalo mínimo de mais 15 dias para que a nova localização do sinal nervoso simpático pudesse ser realizada com segurança. Em relação ao período entre o final do Exercício/Repouso e os períodos Basal/Infusão, o intervalo foi longo devido ao tempo necessário para os procedimentos preparatórios do clampeamento euglicêmico/hiperinsulinêmico e para a localização do sinal nervoso para a técnica de microneurografia. Como esse tempo foi semelhante entre as sessões controle e exercício nos dois grupos, as diferenças observadas entre as sessões não podem ser atribuídas a diferenças nesse tempo. Entretanto, cabe observar que na sessão Controle, o intervalo entre o final do repouso e o início do período Basal//nfusão foi significantemente maior nos indivíduos Resistentes, o que sugere uma maior dificuldade de se localizar a atividade nervosa simpática nesses indivíduos; porém, o motivo dessa dificuldade não é conhecido. Além disso, esse fato não deve ter alterado os resultados, pois a diferença só foi observada na sessão 
controle, na qual os indivíduos permaneceram em repouso e alguns minutos a mais não modificariam a situação fisiológica do organismo, o que certamente ocorreria se a diferença fosse observada após a sessão de exercício.

Diante do exposto, fica claro que o protocolo foi executado conforme o planejado e as poucas modificações observadas não devem ter influenciado os resultados.

\subsection{Respostas metabólicas}

Em relação à glicemia, observou-se que os dois grupos (Sensíveis e Resistentes) apresentaram glicemia semelhante e que essa glicemia foi mantida entre os períodos Basal e de Equilíbrio nas duas sessões experimentais, o que demonstra que a técnica de clampeamento euglicêmico/hiperinsulinêmico foi aplicada com sucesso, ou seja, a glicemia basal foi mantida durante a infusão de insulina nos dois grupos e nas duas sessões. Entretanto, é importante observar que a glicemia plasmática foi significantemente menor na sessão Exercício que na Controle, demonstrando que o exercício prévio reduziu a glicemia após sua execução. No entanto, o nível glicêmico atingido não representa um quadro de hipoglicemia, que se caracteriza por glicemia menor que 40 mg/dl (BECKER et. al., 1995). Portanto, o exercício diminui a glicemia, mas a mantém na faixa de normalidade. De fato, estudos anteriores (ROEF et. al., 2003) já observaram redução da glicemia após a execução de uma única sessão de exercício, o que tem sido atribuído ao aumento da captação de glicose durante a 
contração muscular (SHEPHERD \& KAHN, 1999), sem a compensação total pelo aumento da produção hepática (KOYAMA et. al., 2002).Como o aumento da captação de glicose durante o exercício se deve, principalmente, à captação independente de insulina (SHEPHERD \& KAHN, 1999), esse efeito não diferiu entre os grupos. De fato, vários autores (HOLTEN et. al., 2004) têm observado que a captação de glicose induzida pelo exercício, é semelhante em indivíduos sensíveis e resistentes à ação da insulina.

Como esperado, a infusão de insulina ocasionou um aumento significante na insulinemia plasmática nos dois grupos (Sensíveis e Resistentes). Entretanto, na sessão Controle, apesar de a insulina ter sido infundida na mesma dose nos dois grupos, a concentração plasmática de insulina aumentou mais nos indivíduos resistentes que nos sensíveis. Resultado semelhante foi observado por VOLENWEIDER et al (1994), que verificaram com a infusão de uma mesma dose de insulina que indivíduos obesos e, portanto, resistentes à ação da insulina, apresentavam maior aumento da insulinemia plasmática que indivíduos magros. Um dos fatores que podem explicar essa resposta é a possível presença de uma maior metabolização da insulina nos indivíduos sensíveis que nos resistentes.

Com relação ao efeito do exercício, a execução prévia de uma única sessão de exercício diminuiu a hiperinsulinemia promovida pela infusão de insulina nos indivíduos resistentes e a aumentou nos indivíduos sensíveis, fazendo com que a concentração plasmática de insulina atingida durante o clampeamento realizado pós-exercício fosse igual nos dois grupos. A resposta diferente da insulinemia à infusão de insulina nas duas sessões 
experimentais nos dois grupos pode dever-se ao efeito da insulina sobre a sensibilidade à insulina, ou seja, como na sessão de Exercício houve uma redução da sensibilidade à insulina no grupo Sensível, a taxa de metabolização de glicose desse hormônio também pode ter sido reduzida, resultando no maior aumento da insulinemia durante o clampeamento.

O fato de os indivíduos Resistentes e Sensíveis apresentarem durante o clampeamento níveis diferentes de insulina plasmática na sessão Controle e iguais na sessão Exercício pode influenciar na interpretação dos dados obtidos neste estudo e, portanto, deve ser levado em consideração nessa interpretação.

Em relação às variáveis relacionadas à sensibilidade à insulina, foi possível observar que a taxa de metabolização de glicose foi significantemente menor no grupo Resistente que no Sensível, o que já era esperado, visto que o quadro de resistência à insulina se caracteriza pela menor capacidade de metabolização de glicose plasmática. Entretanto, é interessante observar que essa taxa não se modificou após o exercício, o que difere do encontrado em alguns estudos (BURSTEIN et. al., 1990). Entretanto, para se analisar essa questão, é necessário se observar as respostas da taxa de metabolização de glicose em função dos níveis de insulina atingidos, o que realmente caracteriza a sensibilidade à insulina. Nesse sentido, foi possível observar que a execução prévia do exercício modificou a sensibilidade à insulina (relação M e Insulinemia) de forma diferente nos indivíduos sensíveis e resistentes. De fato, o efeito do exercício sobre a sensibilidade à insulina difere entre os estudos. Alguns autores (BEN-EZRA et. al., 1995; BRAUN et. 
al., 1995; DEVLIN et. al., 1985; MIKINES et. al., 1988; RHEAUME et. al., 2002) verificaram aumento da sensibilidade à insulina após o exercício. Entretanto, outros (FORJAZ et. al., 1999; RHEAUME et. al., 2002; SABELIS et. al., 2003; YOUNG et. al., 1989) não observaram modificação, e outros ainda (FLUCKEY et. al., 1999) observaram diminuição da sensibilidade à insulina após o exercício. A discrepância de respostas entre os estudos têm sido atribuída a diferentes fatores, como o protocolo de exercício empregado, o tempo decorrido pós-exercício e/ou o nível inicial de sensibilidade à insulina. $\mathrm{Na}$ realidade, os resultados obtidos no presente estudo ajudam a esclarecer essa questão e sugerem que o grau inicial de sensibilidade à insulina pode ser um fator chave, visto que a sensibilidade diminuiu nos indivíduos sensíveis e não se alterou nos resistentes. Além disso, fazendo-se uma correlação entre o índice de sensibilidade à insulina na sessão Controle e o aumento dessa sensibilidade após o Exercício, verifica-se uma correlação negativa e significante $(r=-0,86 \quad, p<0,05)$, que demonstra que os indivíduos menos sensíveis apresentaram maior aumento da sensibilidade à insulina após o exercício. Corroborando com esses achados, pudemos observar que, no grupo sensível, apenas 13\% dos indivíduos apresentaram aumento da sensibilidade à insulina na sessão de Exercício, enquanto no grupo resistente, $60 \%$ dos indivíduos apresentaram esse aumento. Dessa forma, é possível dizer que a execução de uma única sessão de exercício terá efeito de aumento ou redução da sensibilidade à insulina de acordo com o nível inicial dessa sensibilidade. É interessante observar que, no presente estudo, o grupo resistente (analisado em sua totalidade) não aumentou a 
sensibilidade à insulina pós-exercício. Porém, devido ao fato de o estudo ter sido realizado com indivíduos saudáveis, o grau de sensibilidade à insulina, mesmo no grupo resistente, era relativamente alto, ou seja, se considerarmos a sensibilidade à insulina esperada para cada indivíduo segundo HOLLENBECK \& REAVEN, a maioria dos indivíduos deste estudo, mesmo os que estavam no grupo resistente, apresentavam sensibilidade à insulina acima do esperado. Dessa forma, é possível supor que, se este estudo fosse repetido com indivíduos mais resistentes à insulina, como diabéticos, obesos ou hipertensos (DEVLIN et. al., 1985; LAAKSO et. al., 1990; LENDER et. al., 1997 MUSCELLI et. al., 1998; SCHERRER \& SARTORI, 1997; VOLLENWEIDER et. al., 1994; RHEAUME et. al., 2002; WEYER et. al., 2000), o aumento da sensibilidade à insulina promovido pelo exercício físico seria mais evidente, demonstrando talvez uma maior importância clínica.

\subsection{Respostas neurais e hemodinâmicas periféricas}

Em relação à atividade nervosa simpática, tal como o descrito pela literatura (BERNE et. al., 1992; FORJAZ et. al.,1999; HAUSBERG et. al.,1995; MUNTZEL et. al., 2001; ROWE et. al., 1981; SCOTT et. al., 2002; VOLLENWEIDER et. al., 1995; VOLLENWEIDER et. al.,1993; VOLLENWEIDER et. al., 1994), a infusão de insulina a aumentou. De fato, esse aumento tem sido atribuído a uma ação central da insulina via liberação de óxido nítrico (MUNTZEL et. al. 2001). Entretanto, no presente estudo, o aumento da atividade nervosa simpática muscular provocado pela insulina 
não diferiu entre os grupos (Sensíveis e Resistentes), o que difere do observado em estudos anteriores (BERGHOLIM et. al., 2001; SCHERRER \& SARTORI, 1997; VOLLENWEIDER et. al., 1994), que demonstraram maior ativação simpática pela insulina em indivíduos sensíveis que nos resistentes. Nesse sentido, VOLLEIWEIDER et al (1994) observaram que o aumento da atividade nervosa simpática com a infusão de insulina foi maior em um grupo de indivíduos magros que em obesos. Entretanto, nesses estudos anteriores, essa análise foi feita na situação controle, ou seja, sem a execução prévia de exercício físico. Assim, observando-se apenas os dados da sessão Controle, verifica-se que, apesar de o aumento da atividade nervosa simpática muscular ter sido semelhante nos dois grupos, ele aconteceu em resposta a uma menor concentração de insulina plasmática no grupo sensível, o que demonstra que esse grupo, realmente, apresentou maior ativação simpática que o grupo resistente para a mesma quantidade de insulina, o que está de acordo com os achados da literatura. Entretanto, na sessão Exercício, o aumento da atividade nervosa simpática foi semelhante entre os grupos e o aumento da insulinemia também; porém, nessa sessão, os indivíduos sensíveis à insulina apresentam redução dessa sensibilidade, o que pode explicar a resposta semelhante à dos indivíduos resistentes.

Em relação ao efeito do exercício físico, foi observado que, independentemente do grupo, esse exercício promoveu redução da atividade nervosa simpática. Além disso, como não houve significância na interação entre os fatores sessão e estágio, pode-se dizer que a redução da atividade nervosa simpática foi observada tanto no período Basal quanto no período de 
Equilíbrio. Dessa forma, a resposta à infusão de insulina, ou seja, o aumento da atividade nervosa simpática promovido pela insulina, não diferiu entre as sessões (Controle e Exercício), mas ocorreu com menores níveis de ativação simpática após o exercício. Corroborando com esse achado, diversos autores (FLORAS et. al., 1989; FORJAZ et. al., 1999; HALLIWILL et. al., 1996) têm observado que o exercício físico reduz a atividade nervosa simpática muscular na situação basal , o que tem sido explicado por diversos mecanismos. Entre eles, o aumento da sensibilidade à insulina promovido pelo exercício físico, tem sido freqüentemente citado (BEN-EZRA et. al., 1995; BRAUN et. al., 1995; DEVLIN et. al., 1985; MIKINES et. al., 1988; RHEAUME et. al., 2002); porém, no presente estudo, a redução da atividade nervosa simpática pós-exercício ocorreu sem o aumento concomitante da sensibilidade à insulina, o que sugere que outros mecanismos devem ser responsáveis por essa resposta.

Como o exposto, é interessante observar que, apesar da redução da atividade nervosa simpática muscular após o exercício na condição Basal, a execução prévia do exercício não modificou a resposta da atividade nervosa simpática à infusão de insulina. Para explicar esses resultados, podemos considerar que, como a insulina promove aumento da atividade nervosa simpática via estímulo central da liberação de óxido nítrico, e o exercício inibe a atividade nervosa simpática por outros mecanismos, como a secreção de opióides e a modificação do barorreflexo (MacDONNALD et. al., 2001), a associação dessas duas intervenções resulta em efeitos aditivos, ou seja, a atividade nervosa simpática está mais baixa após o exercício, mesmo durante 
a infusão de insulina. Cabe ressaltar, entretanto, que quando comparados indivíduos sensíveis e resistentes à insulina, essa mesma resposta à infusão de insulina ocorreu nos indivíduos sensíveis com níveis de insulina menores na sessão controle que na sessão exercício, e vice-versa nos indivíduos resistentes, isto sugere que o efeito do exercício em aumentar ou diminuir a sensibilidade à insulina sobre o metabolismo de carboidratos também se expressa em efeito semelhante sobre a ação da insulina em aumentar mais ou menos a atividade nervosa simpática periférica.

Apesar das considerações expostas, é importante ressaltar que, do ponto de vista clínico, tanto nos indivíduos resistentes quanto nos sensíveis à insulina, a execução de uma sessão prévia de exercício físico diminuiu a atividade nervosa simpática periférica em condições basais e de hiperinsulinemia. Esse fato pode ser importante, principalmente para os indivíduos resistentes à insulina, como diabeticos (HENRIKSEN et. al., 2001; ROTHMAN et. al., 1995), obesos (FAGIUS et. al, 2003; HENRIKSEN et. al., 2001; VOLLENWEIDER et. al., 1994) e hipertensos (HENRIKSEN et. al., 2001; RHÉAUME et. al., 2002), que possuem atividade nervosa simpática periférica aumentada em condições basais e que apresentam um aumento ainda maior dessa atividade em situações de hiperinsulinemia, como após as refeições. É importante apontar que, neste estudo, a atividade nervosa simpática basal dos indivíduos sensíveis e resistentes não foi significantemente diferente, porém os indivíduos estudados não apresentavam doenças concomitantes. De fato, os dados deste estudo foram obtidos em indivíduos resistentes à insulina, mas saudáveis (sem outras 
doenças), de modo que a reprodução desses resultados em indivíduos com outras doenças associadas precisa ser testada no futuro.

Em relação ao fluxo sanguíneo muscular, a infusão de insulina aumentou o fluxo sanguíneo, porém essa resposta foi observada apenas nos indivíduos sensíveis à ação desse hormônio. Diversos autores (ANDERSON et al., 1991, 1992; BARON et al., 1993; FORJAZ et al., 1999; HANN et al., 1997; LAAKSO et al., 1990; LEMBO et al., LIANG et al., 1982; LIND et. al., 2002; NEAHRING et al., 1993; SCHERRER et al., 1994;1992; SCHERRER \& SARTORI, 1997; SCOTT et. al., 2002; VEEN \& CHANG, 1997; VOLLENWEIDER et. al., 1995; VOLLENWEIDER et. al.,1993; VOLLENWEIDER et. al., 1994) têm observado que a insulina possui um efeito vasodilatador local, via liberação de óxido nítrico, que promove aumento do fluxo sanguíneo muscular durante a hiperinsulinêmia. Além disso, esse efeito vasodilatador é maior nos indivíduos sensíveis que nos resistentes à ação da insulina (SCHERRER \& SARTORI, 1997; VOLLENWEIDER et. al., 1994) . Na presente investigação, o fato de o fluxo sanguíneo do antebraço não ter aumentado durante a infusão de insulina nos indivíduos resistentes, sugere que nesta população, o efeito vasoconstritor do aumento da atividade nervosa simpática muscular deva ter contrabalançado o efeito vasodilatador direto da insulina, de modo que o fluxo sanguíneo foi mantido. Entretanto, nos indivíduos sensíveis à insulina, o efeito vasodilatador deve ter sido maior que o efeito vasoconstritor, o que explica o aumento do fluxo sanguíneo muscular. Esse maior efeito vasodilatador nos indivíduos sensíveis está de acordo com os dados observados na literatura e expostos anteriormente. Além disso, ele 
pode ser melhor evidenciado na sessão Controle, na qual o grupo sensível apresentou aumento do fluxo sanguíneo do antebraço com a infusão de insulina e o grupo resistente não, apesar de a hiperinsulinemia ser maior nos resistentes. É interessante observar que, na sessão de Exercício, o maior efeito vasodilatador do grupo sensível se manteve, apesar de haver diminuição da sensibilidade à insulina nesse grupo; porém, apesar dessa redução, esses indivíduos continuaram mais sensíveis que o grupo resistente, o que explica a resposta encontrada.

Em relação ao efeito do exercício físico sobre o fluxo sanguíneo muscular, pode-se dizer que, como não houve interação entre os fatores sessão e estágio, o fluxo sanguíneo muscular aumentou após o exercício de forma semelhante, tanto nos indivíduos sensíveis quanto nos resistentes, tanto na situação basal quanto durante a hiperinsulemia. Em outras palavras, a execução prévia do exercício aumentou o fluxo sanguíneo muscular basal e não modificou sua resposta à infusão de insulina, de modo que o fluxo sanguíneo muscular foi maior durante a hiperinsulinemia conduzida após o exercício que após o repouso. De fato, diversos autores (COATS et. al., 1989) têm demonstrado que o exercício físico promove vasodilatação na musculatura durante sua execução e que essa vasodilatação é mantida por um prolongado período de tempo após a finalização do exercício (FORJAZ et. al., 1999; HALLIWILL et. al., 1996; HARA \& FLORAS 1992; HUSSAIN et. al., 1996; RUECKERT et. al., 1996) . Esse efeito vasodilatador é, pelo menos em parte, mediado pela redução da atividade nervosa simpática periférica observada neste estudo. O fato de a diminuição da atividade nervosa 
simpática pós-exercício ter sido igual nos dois grupos, explica o aumento similar do fluxo sanguíneo do antebraço nos dois grupos. Entretanto, outros mecanismos também podem estar envolvidos, como a secreção de opióides (THOREN et. al., 1990), a vasodilatação termorregulatória (FRANKLIN et. al., 1993), a secreção de metabólitos locais (HUSSAIN et. al., 1996), entre outros. Da mesma forma que analisado para a atividade nervosa simpática, o fato de a resposta vasodilatadora à insulina não diferir entre as sessões Exercício e Controle, pode ocorrer porque o exercício e a insulina agem por mecanismos distintos: o exercício pelos mecanismos expostos acima, e a insulina pela secreção local de óxido nítrico (MUNTZEL et. al., 2001). Além disso, essa resposta semelhante nas duas sessões experimentais está de acordo com a resposta observada na atividade nervosa simpática muscular.

Diante do exposto, fica claro que a execução do exercício físico prévio promoveu aumento do fluxo sanguíneo muscular na situação basal, mas também durante a hiperinsulinemia, tanto nos indivíduos sensíveis como nos resistentes. Essa resposta pode ter importância clínica, principalmente nos indivíduos resistentes à ação da insulina que costuma apresentar resposta vasodilatadora reduzida (RHEAUMÉ et. al., 2002).

Em relação à resistência vascular muscular, observou-se que o exercício físico prévio reduziu essa resistência no período Basal de forma semelhante nos dois grupos. De fato, o aumento do fluxo sanguíneo do antebraço e a redução da atividade nervosa simpática muscular, observados após o exercício, podem explicar essa resposta. Diversos autores (CLEROUX et. al., 1992; HARA \& FLORAS, 1992; HALLIWILL et. al., 1996) têm relatado 
resultados semelhantes na literatura. Em relação ao efeito da insulina, observou-se na sessão Controle redução da resistência vascular do antebraço. Esse efeito da insulina já foi bastante descrito na literatura (LIND et. al., 2002; MUSCELLI et. al., 1998; VEEN \& CHANG, 1996; VOLLENWEIDER et. al., 1993; 1994; VOLLENWEIDER, L et. al.,1995) e normalmente se associa ao aumento do fluxo sanguíneo muscular provocado pela hiperinsulinemia. Como neste estudo o aumento do fluxo sanguíneo muscular só ocorreu nos indivíduos sensíveis, esse mecanismo explica a redução da resistência vascular periférica nessa população, porém na população resistente, na qual o fluxo sanguíneo não se modificou, a queda da resistência vascular periférica deve ser atribuída à ponderação entre as respostas do fluxo sanguíneo do antebraço e da pressão arterial média. Nessa condição, nem o fluxo sanguíneo, nem a pressão arterial média se modificaram significantemente, porém o aumento do fluxo sanguíneo pode ter sido mais importante, resultando na redução da resistência vascular periférica. Na sessão de exercício, o resultado obtido é mais difícil de ser explicado; entretanto, a ausência de redução da resistência vascular periférica com a infusão de insulina neta sessão pode se dever ao fato de o exercício já ter diminuído muito essa resistência no período basal, de modo que uma queda maior seria difícil. Em relação aos fatores determinantes, visto a ausência de resposta, pode-se dizer que, no grupo sensível, o aumento do fluxo sanguíneo com a infusão de insulina se acompanhou de aumento não significante da pressão arterial média, o que pode explicar a manutenção da resistência vascular periférica, enquanto nos indivíduos resistentes, a 
manutenção do fluxo sanguíneo e da pressão arterial média explicam a manutenção da resistência vascular periférica. Cabe aqui ressaltar que a resistência vascular periférica é uma variável calculada e não medida, o que pode dificultar a interpretação de seus resultados.

\subsection{Respostas cardiovasculares}

A infusão de insulina aumentou a pressão arterial sistólica nos dois grupos, nas duas sessões experimentais, porém o aumento foi maior nos indivíduos sensíveis que nos resistentes. O aumento da pressão arterial sistólica com a infusão de insulina já foi relatado em outros estudos (BERNE et. al., 1992; FORJAZ et. al., 1999; VOLLENWEIDER et. al, 1993) e deve estar relacionado ao aumento da atividade nervosa simpática, estimulado pela insulina. Embora neste estudo apenas a atividade nervosa simpática periférica tenha sido avaliada, outros autores (BERGHOLM et. al., 2001) têm demonstrado que a atividade nervosa simpática para o coração também aumenta com a hiperinsulinemia. Além disso, o fato de ter sido observado aumento da freqüência cardíaca com a infusão de insulina, corrobora com a idéia do aumento da ativação nervosa simpática cardíaca, a qual poderia resultar em aumento do débito cardíaco e, conseqüentemente, da pressão arterial sistólica. Além disso, o maior aumento da pressão arterial sistólica no grupo Sensível também pode dever-se a uma maior ativação simpática nesse 
grupo. De fato, BERGOLIM et. al. (2001) observaram que indivíduos sensíveis à ação da insulina possuíam uma maior ativação simpática cardíaca à hiperinsulinemia que indivíduos resistentes.

Em relação à pressão arterial diastólica, o exercício físico reduziu essa pressão no período Basal apenas nos indivíduos sensíveis à insulina.

De fato, o efeito hipotensor do exercício tem sido relatado por diversos autores (FORJAZ et al., 1997; 1998; 1999; 2000; HALLIWILL et al., 2001; MACDONALD et al., 2002; VÉRAS-SILVA et al., 1995). Porém, a ocorrência desse efeito apenas em indivíduos sensíveis, só foi observada neste estudo, talvez, devido ao fato de não haver outros estudos que investigaram essa questão. Os mecanismos que explicam a redução da pressão arterial diastólica apenas nos indivíduos sensíveis ainda são obscuros, visto que a redução da atividade nervosa simpática, o aumento do fluxo sanguíneo e a diminuição da resistência vascular do antebraço após o exercício não diferiram entre os grupos Sensíveis e Resistentes. Entretanto, cabe ressaltar que, embora sem significância estatística, a redução da resistência vascular do antebraço após o exercício tendeu a ser menor nos indivíduos sensíveis ( $p$ $=0,058)$. Além disso, é possível supor que, como os indivíduos sensíveis possuem maior resposta vasodilatadora à insulina (RHEAUMÉ et. al., 2001, SCHERRER \& SARTORI, 1997; VOLLENWEIDER et. al., 1994), eles também responderam com maior vasodilatação a outros estímulos vasodilatadores, tais como os desencadeados pelo exercício (termorregulação, redução da atividade nervosa simpática, etc...). Além disso, essa resposta pode ocorrer principalmente na musculatura ativa, promovendo maior vasodilatação dessa 
musculatura, o que poderia resultar em uma maior redução da resistência vascular periférica total e na redução da pressão arterial diastólica. Porém, neste estudo, a resistência vascular foi medida apenas no território muscular inativo, de modo que essa hipótese precisa ser testada por estudos futuros.

A infusão de insulina aumentou a pressão arterial diastólica apenas na sessão de Exercício, o que pode ser explicado pelo fato de, nessa sessão, ter sido observado aumento da atividade nervosa simpática e manutenção da resistência vascular periférica do antebraço. Assim, o aumento da atividade nervosa simpática pode ter resultado em vasoconstrição de outros territórios, elevando a resistência vascular sistêmica e, conseqüentemente, a pressão arterial diastólica. Já na sessão Controle, apesar do aumento da atividade nervosa simpática, como houve redução da resistência vascular do antebraço, esses efeitos podem ter se compensado explicando a ausência de alterações da pressão arterial diastólica.

É interessante observar que, independentemente da sessão, durante a hiperinsulinemia, os indivíduos sensíveis apresentavam maior pressão arterial diastólica que os resistentes. As variáveis medidas nesse estudo não permitem explicar essa diferença, visto que a atividade nervosa simpática muscular e o fluxo sanguíneo do antebraço durante a hiperinsulinemia não diferiram entre os grupos. Dessa forma, essa diferença deve estar associada a diferenças de respostas entre os grupos em relação à ação vasoconstritora da ativação simpática em outros territórios. Entretanto, novamente esses aspectos precisam ser mais bem investigados em estudos futuros. 
Em relação à pressão arterial média, a infusão de insulina aumentou essa pressão apenas em indivíduos sensíveis após o exercício, o que já era esperado em função de o efeito pressor sistólico e diastólico da infusão de insulina ser mais evidente nos indivíduos sensíveis, e de apenas na sessão de Exercício a infusão de insulina ter aumentado a pressão arterial diastólica.

Quanto à freqüência cardíaca, independentemente do grupo, o exercício físico e a infusão de insulina aumentaram-na. De fato, diversos estudos (BRAUN et. al., 1995; RHEAUME et. al., 2002) têm observado aumento da freqüência cardíaca após a execução de uma única sessão de exercício, o que tem sido atribuído ao aumento da atividade nervosa simpática para o coração (SATO et. al., 2003). Da mesma forma, o aumento da freqüência cardíaca com a insulina também tem sido freqüentemente relatado (BERGHOLM et. al., 2001; BERNE et. al., 1992; HAUSBERG et. a., 1995; MUNZEL et. al., 2001;MUSCELLI et. al., 1998) e se deve ao aumento da atividade nervosa simpática para o coração (BERGHOLM et. al., 2001; MUSCELLI et. al., 1998) .

Analisando-se todos os resultados obtidos neste estudo e levando-se em conta as considerações feitas nessa discussão, é possível levantar algumas hipóteses sobre o efeito do exercício e da infusão de insulina sobre a resposta cardiovascular em indivíduos resistentes e sensíveis à ação da insulina, além de ser possível e se discutir o provável efeito prévio do exercício na resposta à infusão de insulina nessas duas populações. 


\subsection{Efeito fisiológico do exercício físico na condição basal}

A execução de uma única sessão de exercício aeróbio promoveu redução da glicemia, sem causar hipoglicemia, tanto em indivíduos sensíveis quanto em resistentes à insulina. Porém, nos indivíduos sensíveis à insulina, isso ocorreu concomitantemente à redução da sensibilidade à insulina, enquanto nos indivíduos resistentes, houve manutenção da sensibilidade à insulina no grupo como um todo, mas ocorreu aumento dessa sensibilidade à insulina em $60 \%$ dos indivíduos.

Além disso, o exercício físico reduziu a atividade nervosa simpática muscular, aumentou o fluxo sanguíneo do antebraço e diminuiu a resistência vascular do antebraço pós-exercício de forma semelhante nos dois grupos. Entretanto, essas adaptações resultaram na manutenção dos níveis pressóricos sistólicos, diastólicos e médios nos indivíduos resistentes, e manutenção dos níveis pressoricos sistólicos e médios, mas queda da pressão arterial diastólica nos indivíduos sensíveis. Além disso, houve aumento da freqüência cardíaca pós-exercício nos dois grupos.

Esses resultados demonstram que indivíduos sensíveis e resistentes à insulina sofrem adaptações cardiovasculares e metabólicas distintas após a execução de uma única sessão de exercício físico. 


\subsection{Efeitos fisiológicos da infusão de insulina}

Como esperado, a infusão de insulina aumentou a insulinemia nos dois grupos; porém, o aumento foi maior no grupo resistente que no sensível, de modo que a hiperinsulinemia resultante foi maior nos indivíduos resistentes. Apesar da infusão de insulina, a glicemia foi mantida semelhante ao basal durante o clampeamento euglicêmico/hiperinsulinêmico.

A infusão de insulina aumentou a atividade nervosa simpática muscular e reduziu a resistência vascular do antebraço de forma semelhante nos indivíduos sensíveis e resistentes à insulina; entretanto, a hiperinsulinemia foi menor nos indivíduos sensíveis, o que permite dizer que esses efeitos foram maiores nesse grupo. Além disso, a insulina aumentou o fluxo sanguíneo do antebraço apenas nesse grupo. Dessa forma, a infusão de insulina promoveu aumento da pressão arterial sistólica, sem alterar a pressão arterial média e a pressão arterial diastólica, sendo o aumento da pressão arterial sistólica mais evidente nos indivíduos sensíveis.

Diante do exposto, pode se dizer que a infusão de insulina promove aumento da atividade nervosa simpática e redução da resistência vascular do antebraço, o que resulta em aumento da pressão arterial sistólica, sendo que esses efeitos são mais evidentes nos indivíduos sensíveis à ação da insulina. 


\subsection{Efeito do exercício físico prévio na resposta à infusão de insulina}

A execução de uma única sessão de exercício físico modificou a resposta insulinêmica à infusão de insulina, fazendo com que essa resposta aumentasse nos indivíduos resistentes e diminuísse nos sensíveis. Por outro lado, o exercício físico prévio não modifica as respostas de aumento da atividade nervosa simpática muscular, do fluxo sanguíneo do antebraço e da pressão arterial sistólica à infusão de insulina. É interessante observar que essas respostas são iguais nos dois grupos, mas ocorrem com respostas diferentes de insulinemia em cada grupo, sugerindo que, na realidade, essas respostas à insulina no grupo resistente são mais evidentes, pois ocorrem com menores níveis plasmáticos de insulina pós-exercício, e são menos evidentes, nos sensíveis, pois ocorrem com maiores níveis plasmáticos de insulina pós-exercício. Além disso, o exercício prévio impede a redução da resistência vascular do antebraço e aumenta a pressão arterial diastólica e média em resposta Á infusão de insulina nos dois grupos de forma semelhante.

Desse modo, é possível dizer que a execução do exercício físico prévio modifica as respostas fisiológicas à hiperinsulinemia aguda de forma diferenciada em indivíduos sensíveis e resistentes à ação da insulina. 
Capitulo 7:

LIMITAÇÕES

DO ESTUDO 


\section{LIMITAÇÕES DO ESTUDO}

Os dados obtidos neste estudo foram coletados em homens saudáveis, não atletas, submetidos a uma sessão de 45 minutos de exercício físico em cicloergômetro com intensidade correspondente a 50\% do $\mathrm{VO}_{2}$ pico. Além disso, a resposta à insulina foi avaliada por meio de infusão de uma dose fixa de insulina com a técnica do clampeamento euglicêmico/hiperinsulinêmico. Dessa forma, os resultados obtidos são aplicáveis à situação experimental testada e a modificação dessa situação pode gerar resultados diferentes.

Devido ao fato de a infusão ter sido em dose fixa e ter gerado graus de hiperinsulinemia diferentes nos indivíduos sensíveis e resistentes à insulina nas sessões Controle e Exercício, a interpretação dos resultados deve levar esse fato em consideração, conforme o exposto na discussão anterior.

No presente estudo, a atividade nervosa simpática foi medida apenas para a periferia com a técnica da microneuragrafia, o fluxo sanguíneo muscular foi medido no antebraço (musculatura não ativa) pela técnica da pletismografia e a pressão arterial foi aferida no braço de forma intermitente pela técnica oscilométrica. Dessa forma, os resultados obtidos estão sujeitos às limitações impostas pelas técnicas utilizadas. Nesse sentido, os dados 
poderiam ser diferentes, se a atividade nervosa simpática fosse medida em outro território ou mesmo para o coração. O fluxo sanguíneo poderia ser diferente, se medido na musculatura ativa ou em outro território não muscular. Entretanto, essas limitações foram expostas na discussão, e trabalhos futuros devem abordar outras medidas. 
Capitulo 8: CONCLUSÕES 


\section{CONCLUSÕES}

Em indivíduos jovens saudáveis, a execução de uma única sessão de exercício físico dinâmico prolongado:

a) Reduz a glicemia de indivíduos sensíveis e resistentes à insulina.

b) Reduz a sensibilidade à insulina de indivíduos sensíveis e não a modifica em indivíduos resistentes, embora aumente essa sensibilidade em $60 \%$ desses indivíduos.

c) Reduz a atividade nervosa simpática muscular basal, sem modificar o aumento dessa atividade promovido pela infusão de insulina, fazendo com que, mesmo durante a hiperinsulinemia aguda, a atividade nervosa simpática muscular seja menor após o exercício.

d) Aumenta o fluxo sanguíneo do antebraço no período Basal e não modifica resposta desse fluxo à infusão de insulina, o que corresponde a um aumento nos indivíduos sensíveis e à manutenção nos indivíduos resistentes. Assim, após o exercício, tanto os indivíduos sensíveis como os resistentes têm maior fluxo sanguíneo muscular do antebraço tanto no basal quanto durante a hiperinsulinemia. 
e) Reduz a resistência vascular do antebraço basal e impede a redução dessa resistência com a infusão de insulina.

f) Não modifica o aumento da pressão arterial sistólica promovido pela infusão de insulina, que é maior nos indivíduos sensíveis.

g) Reduz a pressão arterial diastólica basal dos indivíduos sensíveis e promove aumento dessa pressão durante a infusão de insulina.

h) Promove aumento da pressão média em resposta à infusão de insulina em indivíduos sensíveis.

i) Aumenta a freqüência cardíaca pós-exercício, não modificando a resposta taquicárdica à infusão de insulina. 
ANEXOS 


\section{ANEXOS}

\section{Anexo 1}

\section{HOSPITAL DAS CLÍNICAS}

DA

FACULDADE DE MEDICINA DA UNIVERSIDADE DE SÃO PAULO

\section{TERMO DE CONSENTIMENTO PÓS -INFORMAÇÃO}

(Instruções para preenchimento no verso)

I - DADOS DE IDENTIFICAÇÃO DO SUJEITO DA PESQUISA OU RESPONSÁVEL LEGAL

1. NOME DO PACIENTE

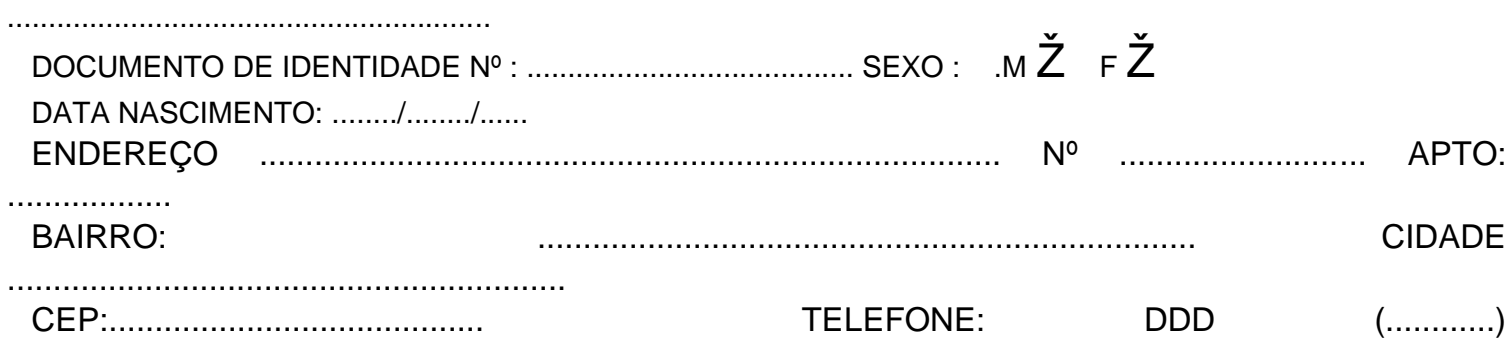

2.RESPONSÁVEL

LEGAL

NATUREZA (grau de parentesco, tutor, curador etc.)

DOCUMENTO DE IDENTIDADE SEXO: $M \check{Z} \quad F \breve{Z}$

DATA NASCIMENTO.: .....................

ENDEREÇO:

№

APTO:

BAIRRO:

CIDADE:

CEP:

TELEFONE:

DDD 


\section{II - DADOS SOBRE A PESQUISA CIENTÍFICA}

1. TÍTULO DO PROTOCOLO DE PESQUISA. Efeito da sensibilização à insulina pelo exercício sobre as respostas pressórica, simpática e vasodilatadora à infusão de insulina pós-exercício

PESQUISADOR: .Prof Dr Carlos Eduardo Negrão/ Médico Responsável: Prof. Dr. Décio Mion Jr.

CARGO/FUNÇÃO: Docente -.Diretor da Unidade de Reabilitação Cardiovascular e Fisiologia do Exercício do InCor /Chefe do Laboratório de Hipertensão do Hospital das Clínicas FMUSP

INSCRIÇÃO CONSELHO REGIONAL № .28828

UNIDADE DO HCFMUSP: Laboratório da Unidade de Reabilitação Cardiovascular e Fisiologia do Exercício do InCor / Laboratório de Hipertensão da Disciplina de Nefrologia do HCFMUSP / Escola de Educação Física e Esporte USP

\section{AVALIAÇÃO DO RISCO DA PESQUISA:}

$\begin{array}{llll}\text { SEM RISCO } & \text { Ž } & \text { RISCO MÍNIMO } & \text { Ž } \\ \text { RISCO BAIXO } & \check{Z} & \text { RISCO MAIOR } & \check{Z}\end{array}$

(probabilidade de que o indivíduo sofra algum dano como conseqüência imediata ou tardia do estudo)

4.DURAÇÃO DA PESQUISA : .2 anos

\section{III - REGISTRO DAS EXPLICAÇÕES DO PESQUISADOR AO PACIENTE OU SEU REPRESENTANTE LEGAL} SOBRE A PESQUISA, CONSIGNANDO:

1. justificativa e os objetivos da pesquisa ; 2. procedimentos que serão utilizados e propósitos, incluindo a identificação dos procedimentos que são experimentais; 3 . desconfortos e riscos esperados; 4 . benefícios que poderão ser obtidos; 5 . procedimentos alternativos que possam ser vantajosos para o indivíduo.

1. Essa pesquisa deseja verificar: a) se após a realização de uma sessão de exercício físico ocorre um aumento da ação da insulina (o hormônio que os diabéticos não possuem), b) se esse aumento modifica a resposta da pressão arterial quando se infunde insulina na pessoa e c) por que essa pressão se altera.

2. O senhor realizará : a) uma consulta médica, b) um teste ergoespirométrico, ou seja, pedalará na bicicleta ergométrica que vai aumentando a carga até o máximo que conseguir; b) uma curva glicêmica, ou seja, o senhor virá em jejum ao laboratório e uma veia será "pega", o senhor tomará um copo de água com açúcar e será coletado sangue a cada 30 minutos por 3 horas e d) duas sessões experimentais. Nas sessões experimentais, o senhor chegará em jejum e permanecerá em repouso ou fará um exercício na bicicleta. Após esse período, o senhor deitará na maca e uma veia do braço direito e uma do braço esquerdo serão "pegas". Em seguida, seu braço direito será posicionado para cima e serão colocados dois aparelhos de pressão nesse braço para medir a quantidade de sangue que passa por ele. Tentaremos então localizar o sinal do nervo, ou seja, sua perna esquerda será posicionada flexionada e dois eletrodos (agulhas finas) serão colocados na parte de trás dessa perna próximo ao joelho e se fará uma estimulação elétrica. Após a localização do nervo, faremos 10 minutos de registro em repouso e iniciaremos a infusão de insulina e glicose (açúcar). Essa infusão durará 2 horas, durante sua execução seu sangue será coletado no braço esquerdo num total de $250 \mathrm{ml}$ (mais ou menos metade do que se tira em uma doação de sangue). Após o término da infusão o senhor será acompanhado por 30 minutos. 
3. Durante o teste ergoespirométrico e a curva glicêmica os riscos são pequenos e os desconfortos esperados são: o senhor poderá sentir um cansaço no final do teste ergoespirométrico e uma pequena dor na punção da veia (quando pega a veia) no teste de curva glicêmica. Durante as sessões experimentais, o senhor poderá sentir alguns desconfortos relacionados: a) à manutenção da posição deitada por um longo período de tempo; b) à punção das 2 veias (pegar as veias), c) à localização do sinal nervoso, pois durante esse procedimento, o senhor poderá ter três sensações: parestesia (choque igual aquele que sentimos quando se bate o cotovelo), dor no local ou contração involuntária (seu pé mexerá sozinho). Quanto aos riscos nas sessões experimentais, a infusão de insulina pode provocar hipoglicemia (reduzir o açúcar no sangue). Para que isso não ocorra, o açúcar do sangue será dosado durante todo o teste e será feita uma infusão de glicose (açúcar). Além disso, para eventuais problemas haverá um médico presente durante toda a sessão experimental e o senhor só será liberado após fazer uma refeição e seu açúcar no sangue estar estabilizado. Após o experimento, devido ao procedimento de medida do sinal nervoso, o senhor pode apresentar nos dias subseqüentes dor, parestesia ou fraqueza muscular na perna. Se esses sintomas surgirem, eles normalmente são de baixa intensidade e costumam durar por 3 a 7 dias, sem prejuízos permanentes.

4. O senhor será avaliado sob vários aspectos clínicos gratuitamente: avaliação clínica, diagnóstico de obesidade, diagnóstico de diabetes, diagnóstico de hipercolesteridemia e trigliceridemia, diagnóstico de hipertensão, diagnóstico de doenças cardiovasculares e avaliação da capacidade aeróbia máxima. Todos esses resultados the serão entregues e, caso haja algum problemas de saúde, o senhor poderá ser encaminhado para tratamento no Hospital das Clínicas.

5.Ao final da pesquisa, se o senhor quiser, podemos fazer uma prescrição para a realização de exercícios físico com base nos resultados obtidos na avaliação ergoespirométrica.

\section{IV - ESCLARECIMENTOS DADOS PELO PESQUISADOR SOBRE GARANTIAS DO SUJEITO DA PESQUISA:}

1. acesso, a qualquer tempo, às informações sobre procedimentos, riscos e benefícios relacionados à pesquisa, inclusive para dirimir eventuais dúvidas? projeto.

Sim, o senhor terá acesso, em qualquer momento, às informações que desejar sobre o

2. liberdade de retirar seu consentimento a qualquer momento e de deixar de participar do estudo, sem que isto traga prejuízo à continuidade da assistência?

Sim, o senhor poderá desistir de participar do estudo a qualquer momento sem deixar de ser atendido pelo Hospital das Clínicas.

3. salva guarda da confidencialidade, sigilo e privacidade?

Sim, os dados obtidos nos testes do
senhor serão guardados em sigilo,
sendo apresentados somente como
médias e de forma anônima.

4. disponibilidade de assistência no HCFMUSP, por eventuais danos à saúde, decorrentes da pesquisa? 
Sim, caso haja algum problema durante o protocolo ou após, devido sua execução, o senhor será atendido pelo Hospital das Clínicas

5. viabilidade de indenização por eventuais danos à saúde decorrentes da pesquisa.

\section{INFORMAÇÕES DE NOMES, ENDERECOS E TELEFONES DOS RESPONSÁVEIS PELO ACOMPANHAMENTO DA PESQUISA, PARA CONTATO EM CASO DE INTERCORRÊNCIAS CLÍNICAS E REAÇÕES ADVERSAS.}

Profa Dra Cláudia Lúcia de Moraes Forjaz Tel (0XX11) 3818 -31 36

Vanessa Aparecida Favero Bisquolo $\quad$ Tel (0XX11) 3818-2149

Dr Décio Mion Jr Tel (0XX11) 282-2659

\section{OBSERVAÇÕES COMPLEMENTARES:}

\section{VII - CONSENTIMENTO PÓS-ESCLARECIDO}

Declaro que, após convenientemente esclarecido pelo pesquisador e ter entendido o que me foi explicado, consinto em participar do presente Protocolo de Pesquisa

São Paulo, de de 


\section{Anexo 2}

\section{HOSPITALDAS CLINICAS}

FACULDADE DE MEDICINA DA UNIVERSIOADE DE SÃO PAULO CAIXA POSTAL, $B 091$ SAO PAULO - BRASIL.

A5EEBEMOS

DIRETORIA CLINIICA

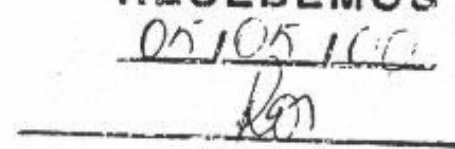

Comissão de Ética para Análise de Projetos de Pesquisa

\section{APROVAÇÃO}

A Comissão de Ética para Análise de Projetos

de Pesquisa - CAPPesq da Diretoria Clínica do Hospital das Clínicas e da Faculdade de Medicina da Universidade de São Paulo, em sessão de 27.04.2000, APROVOU o Protocolo de Pesquisa $n^{\circ} 161 / 00$, intitulado: "Efeito da sensibilização à ação da insulina pelo exercício sobre as respostas pressórica, sımpática e vasodilatatera i infunăa de inaulina pós-exercício", apresentado pelo(a) pesquisador(a) Carlos Eduardo Negrão, do Departamento de Cárdio-Pneumologia, bem como o Termo de Consentimento Livre e Esclarecido.

CAPPesq, 02 de Maio de 2000.

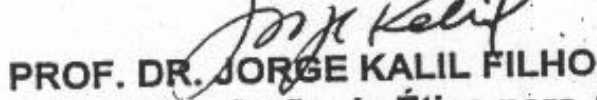

Presidente da Comissão de Ética para Análise de Projetos de Pesquisa 


\title{
Anexo 3
}

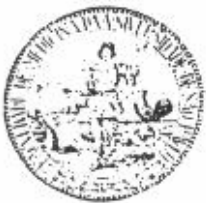

\author{
INSTITUTO DO CORAÇÃO \\ (Fundação E. J. Zerbini) \\ Hospital das Clínicas \\ Faculdade de Medicina da Universidade de Sáo Paulo
}

Vaussa

Mem.CC. $125 / 00$

InCor
$\mathrm{HC}$

São Paulo, 3 de março de 2000.

Ilmo. Sr.

Prof. Dr. Carlos Eduardo Negrão

A Comissão Científica e de Ética do Instituto do Coração apreciou e aprovou na sessão 360/00/03 de 2/3/00

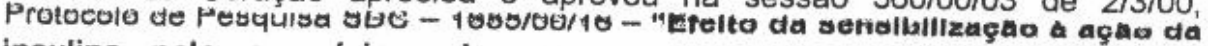
insulina pelo exercicio sobre as respostas pressórica. Simpática e vasodilatadora à infusão de insulina pós-exercicio", e foi o seguinte o parecer do relator :"Aprovado".

Atenciosamente, 
REFERENCIAS

BIBLIOGRÁFICAS 


\section{REFERÊNCIAS BIBLIOGRÁFICAS}

AMERICAN COLLEGE OF SPORTS MEDICINE. Manual de Pesquisa das Diretrizes do ACSM para os Testes de Esforço e sua Prescrição. $6^{\circ} \mathrm{ed}$, Rio de Janeiro, Guanabara Koogan, 2003.

ANDERSON, E.A.; MARK, A.L. Microneurographic measurement of sympathetic nerve activity in humans. In: Handbook of research methods in cardiovascular behavioral medicine. edited by :Schneideman N, Weiss SM and Kaufmann PG. New York: Plenun, 1989.

ANDERSON, E.A., SINKEY C.A., LAWTON W.J.; MARK A.L. Elevated sympathetic nerve activity in borderline hypertensive humans. Evidence from direct intraneural recordings. Hypertension v.14, p.17783, 1989.

BARON, A.D.; BRECHTEL-HOOK, G.; JOHNSON, A.; HARDIN, D. Skeletal muscle blood flow: a possible link between insulin resistence and blood pressure. Hypertension v.21, p. 129-35, 1993.

BECKER, K.L. Principles and pratice of endocrilogy and metabolism. $2^{\circ} \mathrm{ed}$, 1995. 
BEN-EZRA, V., JANKOWSKI, C., KENDRIK, K. ; NICHOLS D. Effect of intensity and energy expenditure on post-exercise insulin responses in women. J. Appl. Physiol. v. 79, p. 2029-34, 1995.

BERGHOLM, R.; WESTERBACKA, J.; VEHKAVAARA; S. SEPPALA-LINDROOS; A. Insulin sensitivity reagulates autonomic control of heart rate variation independent of body weight in normal subjects. J. Clin. Endocrinol. Metab. v. 86, p.1403-9, 2001.

BERNE, C.; FAGIUS, J.; POLLARE, T.; HJEMDAHL, P. The sympathetic response to euglycaemic hyperinsulinaemia. Evidence from microelectrode nerve recordings in healthy subjects. Diabetologia v. 35 , p. 873-9, 1992.

BRAUN, B.; ZIMMERMANN, M.B.; KRETCHMER, N. Effects of exercise intensity on insulin sensitivity in women with non-insulin-dependent diabetes mellitus. J. Appl. Physiol. v. 78, p. 300-6, 1995.

BURSTEIN, R.; EPSTEIN, Y.; SHAPIRO, Y.; CHARUZI, I.; KARNIELI, E. Effect of an acute bout of exercise on glucose disposal in human obesity. J. Appl. Physiol. v. 69(1), p.299-304, 1990.

COATS, J. A.; CONWAY, J.; ISEA, J.E.; PANNARALE, G.; SLEIGHT, $P . ; S O M E R S, V . K$. Systemic and forearm vascular resistence changes after upright bicycle exercise in man. J. Physiol.(Lond) v.413, p. 289-98, 1989.

DEFRONZO, R.A.; FERRANNINI, E. Insulin resistense: a multifaceted syndrome responsible for NIDDm, obesity, dyslepidemia, and artherosclerotic cardiovascular disease. Diabetes Care v.14, p. 173-94, 1991. 
DEFRONZO, R.A.; TOBIN J.D.; ANDRES R. Glucose clamp technic: a method for quantifying insulin secretion and resistance. Am. J. Physiol. v. 237, p. E214-23, 1979.

DEFRONZO, R.A. Pathogenesis of type 2 diabetes: metabolic and molecular implications for identifying diabetes genes. Diabetes Rev. v. 5, p. 177269, 1997

DEVLIN, J.T.; HORTON, E.S. Effects of prior high-intensity exercise on glucose metabolism in normal and insulin-resistent men. Diabetes v. 34 , p.973-79, 1985.

FORJAZ, C.L.; MATSUDAIRA, Y.; RODRIGUES, F.B.; NUNES, N.; NEGRAO, C.E. Post-exercise changes in blood pressure, heart rate and rate pressure product at different exercise intensities in normotensive humans. Braz. J. Med. Biol. Res. v.31(10), p.1247-55, 1998.

FORJAZ, C.L.M.; RAMIRES, P.R.; TINUCCI, T.; ORTEGA, K.C.; SALOMÃO, H.E.H.; IGNÊS E.; WATCHENBERG, B.L.; NEGRÃO, C.E.; MION JR, D. Post exercise responses of muscle sympathetic nerve activity and blood flow to hyperinsulinemia in humans. J. Appl. Physiol. v. 87, p. 824-9, 1999.

FORJAZ, C.L.; SANTAELLA, D.F.; REZENDE, L.O.; BARRETTO, A.C.; NEGRAO, $C$.E. Effect of exercise duration on the magnitude and duration of postexercise hypotension. Arq. Bras. Cardiol. v.70(2), p.99-104, 1998.

FORJAZ, C.L., TINUCCI, T., ORTEGA, K.C., SANTAELLA, D.F., MION JR, D., NEGRAO, C.E. Factors affecting post-exercise hypotension in normotensive and hypertensive humans. Blood Press. Monit. v.5(5-6), p.255-62, 2000. 
FRANKLIN, P.J.; GREEN, D.J.; CABLE, N.T. The influence of thermoregulatory mechanisms on post-exercise hypotension in humans. J. Physiol. v. 470, p.231-41, 1993.

FLUCKEY, J.D.; PLOUG, T.; GALBO, H. Attenuated insulin action on glucose uptake and transport in muscle following resistance exercise in rats. Acta Physiol. Scand. v.167(1), p.77-82, 1999.

GUYTON, A. C.; HALL, J. E. Tratado de fisiologia médica. $8^{\circ}$ ed. Rio de Janeiro, Guanabara, Koogan, 1992.

GUYTON, A. C.; HALL, J. E. Fisiologia humana e mecanismo das doenças. $6^{\circ}$ ed. Rio de Janeiro, Guanabara, Koogan, 1998.

HALLIWILL, J.R.; TAYLOR, J.A.; ECKBERG, D.L. Impaired sympathetic vascular regulation in humans after exercise. J. Appl. Physiol. v. 495, p.279-88, 1996.

HALLIWILL, J.R. Mechanisms and clinical implications of post-exercise hypotension in humans. Ex. Sports Sci. Rev. v. 29, p. 65-70, 2001.

HARA, K.; FLORA, J.S. Effects of naloxone on hemodynamics and sympathetic activity after exercise. J. Appl. Physiol. v.73, p. 2028-35, 1992.

HAUSBERG, M.; MARK, A.L.; HOFFMAN, R.P.; SINKEY, C.A.; ANDERSON E.A. Dissociation of sympathoexcitatory and vasodilation actions of modestly elevated plasma insulin levels. Journal of Hypertension v. 13, p.1015-21, 1995. 
HOLLENBECK, C.; REAVEN, G.C. Variations in insulin-stimulated glucose uptake in healthy individuals with normal glucose tolerance. Journal of Clinical Endocrinology and Metabolism v. 64(6), p. 1169-73; 1987.

HOLTEN, M.K.; ZACHO, M.; GASTER, M.; JUEL, C.; WOJTASZEWSKI, J.F.; DELA, F. Strength training increases insulin-mediated glucose uptake, GLUT4 content, and insulin signaling in skeletal muscle in patients with type 2 diabetes. Diabetes v. 53(2), p.294-305, 2004.

HUSSAIN, S.T.; SMITH, R.E.; MEDBAK, S.; WOOD, R.F.M.; WHIPP, B.J. Haemodynamic and metabolic responses of the lower limb after high intensity exercise in humans. Experimental Physiology v.81, p.173-87, 1996.

JOINT NATIONAL COMMITTEE ON DETECTION, EVALUATION, AND TREATMENT OF HIGH BLOOD PRESSURE. The seventh report of the joint national committee on prevention, evaluation and treatment of high blood pressure(JNC VI). Arch. Intern. Med. v. 157, p.2413-46, 2002.

JUNGERSTAN, L.; AMBRING, A.; WALL, B.; WENNMALM A. Both physical fitiness and acute exercise regulate nitric oxide formation in healthy humans. J. Appl. Physiol. v.82, 760-4, 1997.

KOYAMA, Y.; GALASSETTI, P.; COKER, R.H.; PENCEK, R.R.; LACY, D.B.; DAVIS, S.N.; WASSERMAN, D.H. Prior exercise and the response to insulin-induced hypoglycemia in the dog. Am. J. Physiol. Endocrinol. Metab. V.282(5), p.E1128-38, 2002.

LAAKSO, M.; EDELMAN, S.V.; BRECHTEL, G.; BARON, A.D. Decreased effect of insulin to stimulate skeletal muscle blood flow in obese man. J. Clin. Invest. v. 85, p. 1844-52, 1990. 
LENDER, D.; ARAUZ-PACHECO, C.; ADAMS-HUET, B.; RASKIN, P. Essential hypertension is associated with decreased insulin clearance and insulin resistance. Hypertension v.29, p.111-4, 1997.

LIND, L.; FUGMANN, A.; MILLGARD, J.; BERNE, C.; LITHELL, H. Insulinmediated vasodilation, but not glucose uptake or endothelium-mediated vasodilation, is enhanced in young females compared with males. Clin. Sci. v. 1025, p. 241-246, 2002.

LOOMANS, C.J.; DAO, H.H.; VAN ZONNEVELD, A.J.; RABELINK, T.J. Is endothelial progenitor cell dysfunction involved in altered angiogenic processes in patients with hypertension? Curr. Hypertens. Rep. v. 6(1), p.51-4, 2004.

MACDONALD, J.R. Potential causes, mechanisms, and implications of post exercise hypotension. J. Hum. Hypertens. V.16(4), p.225-36, 2002.

MEYRELLES, S.S.; TINUCCI, T.; HOLLANDA, H.E.; MION JR., D. Baroreflex control of muscle sympathetic nerve activity in mild hypertension. Am. J. Hypertens. v.10, p.162-7, 1997.

MIKENNES, K.J.; SONNE, B.; TRONIER, B.; GALBO, H. Effect of physical exercise on sensitivity and responsiveness to insulin in humans. Am. J. Physiol. v. 254, p. E248-59, 1988.

MUNTZEL, M.S.; MALENA, H.; DRUEKE, T. Inhibition of nitric oxide synthesis attenuates insulin-mediated sympathetic activation in rats. Journal of Hypertension. v. 19, p.1625-31, 2001.

MUSCELLI, E.; EMDIN, M.; NATALI, A.; PRATALI, L.; CAMASTRA, S.; GASTALDELLI, A.; BALDI, S.; FERRANNINI, E. Autonomic and 
hemodynamic responses to insulin in lean and obese humans. J. Clin. Endocrinol. Metab. v. 83, p.2084-90, 1998.

NATIONAL CHOLESTEROL EDUCATION PROGRAM. NATIONAL HEART, LUNG, AND BLOOD INSTITUTE,NATIONAL INSTITUTES OF HEALTH. NIH Publication . v.02, p.5215, 2002.

NATIONAL HEART, LUNG AND BLOOD INSTITUTE. NATIONAL INSTITUTE OF HEALTH. NIH Publication. v. 98, p. 4083, 1998

Negrao, C.E.; Trombetta, I.C.; Batalha, L.T.; Ribeiro, M.M.; Rondon, M.U.; Tinucci, T; Forjaz, C.L.; Barretto, A.C.; Halpern, A; Villares, S.M. Muscle metaboreflex control is diminished in normotensive obese women. Am J. Physiol. Heart. Circ. Physiol. v. 281, p.H469-75, 2001.

RHEAUME, C.; WAIB, P;H;; LACOURCIERE, Y.; NADEAU, A;; CLEROUX, J. Effects of mild exercise on insulin sensitivity in hypertensive subjects. Hypertension. v.39, p. 989-95, 2002.

ROEF, M.J.; DE MEER, K.; KALHAN, S.C.; STRAVER, H.; BERGER, R.; REIJNGOUD, D.J. Gluconeogenesis in humans with induced hyperlactatemia during low-intensity exercise. Am. J. Physiol. Endocrinol. Metab. v.284(6), p.E1162-71, 2003.

ROTHMAN, D.L.; MAGNUSSON, I.; CLINE, G. Decrease muscle glucose transport/phosphorylation is an early defect in the phatogenesis of noninsulin-dependent diabetes mellitus. Proc. Natl. Acad. Sci. USA. v.92, p.983-7, 1995.

ROWE, J.W.; YOUNG, J.B.; MINAKER, K.L.; STEVENS, A.L.; PALLOTTA, J.; LANDSBERG, L. Effect of insulin and glucose infusions on sympathetic nervous activity in normal man. Diabetes. v. 30, p. 219-25, 1981. 
RUECKERT, P.A.; SLANE, P.R.; LILLIS, D.L.; HANSON, P. Hemodynamic patters and duration of post-dynamic exercise hypotension in hypertensive humans. Med. Sci. Sports Exerc. v. 28, p. 24-32, 1996.

SABELIS, L.W.; SENDEN, P.J.; BOEKHORST TE, B.C.; HULZEBOS, E.H.; WIEL, V.D.A.; HAEFTEN, V.T.W.; ZONDERLAND, M.L.; MOSTERD, W.L. Does physical training increase insulin sensitivity in chronic heart failure patients? Clin. Sci. (Lond). v.(6), p.759-65, 2003.

SANTAELLA, D.F.; ARAUJA, E.A., CAMPOS, R.N.; ORTEGA, K.C.; MONTANO, N.; NEGRÃO, C.E.; JORJAZ, C.L.M. Exercise and relaxation have additive post-intervention hypotensive effects. (dados não publicados), 2003, no prelo.

SATO, M.; MAEHARA, K.; YAOITA, H.; OTANI, H.; HIROSAKA, A.; SAITO, T.; ONUKI, N.; KOMATSU, N.; ISHIHATA, T.; MARUYAMA, Y. Correlation between cardiac norepinephrine overflow during exercise and cardiac 123I-MIBG uptake in patients with chronic heart failure. J Nucl Med. v. 44(10), p.1618-24, 2003.

SCHERRER, U.; RANDIN, D.; VOLLENWEIDER, P.; VOLLENWEIDER, L.; NICOD, P. Nitric oxide release accounts for insulin's vascular effects in humans. J. Clin. Invest. v. 94, p. 2511-5, 1994.

SCOTT, E.M.; GREENWOOD, J.P.; VACCA, G.; STOKER, J.B.; GILBEY, S.G.; MARY, D. Carbohydrate ingestion, with transiet endogenous insulinaemia produces both sympathetic activation and vasodilation in normal humans. Clin. Sci. v. 102, p. 523-9, 2002.

SEIBAEK, M.; VESTERGAARD, H.; BURCHARDT, H.; SLOTH, C.; TORPPEDERSEN, C.; NIELSEN, SL.; HILDEBRANDT, P.; PEDERSEN, O. Insulin 
resistance and maximal oxygen uptake. Clin. Cardiol. v. 26(11), p.515-20, 2003.

SIGGAARD-ANDERSEN, J. Venous occlusion plethysmography on the calf: evaluation of diagnosis and results in vascular surgery. Dan. Med. Bull. v. 17, p. 1-72, 1970.

THE EXPERT COMMITTEE ON THE DIAGNOSIS AND CLASSIFICATION OF DIABETES MELLITUS. Report of the Expert Committee on the Diagnosis and Classification of Diabetes Mellitus. Diabetes Care. v. 23(suppl 1), p.S4-19,2000.

VEEN, S.; CHANG, P. C. Prostaglandins and nitric oxide mediate insulininduced vasodilation in the human forearm. Cardiovascular Research. v. 34, p. 223-9, 1997.

VÉRAS-SILVA, A.S; MATTOS, K.C; IDA, F.; NEGRÃO, C.E.; KRIEGER, E.M. Pos-exercise hypotension in spontaneouly hypertensive rats is produced by a decreased in cardiac output. Hypertension. v. 64, p. 383-6, 1995.

VINCENT, MA.; BARRETT, E.J.; LINDNER, J.R.; CLARK, M.G.; RATTIGAN, S. Inhibiting NOS blocks microvascular recruitment and blunts muscle glucose uptake in response to insulin. Am. J. Physiol. Endocrinol. Metab. v. 285, p. E123-9, 2003.

VOLLENWEIDER, L.; TAPPY, L.; OWLYA, R.; JÉQUIER, E.; NICOD, P.; SCHERRER, U. Insulin-induced sympathetic activation and vasodilation in skeletal muscle. Effects of insulin resistence in lean subjects. Diabetes. v. 44, p. 641-5, 1995. 
VOLLENWEIDER, P.; TAPPY, L.; RANDIN; D.; SCHNEITER, P.; JÉQUIER, E.; NICOD, P,; SCHERRER, U. Differential effects of hyperinsulinemia and carbohydrate metabolism on sympathetic nerve activity and muscle blood flow in humans. J. Clin. Invest. v. 92, p. 147-54, 1993.

VOLLENWEIDER, P.; RANDIN, D.; TAPPY, L.; JÉQUIER, E.; NICOD, P.; SCHERRER, U. Impaired insulin-induced sympathetic neural activation and vasodilation in skeletal muscle in obese humans. J. Clin. Invest. v. 93, p. 2365-71, 1994.

WASSERMAN K.; WHIPP B.J. Excercise physiology in health and disease. Am. Rev. Respir. Dis. v. 112(2), p.219-49, 1975.

YOUNG, C.J.; ENSLIN, J.; KUCA, B. Exercise intensity and glucose tolerance in trained and nontrained subjects. J. Appl. Physiol. v. 67, p.39-43, 1989. 